\title{
Identification of a Novel Neuropeptide S Receptor Antagonist Scaffold Based on the SHA-68 Core
}

\author{
Allison Zarkin ${ }^{1}$, Rajwana Jahan ${ }^{1}$, Rajendra Uprety ${ }^{1}$, Yanan Zhang ${ }^{1} \mathbb{D}$, Charles McElhinny ${ }^{1} \mathbb{D}$, Rodney Snyder $^{1}$, \\ Elaine Gay ${ }^{1}$, Gabriel Jewula ${ }^{2}$, Heather Bool ${ }^{2}$, Stewart D Clark ${ }^{2}$ and Scott Runyon 1,* \\ 1 Research Triangle Institute, P.O. Box 12194, Research Triangle Park, NC 27709-2194, USA; \\ azarkin@rti.org (A.Z.); rjahan@rti.org (R.J.); ruprety@rti.org (R.U.); yzhang@rti.org (Y.Z.); cjm@rti.org (C.M.); \\ rsnyder@rti.org (R.S.); egay@rti.org (E.G.) \\ 2 Department of Pharmacology and Toxicology, State University of New York at Buffalo, 3435 Main Street, \\ Buffalo, NY 14214, USA; gijewula@buffalo.edu (G.J.); hmbool@buffalo.edu (H.B.); \\ stewartc@buffalo.edu (S.D.C.) \\ * Correspondence: srunyon@rti.org
}

check for updates

Citation: Zarkin, A.; Jahan, R.; Uprety, R.; Zhang, Y.; McElhinny, C.; Snyder, R.; Gay, E.; Jewula, G.; Bool, H.; Clark, S.D.; et al. Identification of a Novel Neuropeptide S Receptor Antagonist Scaffold Based on the SHA-68 Core. Pharmaceuticals 2021, 14, 1024. https://doi.org/10.3390/ ph14101024

Academic Editors: Chiara Ruzza and Rainer K. Reinscheid

Received: 3 August 2021

Accepted: 25 September 2021

Published: 6 October 2021

Publisher's Note: MDPI stays neutra with regard to jurisdictional claims in published maps and institutional affiliations.

Copyright: (c) 2021 by the authors. Licensee MDPI, Basel, Switzerland. This article is an open access article distributed under the terms and conditions of the Creative Commons Attribution (CC BY) license (https:/ / creativecommons.org/licenses/by/ $4.0 /)$.

\begin{abstract}
Activation of the neuropeptide S receptor (NPSR) system has been shown to produce anxiolytic-like actions, arousal, and enhance memory consolidation, whereas blockade of the NPSR has been shown to reduce relapse to substances of abuse and duration of anesthetics. We report here the discovery of a novel core scaffold (+) N-benzyl-3-(2-methylpropyl)-1-oxo-3-phenyl$1 \mathrm{H}, 3 \mathrm{H}, 4 \mathrm{H}, 5 \mathrm{H}, 6 \mathrm{H}, 7 \mathrm{H}$-furo[3,4-c]pyridine-5-carboxamide with potent NPSR antagonist activity in vitro. Pharmacokinetic parameters demonstrate that $\mathbf{1 4 b}$ reaches pharmacologically relevant levels in plasma and the brain following intraperitoneal (i.p.) administration, but is cleared rapidly from plasma. Compound 14b was able to block NPS (0.3 nmol)-stimulated locomotor activity in C57/B16 mice at $3 \mathrm{mg} / \mathrm{kg}$ (i.p.), indicating potent in vivo activity for the structural class. This suggests that $\mathbf{1 4 b}$ can serve as a useful tool for continued mapping of the pharmacological functions of the NPS receptor system.
\end{abstract}

Keywords: neuropeptide S; antagonist; anxiolytic; NPSR

\section{Introduction}

The neuropeptide S (NPS) system was first described publicly more than 15 years ago [1]; however, its therapeutic potential has not yet been achieved due to the lack of high-affinity drug-like ligands. Central administration of NPS (20 AA peptide) into mice produces anxiolytic-like actions, arousal, and enhances memory consolidation [1-3]. These wide-ranging effects are mediated by NPS receptors (NPSR) distributed throughout the CNS, e.g., cortex, amygdala, parasubiculum, and hypothalamus [4]. Expression of NPS is highly localized to discrete nuclei, e.g., peri-locus coerelus [1], although there are established interactions with the CRF (corticotropin releasing factor) system which support a role for NPS in the modulation of stress [5-7]. The exact connectivity of the NPSR-expressing and NPS-expressing neurons is still under investigation, and so are a number of other fundamental elements of this neuromodulatory system.

The discovery of small-molecule NPSR agonist molecules would represent a new class of non-sedating fast-acting anxiolytics, with memory enhancement properties [3]. However, NPSR antagonists have shown promise for treating relapse to substances of abuse [5,8] and may enhance the duration of mechanistically distinct anesthetics [9]. Improved NPSR agonists would be specifically useful for elucidating aspects of the NPS-system. In addition, more drug-like NPSR antagonists would be useful as tool compounds for target validation. However, currently available NPSR antagonists (Figure 1, Compounds A-D) have good potency but tend to be highly lipophilic and have a high number of sp2 hybridized atoms. These properties result in compounds that are challenging to formulate for in vivo work [10-15]. 


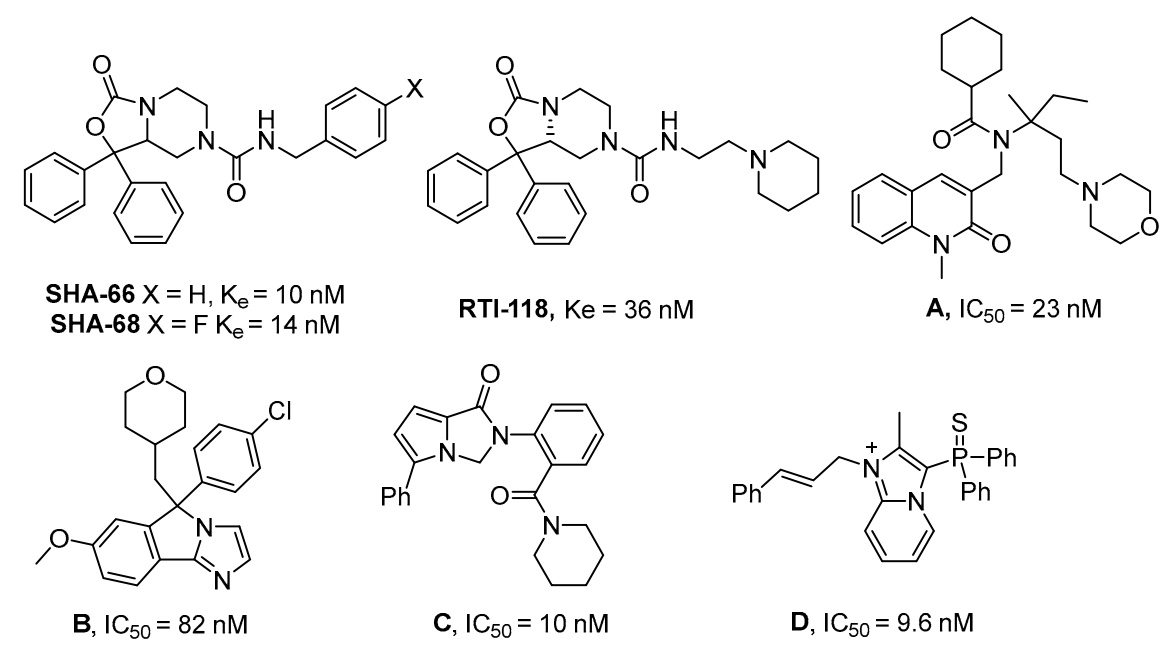

Figure 1. Representative NPSR antagonists.

For a number of known NPSR antagonists, only limited structure-activity relationship (SAR) studies have been reported. The SHA-66/68 class of molecules, which were disclosed by Okamura et al. in 2008, possess poor drug-like properties, particularly aqueous solubility, and several structural modifications have been undertaken by our group and others, resulting in a number of improved analogs such as RTI-118 [10,12]. One structural feature of the SHA class that has not been thoroughly investigated is the diaryl moiety. The chemical synthesis of SHA makes differential modification of the diaryl moiety cumbersome and introduces an additional chiral center. Considering the high sp2 count of SHA and the metabolic liabilities associated with unsubstituted aryl rings, we hypothesized that modification of this feature could lead to improved NPSR antagonists. We envisioned that replacement of the carbamate nitrogen in SHA with an alkene would provide analogs that retain the overall geometry of SHA and keep in place a number of the critical pharmacophoric elements (Figure 2). SHA already contains one chiral center; therefore, differentially substituting the diaryl core would result in a complex mixture of diastereomers that could be challenging to resolve. The addition of a double bond at the bicyclic ring junction eliminates one chiral center, leaving the remaining chiral center at the differentially substituted aryl rings of the oxazolidinone core. Therefore, our group explored structural modifications that retained the overall shape of SHA-68 yet allowed chemically tractable and differential modification of the diaryl ring system. Our resulting core, 4,5,6,7-tetrahydrofuro[3,4-c]pyridin-1(3H)-one, has produced a series of novel NPSR antagonists with similar antagonist potency in vitro, and favorable activity in vivo.

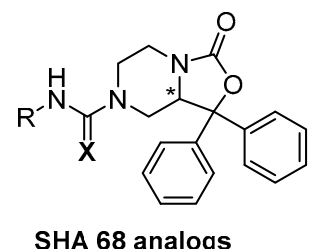

Substituted benzyl $\mathrm{R}=$ alkyl (n-pentyl, piperidinoethyl) $\mathbf{X}=\mathrm{O}, \mathrm{N}, \mathrm{S} ;{ }^{*}$ Chiral center

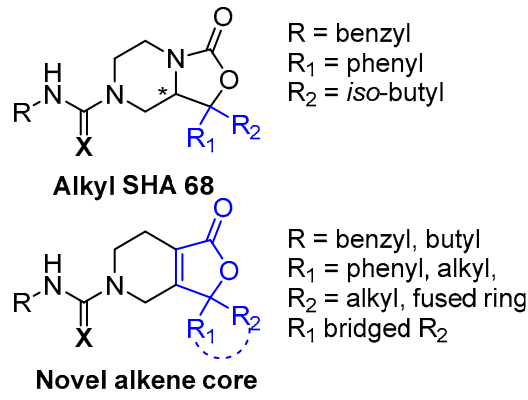

Novel alkene core

Figure 2. Further modifications to SHA led to the identification of novel alkene scaffolds.

\section{Chemistry}

Compounds 1, 2, 8-19, 21, 22, and 24-28 (Tables 1-3; Figures S1-S28, Supplementary Materials) were synthesized in a manner analogous to that outlined in Scheme 1. Previous research by Epsztajn et al. [16] demonstrated that the ortho lithiation of diiso- 
propyl nicotinamides proceeded smoothly and the resulting anion could be condensed with various ketones and aldehydes to afford the precursor to the bicyclic ring structures needed for our investigation. $\mathrm{N}, \mathrm{N}$-diisopropylisonicotinamide $\mathbf{3 0}$ was treated with lithium di-isopropylamide to form the anion of $\mathbf{3 0}$ which was condensed with the appropriate ketone to yield an alcohol intermediate, such as compound 31, in moderate yield. Upon treatment with aqueous acid $(6 \mathrm{~N} \mathrm{HCl})$, the alcohol readily cyclizes into lactone 32 . A series of reduction conditions were evaluated for the pyridyl ring. We discovered reduction of the pyridine ring with 1 equivalent of acid, hydrogen, and platinum oxide as a catalyst partially reduced ring 33 , leaving the tetrasubstituted double bond intact. These reduction conditions afforded the 4,5,6,7-tetrahydrofuro[3,4-c]pyridin-1(3H)-one core 33 in good yield. Final treatment of amine 33 with the desired isocyanate in dichloromethane afforded target compounds $\mathbf{1 4 a}, \mathbf{b}$ in good yield.

Table 1. Modifications of the core oxazolidinone ring.

\begin{tabular}{|c|c|c|c|c|}
\hline Compound No. & Structure & $K_{e}(n M)^{a}$ & $\operatorname{cLog} P$ & TPSA $\left[\AA^{2}\right]$ \\
\hline 1 & & 522 & 4.27 & 58.64 \\
\hline 2 & & 515 & 3.86 & 58.64 \\
\hline 3 & & 761 & 4.03 & 58.64 \\
\hline 4 & & NA & 3.63 & 58.64 \\
\hline 5 & & 170 & 4.03 & 58.64 \\
\hline 6 & & 260 & 3.63 & 58.64 \\
\hline 7 & & 1133 & 4.27 & 58.64 \\
\hline
\end{tabular}

a Calcium Mobilization.

Table 2. Modifications of the diaryl motif.

\begin{tabular}{lllll}
\hline Compound No. & $\mathrm{K}_{\mathrm{e}}(\mathrm{nM})^{\mathrm{a}}$ & $\operatorname{cLogP}$ & TPSA $\left.^{2} \AA^{2}\right]$ \\
\hline
\end{tabular}


Table 2. Cont.

\begin{tabular}{|c|c|c|c|c|}
\hline Compound No. & Structure & $K_{e}(n M)^{a}$ & cLogP & TPSA $\left[\AA^{2}\right]$ \\
\hline 10 & & NA & 4.05 & 58.64 \\
\hline 11 & & 165 & 4.45 & 58.64 \\
\hline & $\mathrm{R}^{1}=n-\mathrm{Bu}, \mathrm{R}^{2}=\mathrm{Ph}$ & & & \\
\hline 12 & $\mathrm{R}^{1}=\mathrm{Bn}, \mathrm{R}^{2}=\mathrm{Ph}$ & 606 & 4.69 & 58.64 \\
\hline 13 & $\mathrm{R}^{1}=$ neo-pentyl, $\mathrm{R}^{2}=\mathrm{Ph}$ & 146 & 4.59 & 58.64 \\
\hline 14 & $\mathrm{R}^{1}=i s o-\mathrm{Bu}, \mathrm{R}^{2}=\mathrm{Ph}$ & 118 & 4.29 & 58.64 \\
\hline 15 & $\mathrm{R}^{1}=\mathrm{Me}, \mathrm{R}^{2}=\mathrm{Ph}$ & NA & 3.04 & 58.64 \\
\hline 16 & $\mathrm{R}^{1}, \mathrm{R}^{2}=$ iso- $\mathrm{Bu}$ & 734 & 4.18 & 58.64 \\
\hline 17 & $\mathrm{R}^{1}=\mathrm{Me}_{2} \mathrm{NCH}_{2} \mathrm{CH}_{2}, \mathrm{R}^{2}=\mathrm{Ph}$ & NA & 2.76 & 61.88 \\
\hline 18 & $\mathrm{R}^{1}=\mathrm{CH}_{2} \mathrm{OH}, \mathrm{R}^{2}=\mathrm{Ph}$ & NA & 1.99 & 78.87 \\
\hline 19 & $\mathrm{R}^{1}=\mathrm{CH}_{2} \mathrm{OAc}, \mathrm{R}^{2}=\mathrm{Ph}$ & NA & 2.43 & 84.94 \\
\hline 20 & $\mathrm{R}^{1}=\mathrm{Me}, \mathrm{R}^{2}=3-\mathrm{OH}-\mathrm{Ph}$ & NA & 2.73 & 78.87 \\
\hline 21 & $\mathrm{R}^{1}=\mathrm{Me}, \mathrm{R}^{2}=3-\mathrm{OBn}-\mathrm{Ph}$ & NA & 4.60 & 67.87 \\
\hline 22 & $\mathrm{R}^{1}=$ iso-Bu, $\mathrm{R}^{2}=2$-Naphthyl & 500 & 5.28 & 58.64 \\
\hline 23 & $\mathrm{R}^{1}=$ iso- $\mathrm{Bu}, \mathrm{R}^{2}=2-\mathrm{OH}-\mathrm{Ph}$ & 1500 & 3.99 & 78.87 \\
\hline 24 & $\mathrm{R}^{1}=i s o-\mathrm{Bu}, \mathrm{R}^{2}=2-\mathrm{OBn}-\mathrm{Ph}$ & 572 & 5.86 & 67.87 \\
\hline 25 & $\mathrm{R}^{1}=$ iso- $\mathrm{Bu}, \mathrm{R}^{2}=3-\mathrm{Cl}-\mathrm{Ph}$ & 136 & 4.89 & 58.64 \\
\hline
\end{tabular}

a Calcium Mobilization.

Table 3. Modifications of urea portion of lead compound 14.

\begin{tabular}{|c|c|c|c|c|}
\hline Compound No. & Structure & $K_{e}(n M)^{a}$ & cLogP & TPSA $\left[\AA^{2}\right]$ \\
\hline 14 & & 118 & 4.29 & 58.64 \\
\hline $14 a$ & (-) Isomer & 432 & & \\
\hline $14 b$ & (+) Isomer & 71.4 & & \\
\hline 26 & & 238 & 3.89 & 58.64 \\
\hline 27 & & 566 & 3.43 & 61.88 \\
\hline 28 & & 386 & 4.32 & 44.81 \\
\hline 29 & & NA & 3.93 & 61.88 \\
\hline
\end{tabular}




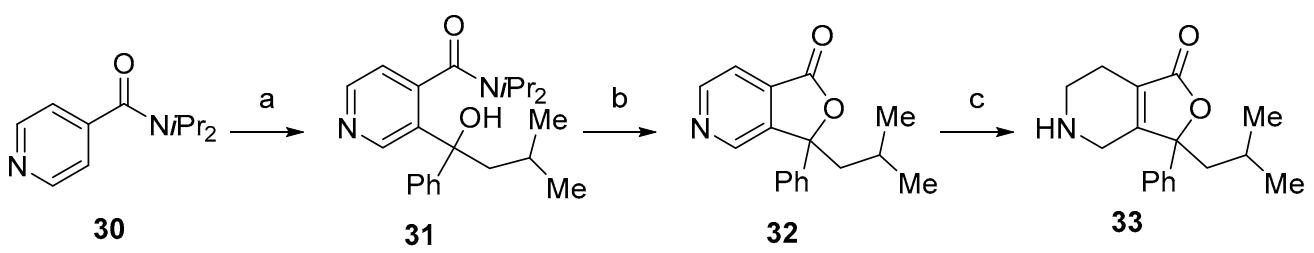<smiles>CC(C)CC1(c2ccccc2)OC(=O)C2=C1CN(C(=O)NCc1ccccc1)CC2</smiles>

Reagents and conditions: a) Isovalerophenone, $\mathrm{LDA}, \mathrm{Et}_{2} \mathrm{O}, 46 \%$ yield; b) $6 \mathrm{~N} \mathrm{HCl}, 70 \%$ yield; c) $\mathrm{PtO}_{2}, \mathrm{HCl}\left(1.25 \mathrm{M}\right.$ in EtOH), $79 \%$ yield; d) benzylisocyanate, $\mathrm{CH}_{2} \mathrm{Cl}_{2}, 69 \%$ yield.

Scheme 1. General synthetic route to alkene-based NPS antagonists.

Reduction of the 4,5,6,7-tetrahydrofuro[3,4-c]pyridin-1(3H)-one core 36 with nickel acetate and sodium borohydride resulted in the reduced cis-intermediate 37 , which was then alkylated with benzyl or butyl isocyanate to yield compounds 3 and 4 , respectively. Prior to alkylation, the cis-intermediate $\mathbf{3 7}$ was also treated with sodium hydride to isomerize the alpha proton to the trans-isomer. Although this resulted in an inseparable mixture of the cis- and trans-diastereomers, after alkylation with benzyl or butyl isocyanate, the diastereomers could be separated to yield the pure trans-analogs 5 and $\mathbf{6}$ (Scheme 2).

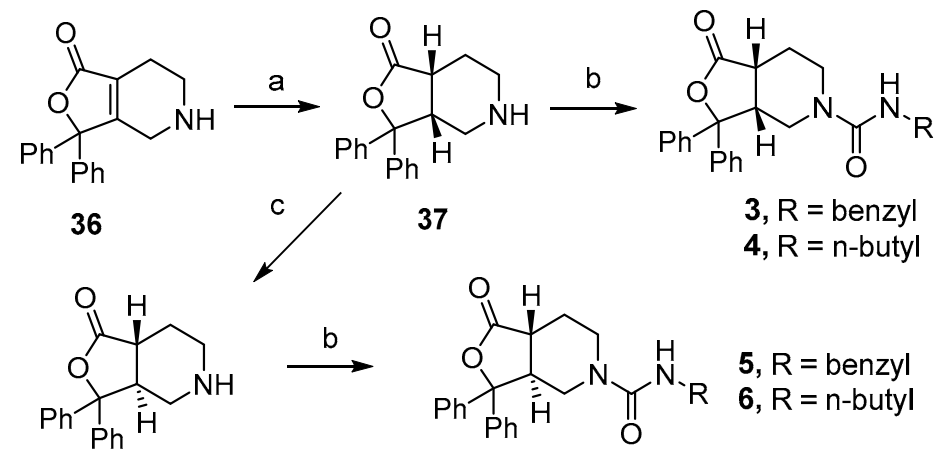

38

Reagents and conditions:a) Nickel acetate, $\left.\mathrm{NaBH}_{4}, \mathrm{THF} ; \mathrm{b}\right)$ isocyanate $\mathrm{CH}_{2} \mathrm{Cl}_{2} ; \mathrm{c}$ ) $\mathrm{NaH}$, THF.

Scheme 2. Synthesis of saturated diaryl analogs using the alkene core.

Previous work by Niiyama and colleagues [17] demonstrated that the addition of aryl Grignard reagents to pyridine 3,4-dicarboxylic acid anhydride affords compounds with selective addition of the Grignard to the carbonyl para to the pyridyl nitrogen. Compound 7 was obtained from the addition of excess phenyl magnesium bromide to pyridine 3,4dicarboxylic acid anhydride to yield pyridine intermediate 39 . The sequence depicted in Scheme 1 was then followed to yield target compound 7.

Oxazolidinone analog 29, which mimics SHA with one phenyl group replaced with an isobutyl group, was synthesized from N-t-butoxy carbonyl, N-benzyl piperidine. Deprotonation of piperidine $\mathbf{9 2}$ was accomplished with sec-butyl lithium and tetramethylene diamine. The anion was quenched with the addition of isovalerophenone followed by cyclization to the oxazolidinone ring 93 . Catalytic reduction of the benzyl ring was unsuccessful due to hydrogenolysis of the oxazolidinone ring. Removal of the benzyl group was undertaken with FMOC-chloride (94) followed by deprotection of the FMOC group with 
piperidine to yield the free amine 95 . Treatment of the free amine 95 with benzyl isocyanate yielded the desired compound 29 (Scheme 3; Figure S29, Supplementary Materials).
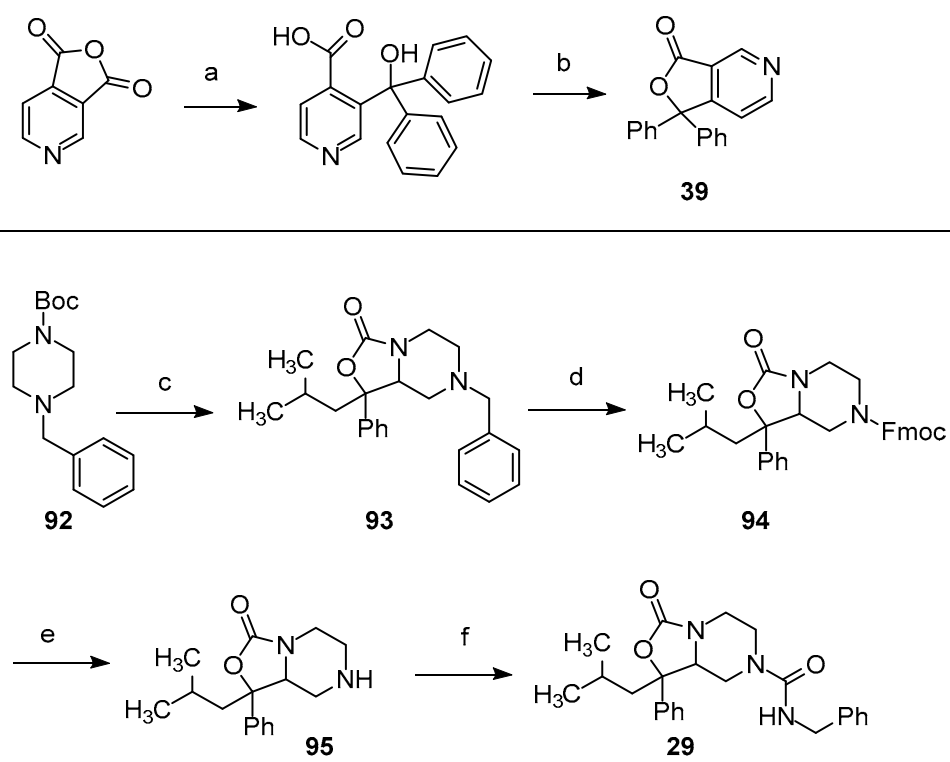

Reagents and conditions: a) PhMgBr, THF. b) $6 \mathrm{~N} \mathrm{HCl}$; c) TMEDA, sec-butyl lithium, isovalerophenone, THF; d) Fmoc-Cl, ACN, $90{ }^{\circ} \mathrm{C}$; e) Piperidine, $\mathrm{ACN}$; f) benzyl isocyanate, $\mathrm{CH}_{2} \mathrm{Cl}_{2}$

Scheme 3. Synthesis of 3-N analogs and isobutyl replacement for phenyl in SHA.

\section{Results and Discussion}

We hypothesized that a 4,5,6,7-tetrahydrofuro[3,4-c]pyridin-1(3H)-one core, which is similar to that of SHA-68, would allow access to broader functional group modifications and, ultimately, allow access to a larger SAR study than those previously reported for SHA-related antagonists. Compound 1 maintained the same substituents as SHA- 68 but incorporated a fused double bond in place of the oxazolidinone nitrogen atom.

A direct comparison of compound $\mathbf{1}(\mathrm{Ke}=522 \mathrm{nM})$ with SHA- $66(\mathrm{Ke}=10 \mathrm{nM})$ indicated that replacement of the nitrogen atom with a double bond was detrimental for antagonist activity by roughly 50 -fold (Table 1 ). We have previously shown that replacement of the benzyl urea on SHA with an $n$-butyl group resulted in compounds with equipotent antagonist activity but more conformational flexibility [10]. Therefore, we evaluated compound 2 with $n$-butyl urea; however, this was also reduced in activity compared to SHA by roughly 50 -fold. This suggested that either the overall conformation of $\mathbf{1}$ was less tolerated by the receptor or the oxazolidinone nitrogen was a critical pharmacophore element. In order to investigate this further, reduction of the double bond to both the cis-isomers $\mathbf{3}$ and $\mathbf{4}$ and trans-isomers $\mathbf{5}$ and $\mathbf{6}$ were undertaken. The cis-isomers with a significantly different three-dimensional shape lacked antagonist activity, whereas the trans-isomers 5 and 6 were moderately potent with Ke values of $170 \mathrm{nM}$ and $260 \mathrm{nM}$, respectively. We then evaluated whether shifting the urea substituent within the ring system, as shown in compound 7 , could restore activity, but this resulted in a significant loss of potency.

Importantly, this new core scaffold allows more efficient access to modification of the 3,3-diphenyl ring system without the introduction of a second chiral center (Table 2). Conformational control is an important aspect of ligand design. Reducing conformational freedom was explored by linking the two aryl rings together (compounds $\mathbf{8}$ and 9 ) as well as removing an aryl ring (compound 10) and activity was lost. In order to reduce the sp2 count for SHA, we envisioned the replacement of one aryl ring with an aliphatic group. Replacement of one phenyl ring into various aliphatic substituents yielded compounds 11-15. The $n$-butyl compound $\mathbf{1 1}$ was moderately potent $\left(\mathrm{K}_{\mathrm{e}}=165 \mathrm{nM}\right)$, but the iso-butyl compound $\mathbf{1 4}$ 
$\left(K_{\mathrm{e}}=118 \mathrm{nM}\right)$ was the most potent and was also anticipated to have an improved metabolic profile. Integrating various heteroatoms with hydrogen bond acceptors or donors into this portion of the molecule, such as a dimethylamino group or a hydroxy group (17-21), resulted in a loss of activity. In order to potentially reduce oxidative metabolism on one of the remaining unsubstituted aryl rings, we explored a series of substituted aryl rings (22-25) and found that the incorporation of naphthyl, hydroxy or benzyl ether groups (22-24) resulted in a reduction in potency. However, the 3-chlorophenyl group 25 only had a modest reduction in potency, at $136 \mathrm{nM}$ compared to $\mathbf{1 4}$.

Our lab has previously shown that replacement of the benzyl urea with a piperidino ethyl urea on the SHA core provides analogs with good brain permeability, enhanced solubility, and favorable in vivo activity $[8,10,18]$. With lead compound $\mathbf{1 4}$ in hand, we moved forward with exploring further modifications to the urea group using the 3-isobutyl-3-phenyl substituted core (Table 3). Incorporating $n$-butyl urea (26), piperidino ethyl urea (27) and piperidino ethyl thiourea (28) substituents resulted in a reduction in potency. The two enantiomers of compound $\mathbf{1 4}$ were separated by chiral HPLC, and we determined that the plus isomer $(\mathbf{1 4 b})$ was the active enantiomer $\left(K_{e}=71.4 \mathrm{nM}\right.$, Table 3$)$ and showed a significant right shift to the agonist activity of NPS at $3 \mu \mathrm{M}$ concentration in calcium mobilization assay (Figure 3). In order to evaluate if this new series was interacting with the NPSR in a similar manner as SHA, we synthesized the SHA analog with isobutyl substituted for one of the aryl rings. Compound 29 was completely inactive, suggesting that this new series binds to the NPSR in an overlapping but distinct manner.

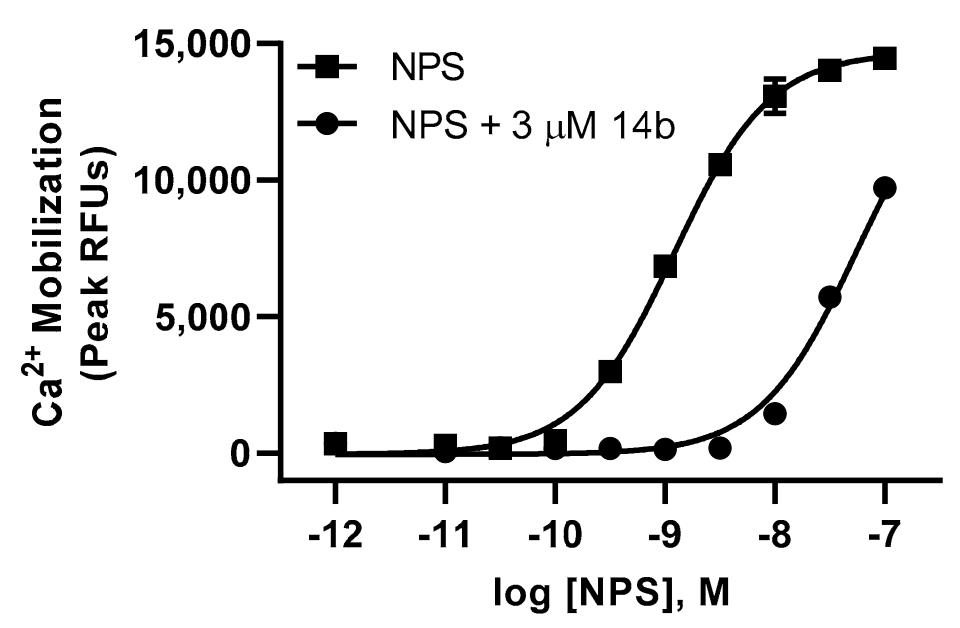

Figure 3. Compound $\mathbf{1 4 b}$ displays a right shift on agonist activity of NPS in calcium mobilization assay $(\mathrm{Ke})$.

One of the primary concerns for compound $\mathbf{1 4 b}$ was the potential to function as a Michael acceptor and non-specifically form covalent bonds to nucleophilic proteins. We therefore evaluated the ability of glutathione to add to the alpha beta unsaturated double bond of $\mathbf{1 4 b}$ (Scheme 4). Compound $\mathbf{1 4 b}$ was incubated in a solution of acetonitrile and water with glutathione, according to the method of Cevher et al. [19]. Over the course of $1,2,4,6,24$, and $48 \mathrm{~h}$, the solution was evaluated for the appearance of molecular ions at 711 and 713 AMU. No glutathione adduct was identified over the course of the study, indicating that the tetrasubstituted double bond is most likely too sterically crowded and does not serve as an electrophilic acceptor for reactive proteins. 

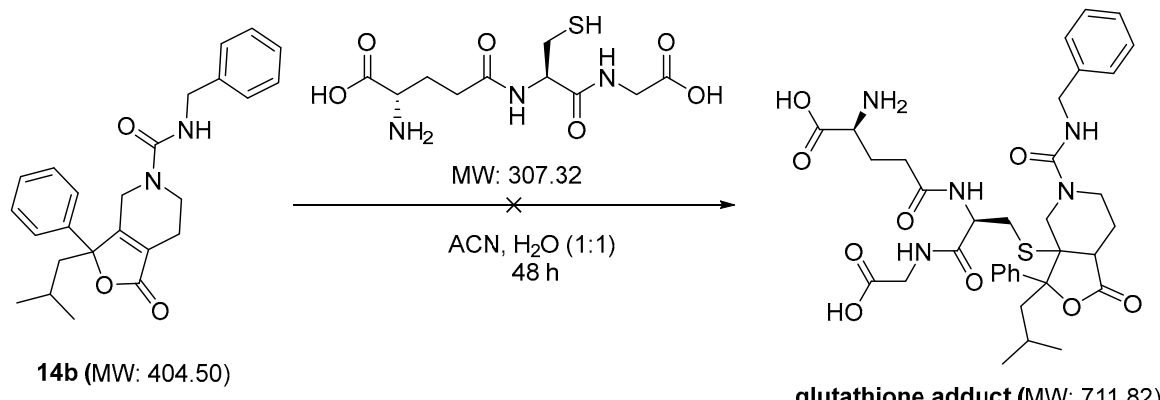

glutathione adduct (MW: 711.82

Scheme 4. Compound $\mathbf{1 4 b}$ is stable in the presence of excess of glutathione (18 $\mathrm{mM})$.

Considering that $\mathbf{1 4 b}$ functions as a potent NPSR antagonist and should not serve as an electrophile in vivo, its ability to access the CNS and metabolic stability were evaluated. A pharmacokinetic study of $\mathbf{1 4 b}$ was undertaken in C57Bl6 mice. Over the four hours following an i.p. dose of $30 \mathrm{mg} / \mathrm{kg}$, blood and brain were collected at 15 and $30 \mathrm{~min}$, followed by 1, 2, and $4 \mathrm{~h}$ (Figure 4). A Cmax of $1938 \mathrm{ng} / \mathrm{mL}$ and $186 \mathrm{ng} / \mathrm{mL}$ was obtained in the plasma and brain, respectively. Clearance in plasma was $288 \mathrm{~mL} / \mathrm{min} / \mathrm{kg}$, indicating a rapid clearance most likely due to oxidative metabolism. Although the clearance was higher than desired, brain levels for the duration of behavioral experiments up to $1 \mathrm{~h}$ were sufficiently above the Ke of $\mathbf{1 4 b}$. Further optimization of metabolic stability will be addressed in future studies.

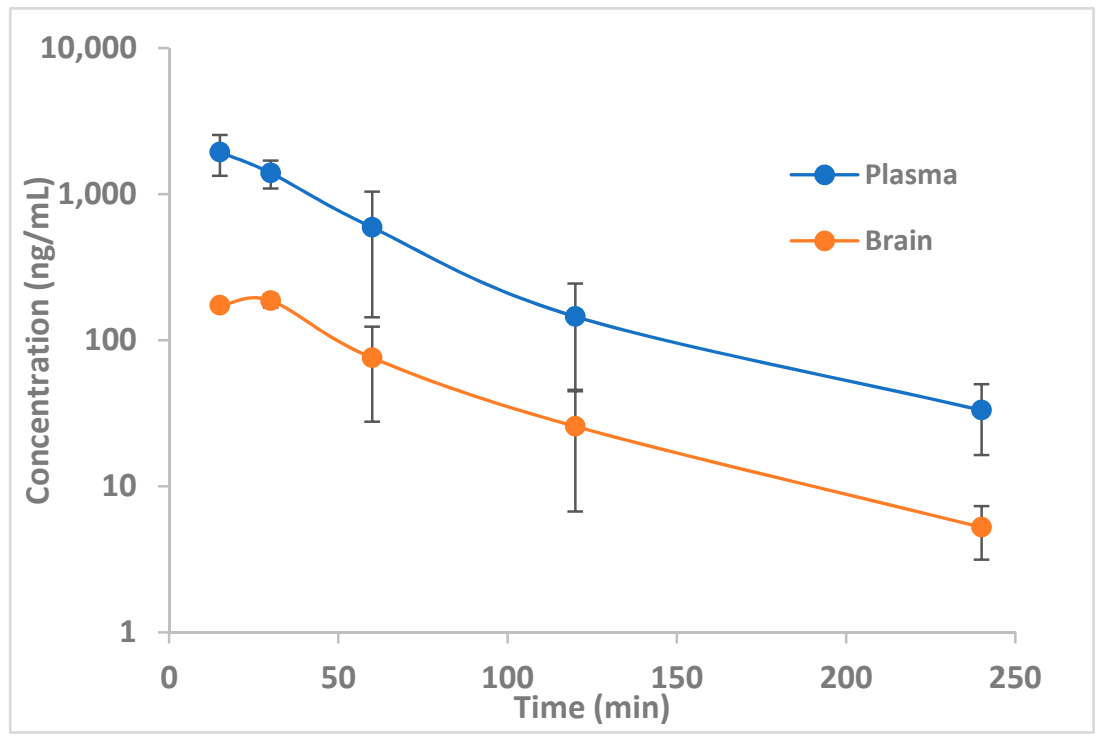

Figure 4. Pharmacokinetic study of $\mathbf{1 4 b}$ in C57/Bl6 mice. Three animals/timepoint $30 \mathrm{mg} / \mathrm{kg}$ i.p. in $1 \%$ (NMP), $0.5 \%$ Tween $80,0.5 \%$ carboxymethyl cellulose).

After establishing that sufficient levels of compound $\mathbf{1 4 b}$ reached the CNS after systemic injection, it was evaluated in vivo for antagonist activity in a well-established NPSRmediated behavior; NPS-mediated hyperlocomotion [1]. In this behavioral paradigm, mice are habituated to an open arena and centrally administered NPS, which has been shown to increase locomotion in a dose-dependent and NPSR-dependent manner. In the current study, this NPS-mediated effect was attenuated with the pretreatment of systemically administered $3 \mathrm{mg} / \mathrm{kg}$ compound 14b (Figure 5; one-way ANOVA found a significant effect, $p=0.004$, with Tukey's post hoc analysis showing significant differences in the following comparisons: Veh-aCSF vs. Veh-NPS $p=0.0004$, Veh-NPS vs. 14b-aCSF $p=0.0020$, Veh-NPS vs. 14b-NPS $p=0.0389$ ). However, compound $14 \mathrm{~b}$ did not decrease locomotion on its own ( $3 \mathrm{mg} / \mathrm{kg}$; Veh-aCSF vs. 14b-aCSF $p=0.8199)$. The data suggest that compound $\mathbf{1 4 b}$ is highly effective in blocking the effects of exogenously administered NPS. The dose of 
NPS used in this study was one-third of that required to produce maximal effects in this paradigm; therefore, it is likely that compound $\mathbf{1 4 b}$ had adequate potency and affinity to antagonize endogenous NPS.

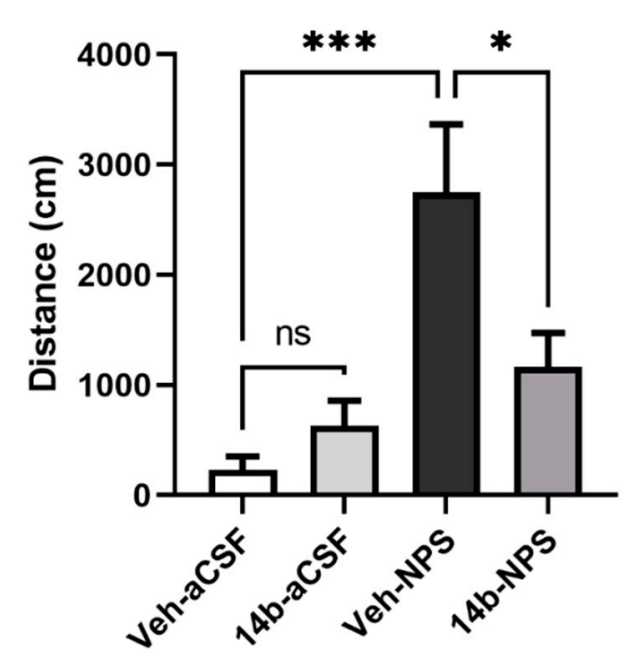

Figure 5. Compound 14b attenuates the hyperlocomotory effects of NPS. After 90 min of habituation, mice were pretreated with vehicle or compound $\mathbf{1 4 b}(3 \mathrm{mg} / \mathrm{kg}$ i.p. $)$, then $10 \mathrm{~min}$ later, injected ICV with aCSF or NPS (0.3 nmole). Total distances traveled for the first $10 \mathrm{~min}$ after the ICV injection are displayed in the above graph. Compound $14 \mathrm{~b}(3 \mathrm{mg} / \mathrm{kg}$ i.p.) significantly decreased the hyperlocomotor effects of NPS. ( ${ }^{* * *} p<0.001,{ }^{*} p<0.05$; Veh-aCSF $n=6,14 \mathrm{~b}-\mathrm{aCSF} n=6$, Veh-NPS $n=5, \mathbf{1 4 b}$-NPS $n=4)$.

\section{Experimental Section}

All standard reagents were commercially available. Compounds were purified by column chromatography on a Teledyne Isco Rf chromatography unit and by HPLC on an Agilent-Varian HPLC system equipped with Prostar 210 dual pumps, a Prostar 335 Diode UV detector and a SEDEX75 (SEDERE, Olivet, France) ELSD detector. The HPLC solvent system was binary, water containing $0.1 \%$ trifluoroacetic acid (TFA) and solvent B (acetonitrile containing 5\% water and 0.1\% TFA). A semi-preparative Synergy Hydro ${ }^{\circledR}$ RP 80A C18 column ( $4 \mu \mathrm{m} 250 \times 21.2 \mathrm{~mm}$ column; Phenomenex) was used to purify final compounds at $15 \mathrm{~mL} / \mathrm{min}$ using a linear gradient from $5 \%$ to 50 or $60 \%$ B over $30 \mathrm{~min}$. The purity of final compounds was determined using an analytical Synergy Hydro ${ }^{\circledR}$ RP80A C18 (4 $\mu \mathrm{m} 250 \times 4.60 \mathrm{~mm}$ column; Phenomenex, Torrance, CA, USA) with a linear gradient of $5-95 \%$ solvent $B$ over 20 or $30 \mathrm{~min}$ at a flow rate of $1 \mathrm{~mL} / \mathrm{min}$. Absorbance was monitored at $220 \mathrm{~nm}$. Cis/Trans diastereomers were separated using a semi-preparative RP HPLC YMC ODS-A (S5 $\mu \mathrm{m}, 120 \AA 2,20 \times 250 \mathrm{~mm} ; 10 \mathrm{~mL} / \mathrm{min}$ ) with isocratic conditions (35:65 acetonitrile/water) at $204 \mathrm{~nm}$. Diastereomeric purity was determined using an analytical RP HPLC YMC ODS-A (S5 $\mu \mathrm{m}, 120 \AA, 4.6 \times 250 \mathrm{~mm} ; 1 \mathrm{~mL} / \mathrm{min})$. Enantiomers of compound 14 were separated by analytical and semi-preparative chiral HPLC performed using a dual-pump system (Dynamax SD-300 solvent system delivery system with $25 \mathrm{~mL}$ pump heads), a Rheodyne injector and a Varian ProStar 330 diode-array detector (DAD) controlled by Varian Star Workstation software.

The molecular ion of final compounds was determined using a PE Sciex API 150 EX LC/MS system from Perkin Elmer (San Jose, California). Reactions were monitored by thin-layer chromatography (TLC) carried out on pre-coated $60 \AA 250 \mathrm{~mm}$ silica gel TLC plates with F-254 indicator visualized under UV light, and developed using ceric ammonium molybdate. ${ }^{1} \mathrm{H}$ NMR spectra were recorded at $300 \mathrm{MHz}$ on a Bruker Avance 300 Spectrospin instrument and are reported as follows: chemical shift $\delta$ in ppm (multiplicity, coupling constant $(\mathrm{Hz})$, and integration. The following abbreviations were used to explain multiplicities: $s$, singlet; $d$, doublet; $t$, triplet; q, quartet; quin, quintet; $m$, multiplet; br, 
broad; dd, doublet of doublets; $\mathrm{dt}$, doublet of triplets; ddd, doublet of doublets of doublets; $\mathrm{ddt}$, doublet of doublet of triplets.

4.1. Procedure A. 3-(1-Hydroxy-3-methyl-1-phenylbutyl)-N,N-bis(1-methylethyl)pyridine4-carboxamide (31)

LDA (2.0 M, $14.5 \mathrm{~mL}, 29.1 \mathrm{mmol}, 3$ equiv.) was added to $\mathrm{N}, \mathrm{N}$-diisopropylisonicotinamide $30\left(2.0 \mathrm{~g}, 9.70 \mathrm{mmol}, 1\right.$ equiv.) at $-78^{\circ} \mathrm{C}$. The reaction was stirred for $1.5 \mathrm{~h}$ and a solution of isovalerophenone $(4.72 \mathrm{~g}, 29.1 \mathrm{mmol}, 3$ equiv.) in ether was then added and stirred for $40 \mathrm{~min}$ at $-78{ }^{\circ} \mathrm{C}$. The reaction mixture was quenched with water and extracted. The organic layers were combined, dried with sodium sulfate, and concentrated under reduced pressure. The resulting residue was purified by silica gel column chromatography to yield compound 31 (1.65 g, $4.48 \mathrm{mmol}, 46 \%$ yield). ${ }^{1} \mathrm{H}$ NMR $\left(300 \mathrm{MHz}, \mathrm{CDCl}_{3}\right) \delta \mathrm{ppm} 0.37(\mathrm{~d}$, $J=6.78 \mathrm{~Hz}, 3 \mathrm{H}), 0.57(\mathrm{~d}, J=6.78 \mathrm{~Hz}, 3 \mathrm{H}), 0.89-1.02(\mathrm{~m}, 6 \mathrm{H}), 1.19-1.30(\mathrm{~m}, 3 \mathrm{H}), 1.39(\mathrm{~d}$, $\mathrm{J}-6.78 \mathrm{~Hz}, 3 \mathrm{H}), 1.98-2.14(\mathrm{~m}, 2 \mathrm{H}), 2.21-2.36(\mathrm{~m}, 1 \mathrm{H}), 3.08-3.32(\mathrm{~m}, 2 \mathrm{H}), 6.16(\mathrm{~d}, J=1.51 \mathrm{~Hz}$, $1 \mathrm{H}), 7.14-7.41(\mathrm{~m}, 5 \mathrm{H}), 8.54(\mathrm{~d}, J=4.90 \mathrm{~Hz}, 1 \mathrm{H}), 8.60-8.71(\mathrm{~m}, 1 \mathrm{H}), 8.96(\mathrm{~s}, 1 \mathrm{H})$.

\subsection{Procedure B. 3-(2-Methylpropyl)-3-phenylfuro[3,4-c]pyridin-1(3H)-one (32)}

Compound $31(2.2 \mathrm{~g}, 5.69 \mathrm{mmol})$ was dissolved in $6 \mathrm{M} \mathrm{HCl}$ in dioxane $(40 \mathrm{~mL})$. The reaction was stirred at room temperature overnight. The reaction was then basified with aqueous sodium bicarbonate, diluted with $\mathrm{CH}_{2} \mathrm{Cl}_{2}$, and extracted. The organic layers were combined, dried with sodium sulfate, and concentrated under reduced pressure. The resulting residue was purified by silica gel column chromatography to yield compound 32 (1.12 g, $4.19 \mathrm{mmol}, 74 \%$ yield). ${ }^{1} \mathrm{H}$ NMR $\left(300 \mathrm{MHz}, \mathrm{CDCl}_{3}\right) \delta \mathrm{ppm} 0.86$ (dd, $J=11.68$, $6.78 \mathrm{~Hz}, 6 \mathrm{H}), 1.47-1.71(\mathrm{~m}, 1 \mathrm{H}), 1.99-2.14(\mathrm{~m}, 1 \mathrm{H}), 2.52(\mathrm{dd}, J=14.88,5.09 \mathrm{~Hz}, 1 \mathrm{H}), 7.27-7.46$ $(\mathrm{m}, 3 \mathrm{H}), 7.48-7.61(\mathrm{~m}, 2 \mathrm{H}), 7.76(\mathrm{dd}, J=4.90,1.13 \mathrm{~Hz}, 1 \mathrm{H}), 8.83(\mathrm{~d}, J=4.90 \mathrm{~Hz}, 1 \mathrm{H}), 9.04(\mathrm{~d}$, $J=1.13 \mathrm{~Hz}, 1 \mathrm{H})$.

\subsection{Procedure C. 3-(2-Methylpropyl)-3-phenyl-4,5,6,7-tetrahydrofuro[3,4-c]pyridin-1(3H)- one (33)}

Compound 32 (1.12 g, $4.19 \mathrm{mmol}, 1$ equiv.) was dissolved in $1.25 \mathrm{M} \mathrm{HCl}$ in ethanol ( $3.35 \mathrm{~mL}, 1$ equiv.). A catalytic amount of $\mathrm{PtO}_{2}$ was added and the mixture was put under hydrogen on a parr hydrogenator at $40 \mathrm{psi}$ for $4 \mathrm{~h}$. The $\mathrm{PtO}_{2}$ was removed by filtration and the solvent was removed under reduced pressure. EtOAc was added to the residue, and it was basified with aqueous sodium bicarbonate and extracted. The organic layer was dried with sodium sulfate and concentrated under reduced pressure, and the residue was purified by silica gel column chromatography to yield alkene $33(0.90 \mathrm{~g}, 3.32 \mathrm{mmol}, 79 \%$ yield). ${ }^{1} \mathrm{H}$ NMR $\left(300 \mathrm{MHz}, \mathrm{CDCl}_{3}\right) \delta \mathrm{ppm} 0.77-1.01(\mathrm{~m}, 6 \mathrm{H}), 1.56-1.71(\mathrm{~m}, 1 \mathrm{H}), 1.73-1.84(\mathrm{~m}$, $1 \mathrm{H}), 1.96-2.14(\mathrm{~m}, 1 \mathrm{H}), 2.15-2.40(\mathrm{~m}, 3 \mathrm{H}), 2.81-3.06(\mathrm{~m}, 2 \mathrm{H}), 3.40-3.51(\mathrm{~m}, 1 \mathrm{H}), 3.59-3.74(\mathrm{~m}$, $1 \mathrm{H}), 7.20-7.44(\mathrm{~m}, 5 \mathrm{H})$. ESI MS $m / z$ : Calculated for $\mathrm{C}_{17} \mathrm{H}_{21} \mathrm{NO}_{2} 271.16$, Found $270.2(\mathrm{M}-\mathrm{H})^{-}$.

\subsection{Procedure $D$}

4.4.1. N-Benzyl-3-(2-methylpropyl)-1-oxo-3-phenyl- $1 \mathrm{H}, 3 \mathrm{H}, 4 \mathrm{H}, 5 \mathrm{H}, 6 \mathrm{H}, 7 \mathrm{H}-$ furo[3,4-c]pyridine-5-carboxamide (14a,b)

Benzyl isocyanate $(0.029 \mathrm{~g}, 0.22 \mathrm{mmol}, 1.2$ equiv.) was added to compound $33(0.05 \mathrm{~g}$, $0.184 \mathrm{mmol}, 1$ equiv.) in $\mathrm{CH}_{2} \mathrm{Cl}_{2}(10 \mathrm{~mL})$. The reaction was stirred at room temperature for $1 \mathrm{~h}$. The reaction mixture was concentrated under reduced pressure and the resulting reside was purified via silica gel chromatography $(20 \%$ EtOAc/hexane) to yield compound $14\left(0.051 \mathrm{~g}, 0.13 \mathrm{mmol}, 69 \%\right.$ yield). ${ }^{1} \mathrm{H}$ NMR $\left(300 \mathrm{MHz}, \mathrm{CDCl}_{3}\right) \delta \mathrm{ppm} 0.85(\mathrm{~d}, J=6.40 \mathrm{~Hz}$, $3 \mathrm{H}), 0.89-0.98(\mathrm{~m}, 3 \mathrm{H}), 1.65(\mathrm{ddd}, J=13.56,6.78,4.90 \mathrm{~Hz}, 1 \mathrm{H}), 1.73-1.87(\mathrm{~m}, 1 \mathrm{H}), 2.24-2.40$ $(\mathrm{m}, 3 \mathrm{H}), 3.27(\mathrm{ddd}, J=13.56,7.35,5.09 \mathrm{~Hz}, 1 \mathrm{H}), 3.54(\mathrm{dt}, J=13.66,5.23 \mathrm{~Hz}, 1 \mathrm{H}), 3.92(\mathrm{dt}$, $J=18.84,2.64 \mathrm{~Hz}, 1 \mathrm{H}), 4.40(\mathrm{~d}, J=5.65 \mathrm{~Hz}, 2 \mathrm{H}), 4.49(\mathrm{dt}, J=19.12,2.12 \mathrm{~Hz}, 1 \mathrm{H}), 5.00$ $(\mathrm{t}, J=5.46 \mathrm{~Hz}, 1 \mathrm{H}), 7.21-7.42(\mathrm{~m}, 10 \mathrm{H})$. The separation of the enantiomers of compound 14 was achieved by semi-preparative chiral HPLC performed on an amylose-based chiral column (Chiralpak IA $250 \times 20 \mathrm{~mm}, 5 \mu \mathrm{m}$ ). An isocratic elution employing hexanes with $0.1 \%$ diethylamine / isopropanol with $0.1 \%$ diethylamine (90:10) at a flow rate of 
$15 \mathrm{~mL} / \mathrm{min}$ and following by UV ( $240 \mathrm{~nm}$ ) afforded the purified enantiomers. HPLC analysis (Chiralpak IA, $4.6 \times 250 \mathrm{~mm}, 5 \mu \mathrm{M}$, hexanes containing $0.1 \%$ diethylamine/isopropanol containing $0.1 \%$ diethylamine (90:10), $1.0 \mathrm{~mL} / \mathrm{min}, 240 \mathrm{~nm}$ ) indicated that peak 1 $(8.760 \mathrm{~min})$ was $>99 \%$ ee (did not detect the other enantiomer) $[\alpha]_{\mathrm{D}}{ }^{22}=-60.9$ (c 0.96 , $\mathrm{MeOH})$ and peak $2(10.067 \mathrm{~min})$ was $96.2 \%$ ee. $[\alpha]_{\mathrm{D}}^{22}=+61.9(\mathrm{c} 1.03, \mathrm{MeOH})$.

4.4.2. N-Benzyl-1-oxo-3,3-diphenyl-1H,3H,4H,5H,6H,7H-furo[3,4-c]pyridine5-carboxamide (1)

Benzyl isocyanate was reacted with 36 according to procedure $\mathrm{D}$ to yield compound $1\left(0.031 \mathrm{~g}, 0.073 \mathrm{mmol}, 86 \%\right.$ yield). ${ }^{1} \mathrm{H}$ NMR $\left(300 \mathrm{MHz}, \mathrm{CDCl}_{3}\right) \delta \mathrm{ppm} 2.47$ (tt, $J=5.46$, $2.45 \mathrm{~Hz}, 2 \mathrm{H}), 3.51(\mathrm{t}, J=5.65 \mathrm{~Hz}, 2 \mathrm{H}), 4.27(\mathrm{t}, J=2.45 \mathrm{~Hz}, 2 \mathrm{H}), 4.41(\mathrm{~d}, J=5.65 \mathrm{~Hz}, 2 \mathrm{H})$, $4.97(\mathrm{t}, J=5.27 \mathrm{~Hz}, 1 \mathrm{H}), 7.18-7.32(\mathrm{~m}, 8 \mathrm{H}), 7.31-7.40(\mathrm{~m}, 7 \mathrm{H})$; MS (ESI) $m / z$ : calcd for $\mathrm{C}_{27} \mathrm{H}_{24} \mathrm{~N}_{2} \mathrm{O}_{3} 424.49$, found $425.4[\mathrm{M}+\mathrm{H}]^{+}$. HPLC $(220 \mathrm{~nm}) t_{\mathrm{R}}=15.68 \mathrm{~min}$.

4.4.3. N-Butyl-1-oxo-3,3-diphenyl-1H,3H,4H,5H,6H,7H-furo[3,4-c]pyridine5-carboxamide (2)

Butyl isocyanate was reacted with 36 according to procedure $\mathrm{D}$ to yield compound $2(0.024 \mathrm{~g}, 0.061 \mathrm{mmol}, 72 \%$ yield $) .{ }^{1} \mathrm{H}$ NMR $\left(300 \mathrm{MHz}, \mathrm{CDCl}_{3}\right) \delta \mathrm{ppm} 0.85-0.97(\mathrm{~m}, 3 \mathrm{H})$, $1.18-1.54(\mathrm{~m}, 4 \mathrm{H}), 2.49(\mathrm{tt}, J=5.46,2.45 \mathrm{~Hz}, 2 \mathrm{H}), 3.23(\mathrm{td}, J=7.06,5.46 \mathrm{~Hz}, 2 \mathrm{H}), 3.50$ $(\mathrm{t}, J=5.65 \mathrm{~Hz}, 2 \mathrm{H}), 4.25(\mathrm{t}, J=2.45 \mathrm{~Hz}, 2 \mathrm{H}), 4.55(\mathrm{t}, J=5.46 \mathrm{~Hz}, 1 \mathrm{H}), 7.20-7.31(\mathrm{~m}, 4 \mathrm{H})$, 7.33-7.41 (m, 6H). MS (ESI) $m / z$ : calcd for $\mathrm{C}_{24} \mathrm{H}_{26} \mathrm{~N}_{2} \mathrm{O}_{3} 390.47$, found $391.4[\mathrm{M}+\mathrm{H}]^{+}$. $\operatorname{HPLC}(220 \mathrm{~nm}) t_{\mathrm{R}}=15.63 \mathrm{~min}$.

4.4.4. (3,7)-N-Benzyl-1-oxo-3,3-diphenyl-octahydrofuro[3,4-c]pyridine-5-carboxamide (3 and 5)

The mixture of cis and trans amines 37 and 38 was reacted with benzyl isocyanate according to procedure D. The mixture was then separated by HPLC to yield cis isomer compound 3 and trans isomer $5 .{ }^{1} \mathrm{H} \mathrm{NMR}\left(300 \mathrm{MHz}, \mathrm{CDCl}_{3}\right) \delta \mathrm{ppm} 7.54(\mathrm{~d}, J=7.7 \mathrm{~Hz}, 2 \mathrm{H})$, $7.44(\mathrm{~d}, J=7.7 \mathrm{~Hz}, 2 \mathrm{H}), 7.39-7.18(\mathrm{~m}, 11 \mathrm{H}), 4.79-4.68(\mathrm{~m}, 1 \mathrm{H}), 4.48-4.31(\mathrm{~m}, 2 \mathrm{H}), 3.94(\mathrm{dd}$, $J=14.1,5.8 \mathrm{~Hz}, 1 \mathrm{H}), 3.64-3.49(\mathrm{~m}, 2 \mathrm{H}), 2.96-2.78(\mathrm{~m}, 2 \mathrm{H}), 2.38-2.24(\mathrm{~m}, 1 \mathrm{H}), 2.10(\mathrm{~d}$, $J=13.7 \mathrm{~Hz}, 1 \mathrm{H}), 1.93-1.75(\mathrm{~m}, 1 \mathrm{H})$; MS (ESI) $m / z$ : calcd for $\mathrm{C}_{27} \mathrm{H}_{26} \mathrm{~N}_{2} \mathrm{O}_{3} 426.51$, found 427.4 $[\mathrm{M}+\mathrm{H}]^{+}$. HPLC $(220 \mathrm{~nm}) t_{\mathrm{R}}=15.80 \mathrm{~min}$. Trans isomer 5 HPLC $(220 \mathrm{~nm})$ $t_{\mathrm{R}}=15.89 \mathrm{~min}$.

\subsection{5. (3,7)-N-Butyl-1-oxo-3,3-diphenyl-octahydrofuro[3,4-c]pyridine-5-carboxamide (4)}

Cis amine 37 was reacted with butyl isocyanate according to procedure $\mathrm{D}$ to yield compound $4(0.031 \mathrm{~g}, 0.079 \mathrm{mmol}, 92 \%$ yield $) .{ }^{1} \mathrm{H}$ NMR $\left(300 \mathrm{MHz}, \mathrm{CDCl}_{3}\right) \delta \mathrm{ppm} 0.92(\mathrm{t}$, $J=7.35 \mathrm{~Hz}, 3 \mathrm{H}), 1.24-1.52(\mathrm{~m}, 4 \mathrm{H}), 1.75-1.92(\mathrm{~m}, 1 \mathrm{H}), 2.10(\mathrm{~d}, J=13.94,1 \mathrm{H}), 2.28(\mathrm{dd}$, $J=14.13,11.87,1 \mathrm{H}), 2.77-2.96(\mathrm{~m}, 2 \mathrm{H}), 3.11-3.28(\mathrm{~m}, 2 \mathrm{H}), 3.47-3.62(\mathrm{~m}, 2 \mathrm{H}), 3.91(\mathrm{dd}$, $J=14.32,5.65 \mathrm{~Hz}, 1 \mathrm{H}), 4.40(\mathrm{t}, J=5.27 \mathrm{~Hz}, 1 \mathrm{H}), 7.17-7.38(\mathrm{~m}, 6 \mathrm{H}), 7.42-7.48(\mathrm{~m}, 2 \mathrm{H}), 7.50$ $7.59(\mathrm{~m}, 2 \mathrm{H})$; MS (ESI) $m / z$ : calcd for $\mathrm{C}_{24} \mathrm{H}_{28} \mathrm{~N}_{2} \mathrm{O}_{3} 392.49$, $\mathrm{HPLC}(220 \mathrm{~nm}) t_{\mathrm{R}}=16.42 \mathrm{~min}$.

4.4.6. (3,7)-N-Butyl-1-oxo-3,3-diphenyl-octahydrofuro[3,4-c]pyridine-5-carboxamide (6)

The isomerized mixture of $c i s$ and trans amines 37 and 38 was reacted with butyl isocyanate according to procedure $\mathrm{D}$. The mixture of isomers was separated by HPLC to yield compound $6(0.036 \mathrm{~g}, 0.095 \mathrm{mmol}, 35 \%$ yield $) .{ }^{1} \mathrm{H}$ NMR $\left(300 \mathrm{MHz}, \mathrm{CDCl}_{3}\right) \delta \mathrm{ppm}$ $0.94(\mathrm{t}, J=7.16,3 \mathrm{H}), 1.30-1.71(\mathrm{~m}, 6 \mathrm{H}), 2.10-2.43(\mathrm{~m}, 2 \mathrm{H}), 2.59-2.90(\mathrm{~m}, 2 \mathrm{H}), 3.16-3.38(\mathrm{~m}$, 2H), $3.74(\mathrm{~d}, J=12.43 \mathrm{~Hz}, 1 \mathrm{H}), 4.49$ (br.s, $1 \mathrm{H}), 4.96(\mathrm{~d}, J=10.55 \mathrm{~Hz}, 1 \mathrm{H}), 7.12-7.22(\mathrm{~m}, 2 \mathrm{H})$, 7.28-7.44 (m, 6H), 7.51-7.59 (m, 2H); MS (ESI) $m / z$ : calcd for $\mathrm{C}_{24} \mathrm{H}_{28} \mathrm{~N}_{2} \mathrm{O}_{3} 392.49$, found $393.4[\mathrm{M}+\mathrm{H}]^{+}$. HPLC $(220 \mathrm{~nm}) t_{\mathrm{R}}=3.21 \mathrm{~min}$.

4.4.7. N-Benzyl-3-oxo-1,1-diphenyl-1H,3H,4H,5H,6H,7H-furo[3,4-c]pyridine5-carboxamide (7)

Amine 40 was reacted with benzyl isocyanate according to procedure $\mathrm{D}$ to yield compound 7 (0.038 mg, $0.09 \mathrm{mmol}, 52 \%$ yield). ${ }^{1} \mathrm{H} \mathrm{NMR}\left(300 \mathrm{MHz}, \mathrm{CDCl}_{3}\right) \delta \mathrm{ppm} 2.48(\mathrm{dt}$, 
$J=5.27,2.64 \mathrm{~Hz}, 2 \mathrm{H}), 3.68(\mathrm{t}, J=5.46 \mathrm{~Hz}, 2 \mathrm{H}), 4.09-4.16(\mathrm{~m}, 2 \mathrm{H}), 4.41(\mathrm{~d}, J=5.27 \mathrm{~Hz}, 2 \mathrm{H})$, 5.03-5.14 (m, 1H), 7.13-7.33 (m, 9H), 7.34-7.42 (m, 6H); MS (ESI) $m / z$ : calcd for $\mathrm{C}_{27} \mathrm{H}_{24} \mathrm{~N}_{2} \mathrm{O}_{3}$ 424.49 , found $425.4[\mathrm{M}+\mathrm{H}]^{+}$. HPLC $(220 \mathrm{~nm}) t_{\mathrm{R}}=15.74 \mathrm{~min}$.

4.4.8. N-Benzyl-3'-oxo-4 $4^{\prime}, 5^{\prime}, 6^{\prime}, 7^{\prime}$-tetrahydro-3' $\mathrm{H}$-spiro[fluorene-9, $1^{\prime}$-furo[3,4-c]pyridine]6 -carboxamide (8)

Amine 43 was reacted with benzyl isocyanate according to procedure $\mathrm{D}$ to yield compound 8 (0.032 g, $0.076 \mathrm{mmol}, 88 \%$ yield). ${ }^{1} \mathrm{H}$ NMR $\left(300 \mathrm{MHz}, \mathrm{CDCl}_{3}\right) \delta \mathrm{ppm} 2.61(\mathrm{tt}$, $J=5.46,2.45 \mathrm{~Hz}, 2 \mathrm{H}), 3.53-3.62(\mathrm{~m}, 4 \mathrm{H}), 4.33(\mathrm{~d}, J=5.27 \mathrm{~Hz}, 2 \mathrm{H}), 4.59(\mathrm{t}, J=5.27 \mathrm{~Hz}, 1 \mathrm{H})$, 7.17-7.34 (m, 9H), $7.45(\mathrm{td}, J=7.44,1.32 \mathrm{~Hz}, 2 \mathrm{H}), 7.65-7.75(\mathrm{~m}, 2 \mathrm{H})$; MS (ESI) $m / z$ : calcd for $\mathrm{C}_{27} \mathrm{H}_{22} \mathrm{~N}_{2} \mathrm{O}_{3} 422.48$, found $423.4[\mathrm{M}+\mathrm{H}]^{+}$. HPLC $(220 \mathrm{~nm}) t_{\mathrm{R}}=15.48 \mathrm{~min}$.

4.4.9. N-Benzyl-3-oxo-4,5,6,7-tetrahydro-3H-spiro[furo[3,4-c]pyridine-1,2' tricyclo[9.4.0.0^\{3,8\}]pentadecane]-1 $1^{\prime}\left(11^{\prime}\right), 3^{\prime}, 5^{\prime}, 7^{\prime}, 12^{\prime}, 14^{\prime}$-hexaene-6-carboxamide (9)

Amine 46 was reacted with benzyl isocyanate according to procedure $\mathrm{D}$ to yield compound $9(0.048 \mathrm{~g}, 0.11 \mathrm{mmol}, 79 \%$ yield $) .{ }^{1} \mathrm{H}$ NMR $\left(300 \mathrm{MHz}, \mathrm{CDCl}_{3}\right) \delta \mathrm{ppm} 2.49(\mathrm{tt}$, $J=5.32,2.59 \mathrm{~Hz}, 2 \mathrm{H}), 3.05-3.19(\mathrm{~m}, 4 \mathrm{H}), 3.44(\mathrm{t}, J=5.65 \mathrm{~Hz}, 2 \mathrm{H}), 4.08-4.12(\mathrm{~m}, 2 \mathrm{H}), 4.34$ $(\mathrm{d}, J=5.27 \mathrm{~Hz}, 2 \mathrm{H}), 4.85(\mathrm{t}, J=5.27,1 \mathrm{H}), 7.12-7.34(\mathrm{~m}, 13 \mathrm{H})$; MS (ESI) $m / z$ : calcd for $\mathrm{C}_{29} \mathrm{H}_{26} \mathrm{~N}_{2} \mathrm{O}_{3} 450.53$, found $451.4[\mathrm{M}+\mathrm{H}]^{+}$. HPLC $(220 \mathrm{~nm}) t_{\mathrm{R}}=16.09 \mathrm{~min}$.

4.4.10. N-Benzyl-3'-oxo-4', $5^{\prime}, 6,6^{\prime}, 7,7^{\prime}, 8,9$-octahydro-3'H-spiro[-benzo[7]annulene-5, $1^{\prime}$ furo[3,4-c]pyridine]-6'-carboxamide (10)

Amine 49 was reacted with benzyl isocyanate according to procedure $\mathrm{D}$ to yield compound $10(0.071 \mathrm{~g}, 0.18 \mathrm{mmol}, 71 \%$ yield $) .{ }^{1} \mathrm{H}$ NMR $\left(300 \mathrm{MHz}, \mathrm{CDCl}_{3}\right) \delta \mathrm{ppm} 1.62-1.77$ $(\mathrm{m}, 1 \mathrm{H}), 1.79-2.11(\mathrm{~m}, 4 \mathrm{H}), 2.12-2.27(\mathrm{~m}, 1 \mathrm{H}), 2.35-2.44(\mathrm{~m}, 2 \mathrm{H}), 2.78-2.92(\mathrm{~m}, 1 \mathrm{H})$, $2.99-3.12(\mathrm{~m}, 1 \mathrm{H}), 3.53(\mathrm{td}, J=5.56,2.07 \mathrm{~Hz}, 2 \mathrm{H}), 4.18-4.32(\mathrm{~m}, 1 \mathrm{H}), 4.33-4.45(\mathrm{~m}, 3 \mathrm{H}), 5.14(\mathrm{t}$, $J=5.46,1 \mathrm{H}), 6.91-6.98(\mathrm{~m}, 1 \mathrm{H}), 7.07-7.38(\mathrm{~m}, 8 \mathrm{H})$; MS (ESI) $m / z$ : calcd for $\mathrm{C}_{25} \mathrm{H}_{26} \mathrm{~N}_{2} \mathrm{O}_{3}$ 402.49, found $403.4[\mathrm{M}+\mathrm{H}]^{+}$. HPLC $(220 \mathrm{~nm}) t_{\mathrm{R}}=15.33 \mathrm{~min}$.

4.4.11. N-Benzyl-3-butyl-1-oxo-3-phenyl-1H,3H,4H,5H,6H,7H-furo[3,4-c]pyridine5-carboxamide (11)

Amine 52 was reacted with benzyl isocyanate according to procedure $\mathrm{D}$ to yield compound 11 (0.018 g, $0.044 \mathrm{mmol}, 49 \%$ yield). ${ }^{1} \mathrm{H}$ NMR $\left(300 \mathrm{MHz}, \mathrm{CDCl}_{3}\right) \delta \mathrm{ppm} 0.79(\mathrm{t}$, $J=7.16 \mathrm{~Hz}, 3 \mathrm{H}), 1.06-1.33(\mathrm{~m}, 4 \mathrm{H}), 1.83-1.97(\mathrm{~m}, 1 \mathrm{H}), 2.14-2.43(\mathrm{~m}, 3 \mathrm{H}), 3.18-3.31(\mathrm{~m}, 1 \mathrm{H})$, 3.36-3.51 (m, 1H), $3.85(\mathrm{dt}, J=18.84,2.64 \mathrm{~Hz}, 1 \mathrm{H}), 4.26-4.39(\mathrm{~m}, 3 \mathrm{H}), 4.90(\mathrm{t}, J=5.27 \mathrm{~Hz}$, $1 \mathrm{H}), 7.11-7.36(\mathrm{~m}, 10 \mathrm{H})$; MS (ESI) $\mathrm{m} / z$ : calcd for $\mathrm{C}_{25} \mathrm{H}_{28} \mathrm{~N}_{2} \mathrm{O}_{3} 404.50$, found $405.6[\mathrm{M}+\mathrm{H}]^{+}$. $\operatorname{HPLC}(220 \mathrm{~nm}) t_{\mathrm{R}}=16.05 \mathrm{~min}$.

4.4.12. N-3-Dibenzyl-1-oxo-3-phenyl-1H,3H,4H,5H,6H,7H-furo[3,4-c]pyridine5-carboxamide (12)

Amine 55 was reacted with benzyl isocyanate according to procedure $\mathrm{D}$ to yield compound $12(0.036 \mathrm{~g}, 0.082 \mathrm{mmol}, 50 \%$ yield $) .{ }^{1} \mathrm{H}$ NMR $\left(300 \mathrm{MHz}, \mathrm{CDCl}_{3}\right)$

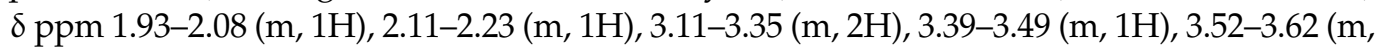
$1 \mathrm{H}), 3.97-4.08(\mathrm{~m}, 1 \mathrm{H}), 4.42(\mathrm{dd}, J=5.27,2.64 \mathrm{~Hz}, 2 \mathrm{H}), 4.59(\mathrm{dt}, J=19.12,2.12 \mathrm{~Hz}, 1 \mathrm{H}), 4.90(\mathrm{t}$, $J=5.46 \mathrm{~Hz}, 1 \mathrm{H}), 7.15-7.47(\mathrm{~m}, 15 \mathrm{H})$; MS (ESI) $m / z$ : calcd for $\mathrm{C}_{28} \mathrm{H}_{26} \mathrm{~N}_{2} \mathrm{O}_{3} 438.52$, found $439.6[\mathrm{M}+\mathrm{H}]^{+}$. HPLC $(220 \mathrm{~nm}) t_{\mathrm{R}}=15.66 \mathrm{~min}$.

4.4.13. N-Benzyl-3-(2,2-dimethylpropyl)-1-oxo-3-phenyl-1H,3H,4H,5H,6H,7H-furo[3,4c]pyridine-5-carboxamide (13)

Amine 59 was reacted with benzyl isocyanate according to procedure $\mathrm{D}$ to yield compound $13\left(0.041 \mathrm{~g}, 0.098 \mathrm{mmol}, 65 \%\right.$ yield). ${ }^{1} \mathrm{H} \mathrm{NMR}\left(300 \mathrm{MHz}, \mathrm{CDCl}_{3}\right) \delta \mathrm{ppm} 0.87$ $(\mathrm{s}, 9 \mathrm{H}), 1.88(\mathrm{~d}, J=14.88 \mathrm{~Hz}, 1 \mathrm{H}), 2.28-2.43(\mathrm{~m}, 2 \mathrm{H}), 2.38(\mathrm{~d}, J=14.88 \mathrm{~Hz}, 1 \mathrm{H}), 3.16-3.28$ $(\mathrm{m}, 1 \mathrm{H}), 3.53(\mathrm{~s}, 1 \mathrm{H}), 3.96(\mathrm{dt}, J=19.03,2.50 \mathrm{~Hz}, 1 \mathrm{H}), 4.42(\mathrm{~d}, J=5.65 \mathrm{~Hz}, 2 \mathrm{H}), 4.59(\mathrm{~s}, 1 \mathrm{H})$, 4.88-4.99 (m, 1H), 7.20-7.41 (m, 10H); MS (ESI) $m / z$ : calcd for $\mathrm{C}_{26} \mathrm{H}_{30} \mathrm{~N}_{2} \mathrm{O}_{3} 418.53$, found $419.4[\mathrm{M}+\mathrm{H}]^{+}$. HPLC $(220 \mathrm{~nm}) t_{\mathrm{R}}=16.43 \mathrm{~min}$. 
4.4.14. N-Benzyl-3-methyl-1-oxo-3-phenyl-1H,3H,4H,5H,6H,7H-furo[3,4-c]pyridine5-carboxamide (15)

Amine 62 was reacted with benzyl isocyanate according to procedure $\mathrm{D}$ to yield compound 15 (0.028 g, $0.077 \mathrm{mmol}, 39 \%$ yield). ${ }^{1} \mathrm{H}$ NMR $\left(300 \mathrm{MHz}, \mathrm{CDCl}_{3}\right) \delta \mathrm{ppm} 1.88(\mathrm{~s}$, $3 \mathrm{H}), 2.40(\mathrm{dt}, J=5.18,2.87 \mathrm{~Hz}, 2 \mathrm{H}), 3.35(\mathrm{dt}, J=13.56,6.03 \mathrm{~Hz}, 1 \mathrm{H}), 3.55(\mathrm{dt}, J=13.56,5.27$ $\mathrm{Hz}, 1 \mathrm{H}), 3.85(\mathrm{dt}, J=19.12,2.50 \mathrm{~Hz}, 1 \mathrm{H}), 4.34(\mathrm{t}, J=2.26 \mathrm{~Hz}, 1 \mathrm{H}), 4.38-4.45(\mathrm{~m}, 2 \mathrm{H}), 4.97(\mathrm{t}$, $J=5.27 \mathrm{~Hz}, 1 \mathrm{H}), 7.22-7.41(\mathrm{~m}, 10 \mathrm{H})$; MS (ESI) $m / z$ : calcd for $\mathrm{C}_{22} \mathrm{H}_{22} \mathrm{~N}_{2} \mathrm{O}_{3} 362.42$, found $363.4[\mathrm{M}+\mathrm{H}]^{+}$. HPLC $(220 \mathrm{~nm}) t_{\mathrm{R}}=14.12 \mathrm{~min}$.

4.4.15. N-Benzyl-3,3-bis(2-methylpropyl)-1-oxo-1H,3H,4H,5H,6H,7H-furo[3,4-c]pyridine5-carboxamide (16)

Amine 65 was reacted with benzyl isocyanate according to procedure $\mathrm{D}$ to yield compound $16\left(0.042 \mathrm{~g}, 0.11 \mathrm{mmol}, 36 \%\right.$ yield). ${ }^{1} \mathrm{H}$ NMR $\left(300 \mathrm{MHz}, \mathrm{CDCl}_{3}\right) \delta \mathrm{ppm} 0.75-0.93$ $(\mathrm{m}, 12 \mathrm{H}), 1.39-1.60(\mathrm{~m}, 4 \mathrm{H}), 1.77-1.92(\mathrm{~m}, 2 \mathrm{H}), 2.28-2.45(\mathrm{~m}, 2 \mathrm{H}), 3.36-3.55(\mathrm{~m}, 2 \mathrm{H})$, 4.03-4.18 (m, 2H), 4.34-4.48 (m, 2H), 4.85-5.03 (m, 1H), 7.17-7.39 (m, 5H); MS (ESI) $m / z$ : calcd for $\mathrm{C}_{23} \mathrm{H}_{32} \mathrm{~N}_{2} \mathrm{O}_{3} 384.51$, found $385.4[\mathrm{M}+\mathrm{H}]^{+}$. HPLC $(220 \mathrm{~nm}) t_{\mathrm{R}}=16.06 \mathrm{~min}$.

4.4.16. N-Benzyl-3-[2-(dimethylamino)ethyl]-1-oxo-3-phenyl-1H,3H,4H,5H,6H,7Hfuro[3,4-c]pyridine-5-carboxamide (17)

Amine 68 was reacted with benzyl isocyanate according to procedure $\mathrm{D}$ to yield compound 17 ( $0.015 \mathrm{~g}, 0.036 \mathrm{mmol}, 28 \%$ yield). ${ }^{1} \mathrm{H} \mathrm{NMR}\left(300 \mathrm{MHz}, \mathrm{CDCl}_{3}\right) \delta \mathrm{ppm} 2.15-2.19$ $(\mathrm{m}, 6 \mathrm{H}), 2.20-2.53(\mathrm{~m}, 6 \mathrm{H}), 3.23-3.38(\mathrm{~m}, 1 \mathrm{H}), 3.59(\mathrm{~d}, J=13.56 \mathrm{~Hz}, 1 \mathrm{H}), 3.86-3.98(\mathrm{~m}, 1 \mathrm{H})$, 4.38-4.44 (m, 2H), $4.49(\mathrm{t}, J=2.07 \mathrm{~Hz}, 1 \mathrm{H}), 4.98$ (br. s, $1 \mathrm{H}), 7.20-7.44(\mathrm{~m}, 10 \mathrm{H})$; MS (ESI) $m / z$ : calcd for $\mathrm{C}_{25} \mathrm{H}_{29} \mathrm{~N}_{3} \mathrm{O}_{3} 419.52$, found $420.6[\mathrm{M}+\mathrm{H}]^{+}$. HPLC $(220 \mathrm{~nm}) t_{\mathrm{R}}=11.95 \mathrm{~min}$.

4.4.17. N-Benzyl-3-(hydroxymethyl)-1-oxo-3-phenyl-1H,3H,4H,5H,6H,7H-furo[3,4c]pyridine-5-carboxamide (18)

Amine $\mathbf{7 2}$ was reacted with benzyl isocyanate according to procedure $\mathrm{D}$ to yield compound 18 (0.101 g, $0.27 \mathrm{mmol}, 51 \%$ yield). ${ }^{1} \mathrm{H}$ NMR $\left(300 \mathrm{MHz}, \mathrm{CDCl}_{3}\right) \delta \mathrm{ppm} 2.18-2.47$ $(\mathrm{m}, 2 \mathrm{H}), 3.19-3.31(\mathrm{~m}, 1 \mathrm{H}), 3.63(\mathrm{dt}, J=13.75,4.99 \mathrm{~Hz}, 1 \mathrm{H}), 3.94-4.07(\mathrm{~m}, 3 \mathrm{H}), 4.07-4.18(\mathrm{~m}$, $1 \mathrm{H}), 4.35(\mathrm{~d}, J=5.65 \mathrm{~Hz}, 2 \mathrm{H}), 4.47(\mathrm{~d}, J=18.84 \mathrm{~Hz}, 1 \mathrm{H}), 5.50(\mathrm{t}, J=5.65 \mathrm{~Hz}, 1 \mathrm{H}), 7.15-7.25(\mathrm{~m}$, $4 \mathrm{H}), 7.27-7.42(\mathrm{~m}, 6 \mathrm{H})$; MS (ESI) $m / z$ : calcd for $\mathrm{C}_{22} \mathrm{H}_{22} \mathrm{~N}_{2} \mathrm{O}_{4} 378.42$, found $379.4[\mathrm{M}+\mathrm{H}]^{+}$. $\operatorname{HPLC}(220 \mathrm{~nm}) t_{\mathrm{R}}=12.93 \mathrm{~min}$.

4.4.18. [5-(Benzylcarbamoyl)-1-oxo-3-phenyl-1H,3H,4H,5H,6H,7H-furo[3,4-c]pyridin-3yl]methyl Acetate (19)

Compound 18 ( $0.05 \mathrm{~g}, 0.13 \mathrm{mmol}, 1$ equiv. $)$ was combined with triethylamine $(0.016 \mathrm{~mL}$, $0.16 \mathrm{mmol}, 1.2$ equiv. $)$ and cooled to $0{ }^{\circ} \mathrm{C}$. Acetyl chloride $(0.13 \mathrm{~g}, 0.16 \mathrm{mmol}, 1.2$ equiv. $)$ was then added slowly and the reaction was allowed to warm to room temperature and stir for $1 \mathrm{~h}$. The reaction was quenched with saturated sodium bicarbonate and extracted with EtOAc. The organic layer was dried with sodium sulfate and concentrated under reduced pressure. The residue was purified by column chromatography to yield compound 19 (0.031 g, $0.073 \mathrm{mmol}, 57 \%$ yield). ${ }^{1} \mathrm{H}$ NMR $\left(300 \mathrm{MHz}, \mathrm{CDCl}_{3}\right) \delta \mathrm{ppm} 2.00(\mathrm{~s}, 3 \mathrm{H}), 2.42(\mathrm{tt}$, $J=4.85,2.68 \mathrm{~Hz}, 2 \mathrm{H}), 3.33(\mathrm{ddd}, J=13.66,6.50,5.09 \mathrm{~Hz}, 1 \mathrm{H}), 3.58-3.69(\mathrm{~m}, 1 \mathrm{H}), 4.01(\mathrm{dt}$, $J=18.84,2.64 \mathrm{~Hz}, 1 \mathrm{H}), 4.35-4.45(\mathrm{~m}, 3 \mathrm{H}), 4.50(\mathrm{~d}, J=12.06,1 \mathrm{H}), 4.94(\mathrm{t}, J=5.46 \mathrm{~Hz}, 1 \mathrm{H})$, 7.23-7.45 (m, 10H); MS (ESI) $m / z$ : calcd for $\mathrm{C}_{24} \mathrm{H}_{24} \mathrm{~N}_{2} \mathrm{O}_{5} 420.46$, found $421.4[\mathrm{M}+\mathrm{H}]^{+}$. $\operatorname{HPLC}(220 \mathrm{~nm}) t_{\mathrm{R}}=14.21 \mathrm{~min}$.

4.4.19. N-Benzyl-3-(3-hydroxyphenyl)-3-methyl-1-oxo-1H,3H,4H,5H,6H,7H-furo[3,4c]pyridine-5-carboxamide (20)

Amine 73 was reacted with benzyl isocyanate according to procedure $\mathrm{D}$ to yield compound 20 (68 mg, $0.18 \mathrm{mmol}, 58 \%$ yield). ${ }^{1} \mathrm{H}$ NMR $\left(300 \mathrm{MHz}, \mathrm{CDCl}_{3}\right) \delta \mathrm{ppm} 1.78-1.88$ $(\mathrm{m}, 3 \mathrm{H}), 2.31-2.45(\mathrm{~m}, 2 \mathrm{H}), 3.28-3.58(\mathrm{~m}, 2 \mathrm{H}), 3.86-4.00(\mathrm{~m}, 1 \mathrm{H}), 4.26-4.51(\mathrm{~m}, 3 \mathrm{H}), 5.00(\mathrm{t}$, $J=5.46 \mathrm{~Hz}, 1 \mathrm{H}), 6.73-6.88(\mathrm{~m}, 3 \mathrm{H}), 7.04-7.44(\mathrm{~m}, 7 \mathrm{H})$; $\mathrm{MS}$ (ESI) $m / z$ : calcd for $\mathrm{C}_{22} \mathrm{H}_{22} \mathrm{~N}_{2} \mathrm{O}_{4}$ 378.42 , found $379.4[\mathrm{M}+\mathrm{H}]^{+}$. HPLC $(280 \mathrm{~nm}) t_{\mathrm{R}}=12.88 \mathrm{~min}$. 
4.4.20. N-Benzyl-3-[3-(benzyloxy)phenyl]-3-methyl-1-oxo-1H,3H,4H,5H,6H,7H-furo[3,4c]pyridine-5-carboxamide (21)

Amine 77 was reacted with benzyl isocyanate according to procedure $\mathrm{D}$ to yield compound 21 (43 mg, $0.09 \mathrm{mmol}, 60 \%$ yield). ${ }^{1} \mathrm{H}$ NMR $\left(300 \mathrm{MHz}, \mathrm{CDCl}_{3}\right) \delta \mathrm{ppm} 1.79-1.89$ $(\mathrm{m}, 3 \mathrm{H}), 2.28-2.45(\mathrm{~m}, 2 \mathrm{H}), 3.21-3.38(\mathrm{~m}, 1 \mathrm{H}), 3.55(\mathrm{dt}, J=13.56,5.09 \mathrm{~Hz}, 1 \mathrm{H}), 3.72-3.88(\mathrm{~m}$, $1 \mathrm{H}), 4.27-4.35(\mathrm{~m}, 1 \mathrm{H}), 4.37-4.43(\mathrm{~m}, 2 \mathrm{H}), 4.95(\mathrm{t}, J=5.46 \mathrm{~Hz}, 1 \mathrm{H}), 5.04(\mathrm{~s}, 2 \mathrm{H}), 6.83-6.96$ $(\mathrm{m}, 3 \mathrm{H}), 7.22-7.45(\mathrm{~m}, 10 \mathrm{H}), 8.26-8.28(\mathrm{~m}, 1 \mathrm{H})$; $\mathrm{MS}$ (ESI) $m / z$ : calcd for $\mathrm{C}_{29} \mathrm{H}_{28} \mathrm{~N}_{2} \mathrm{O}_{4} 468.54$, found $469.6[\mathrm{M}+\mathrm{H}]^{+}$. HPLC $(280 \mathrm{~nm}) t_{\mathrm{R}}=16.36 \mathrm{~min}$.

4.4.21. N-Benzyl-3-(2-methylpropyl)-3-(naphthalen-2-yl)-1-oxo-1H,3H,4H,5H,6H,7Hfuro[3,4-c]pyridine-5-carboxamide (22)

Amine 82 was reacted with benzyl isocyanate according to procedure $\mathrm{D}$ to yield compound 22 (77 mg, $0.17 \mathrm{mmol}, 89 \%$ yield). ${ }^{1} \mathrm{H}$ NMR $\left(300 \mathrm{MHz}, \mathrm{CDCl}_{3}\right) \delta \mathrm{ppm} 0.88(\mathrm{~d}$, $J=6.78 \mathrm{~Hz}, 3 \mathrm{H}), 0.98(\mathrm{~d}, J=6.40 \mathrm{~Hz}, 3 \mathrm{H}), 1.61-1.78(\mathrm{~m}, 1 \mathrm{H}), 1.81-1.96(\mathrm{~m}, 1 \mathrm{H}), 2.30-2.53$ $(\mathrm{m}, 3 \mathrm{H}), 3.16-3.32(\mathrm{~m}, 1 \mathrm{H}), 3.55(\mathrm{dt}, J=13.85,4.94 \mathrm{~Hz}, 1 \mathrm{H}), 3.94(\mathrm{dt}, J=19.21,2.64 \mathrm{~Hz}$, $1 \mathrm{H}), 4.33-4.49(\mathrm{~m}, 2 \mathrm{H}), 4.60(\mathrm{~d}, J=18.84,1 \mathrm{H}), 4.80(\mathrm{t}, J=5.46 \mathrm{~Hz}, 1 \mathrm{H}), 7.20-7.40(\mathrm{~m}, 5 \mathrm{H})$, 7.45-7.58 (m, 2H), 7.79-7.92 (m, 4H); MS (ESI) $m / z$ : calcd for $\mathrm{C}_{29} \mathrm{H}_{30} \mathrm{~N}_{2} \mathrm{O}_{3} 454.56$, found $455.6[\mathrm{M}+\mathrm{H}]^{+}$. HPLC $(280 \mathrm{~nm}) \mathrm{t}_{\mathrm{R}}=17.21 \mathrm{~min}$.

4.4.22. N-Benzyl-3-(2-hydroxyphenyl)-3-(2-methylpropyl)-1-oxo-1H,3H,4H,5H,6H,7Hfuro[3,4-c]pyridine-5-carboxamide (23)

Amine 88 was reacted with benzyl isocyanate according to procedure $\mathrm{D}$ to yield compound 23 (0.02 g, $0.05 \mathrm{mmol}, 28 \%$ yield over two steps). ${ }^{1} \mathrm{H}$ NMR $\left(300 \mathrm{MHz}, \mathrm{CDCl}_{3}\right)$

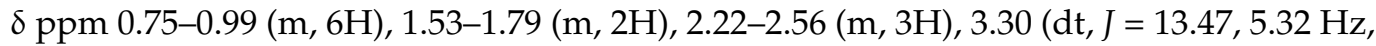
$1 \mathrm{H}), 3.42-3.61(\mathrm{~m}, 1 \mathrm{H}), 3.94(\mathrm{~d}, J=19.21 \mathrm{~Hz}, 1 \mathrm{H}), 4.26-4.54(\mathrm{~m}, 3 \mathrm{H}), 5.06(\mathrm{t}, J=5.46 \mathrm{~Hz}, 1 \mathrm{H})$, $5.95(\mathrm{t}, J=6.03 \mathrm{~Hz}, 1 \mathrm{H}), 7.08-7.57(\mathrm{~m}, 9 \mathrm{H}) ; \mathrm{MS}(\mathrm{ESI}) \mathrm{m} / z$ : calcd for $\mathrm{C}_{25} \mathrm{H}_{28} \mathrm{~N}_{2} \mathrm{O}_{4} 420.50$, found $421.4[\mathrm{M}+\mathrm{H}]^{+}$.

4.4.23. N-Benzyl-3-[2-(benzyloxy)phenyl]-3-(2-methylpropyl)-1-oxo-1H, $3 \mathrm{H}, 4 \mathrm{H}, 5 \mathrm{H}, 6 \mathrm{H}, 7 \mathrm{H}$-furo[3,4-c]pyridine-5-carboxamide (24)

Amine 87 was reacted with benzyl isocyanate according to procedure $\mathrm{D}$ to yield compound 24 (0.021 g, $0.04 \mathrm{mmol}, 44 \%$ yield). $\left.{ }^{1} \mathrm{H} \mathrm{NMR} \mathrm{(300} \mathrm{MHz,} \mathrm{CDCl}_{3}\right) \delta \mathrm{ppm} 0.85$ $(\mathrm{dd}, J=15.07,6.40 \mathrm{~Hz}, 6 \mathrm{H}), 1.48-1.69(\mathrm{~m}, 2 \mathrm{H}), 2.13-2.41(\mathrm{~m}, 2 \mathrm{H}), 2.53-2.69(\mathrm{~m}, 1 \mathrm{H}), 3.17$ $(\mathrm{ddd}, J=13.09,8.01,4.90 \mathrm{~Hz}, 1 \mathrm{H}), 3.69(\mathrm{dt}, J=13.37,4.99 \mathrm{~Hz}, 1 \mathrm{H}), 3.92-4.02(\mathrm{~m}, 1 \mathrm{H}), 4.17$ $(\mathrm{dd}, J=12.81,6.40 \mathrm{~Hz}, 1 \mathrm{H}), 4.33(\mathrm{~d}, J=5.27 \mathrm{~Hz}, 2 \mathrm{H}), 4.99-5.11(\mathrm{~m}, 2 \mathrm{H}), 6.96-7.08(\mathrm{~m}, 2 \mathrm{H})$, 7.20-7.47 (m, 12H), $7.59(\mathrm{dd}, J=8.10,1.70 \mathrm{~Hz}, 1 \mathrm{H})$; $\mathrm{MS}(\mathrm{ESI}) \mathrm{m} / \mathrm{z}$ : calcd for $\mathrm{C}_{32} \mathrm{H}_{34} \mathrm{~N}_{2} \mathrm{O}_{4}$ 510.62 , found $511.6[\mathrm{M}+\mathrm{H}]^{+}$. HPLC $(280 \mathrm{~nm}) t_{\mathrm{R}}=18.02 \mathrm{~min}$.

4.4.24. N-Benzyl-3-(3-chlorophenyl)-3-(2-methylpropyl)-1-oxo-1H,3H,4H,5H,6H,7Hfuro[3,4-c]pyridine-5-carboxamide (25)

Amine 91 was reacted with benzyl isocyanate according to procedure $\mathrm{D}$ to yield compound $24\left(0.105 \mathrm{~g}, 0.23 \mathrm{mmol}\right.$, quantitative yield). ${ }^{1} \mathrm{H} \mathrm{NMR}\left(300 \mathrm{MHz}, \mathrm{CDCl}_{3}\right) \delta \mathrm{ppm}$ $0.85(\mathrm{~d}, J=6.78 \mathrm{~Hz}, 3 \mathrm{H}), 0.94(\mathrm{~d}, J=6.40 \mathrm{~Hz}, 3 \mathrm{H}), 1.54-1.69(\mathrm{~m}, 1 \mathrm{H}), 1.71-1.84(\mathrm{~m}, 1 \mathrm{H})$, $2.26(\mathrm{dd}, J=14.69,4.90 \mathrm{~Hz}, 2 \mathrm{H}), 2.30-2.39(\mathrm{~m}, 1 \mathrm{H}), 3.24(\mathrm{ddd}, J=13.37,7.72,5.27 \mathrm{~Hz}, 1 \mathrm{H})$, $3.57(\mathrm{dt}, J=13.56,5.09 \mathrm{~Hz}, 1 \mathrm{H}), 3.90(\mathrm{dt}, J=19.21,2.64 \mathrm{~Hz}, 1 \mathrm{H}), 4.39(\mathrm{~d}, J=5.27 \mathrm{~Hz}, 2 \mathrm{H})$, 4.43-4.54 (m, 1H), $5.22(\mathrm{t}, J=5.46 \mathrm{~Hz}, 1 \mathrm{H}), 7.14-7.37(\mathrm{~m}, 9 \mathrm{H})$; MS (ESI) $m / z$ : calcd for $\mathrm{C}_{25} \mathrm{H}_{27} \mathrm{ClN}_{2} \mathrm{O}_{3} 438.95$, found $439.6[\mathrm{M}+\mathrm{H}]^{+}$. $\operatorname{HPLC}(220 \mathrm{~nm}) t_{\mathrm{R}}=16.85 \mathrm{~min}$.

4.4.25. N-Butyl-3-(2-methylpropyl)-1-oxo-3-phenyl-1H,3H,4H,5H,6H,7H-furo[3,4c]pyridine-5-carboxamide (26)

Amine 33 was reacted with benzyl isocyanate according to procedure $\mathrm{D}$ to yield compound $26\left(0.054 \mathrm{~g}, 0.15 \mathrm{mmol}\right.$, quantitative yield). ${ }^{1} \mathrm{H} \mathrm{NMR}\left(300 \mathrm{MHz}, \mathrm{CDCl}_{3}\right) \delta \mathrm{ppm}$ 0.79-1.01 (m, 9H), 1.18-1.42 (m, 3H), 1.42-1.56 (m, 2H), 1.56-1.73 (m, 1H), 1.75-1.88 (m, $1 \mathrm{H}), 2.26-2.51(\mathrm{~m}, 2 \mathrm{H}), 3.15-3.35(\mathrm{~m}, 2 \mathrm{H}), 3.53(\mathrm{dt}, J=13.75,4.99 \mathrm{~Hz}, 1 \mathrm{H}), 3.82-3.96(\mathrm{~m}$, 
$1 \mathrm{H}), 4.41-4.55(\mathrm{~m}, 1 \mathrm{H}), 4.64(\mathrm{t}, J=5.27 \mathrm{~Hz}, 1 \mathrm{H}), 7.23-7.49(\mathrm{~m}, 5 \mathrm{H})$; MS (ESI) $m / z$ : calcd for $\mathrm{C}_{22} \mathrm{H}_{30} \mathrm{~N}_{2} \mathrm{O}_{3} 370.49$, found $371.4[\mathrm{M}+\mathrm{H}]^{+}$. HPLC $(220 \mathrm{~nm}) t_{\mathrm{R}}=15.88 \mathrm{~min}$.

4.4.26. 3-(2-Methylpropyl)-1-oxo-3-phenyl-N-[2-(piperidin-1-yl)Ethyl]-1H,3H,4H,5H, $6 \mathrm{H}, 7 \mathrm{H}$-furo[3,4-c]pyridine-5-carboxamide (27)

Triphosgene $(0.023 \mathrm{~g}, 0.09 \mathrm{mmol}, 1$ equiv.) was added to amine $33(0.07 \mathrm{~g}, 0.26 \mathrm{mmol}$, 2.9 equiv.) in THF at $0{ }^{\circ} \mathrm{C}$, and the reaction was allowed to stir for $10 \mathrm{~min}$. Triethylamine $(0.053 \mathrm{~g}, 0.52 \mathrm{mmol}, 5.8$ equiv.) was then added slowly and the reaction was stirred for $15 \mathrm{~min}$. 1-(2-aminoethyl)piperidine ( $0.033 \mathrm{~g}, 0.26 \mathrm{mmol}, 2.9$ equiv.) was then added slowly and the reaction was allowed to adjust to room temperature over $30 \mathrm{~min}$. The reaction was quenched with saturated sodium bicarbonate and extracted with EtOAc. The organic layer was dried with sodium sulfate and concentrated under reduced pressure. The residue was purified by column chromatography to yield compound $27(0.061 \mathrm{~g}, 0.14 \mathrm{mmol}, 55 \%$ yield). ${ }^{1} \mathrm{H}$ NMR $\left(300 \mathrm{MHz}, \mathrm{CDCl}_{3}\right) \delta \mathrm{ppm} 0.86(\mathrm{~d}, J=6.78 \mathrm{~Hz}, 3 \mathrm{H}), 0.95(\mathrm{~d}, J=6.78 \mathrm{~Hz}$, $3 \mathrm{H}), 1.40-1.72(\mathrm{~m}, 7 \mathrm{H}), 1.81(\mathrm{dd}, J=14.51,7.35 \mathrm{~Hz}, 1 \mathrm{H}), 2.25-2.55(\mathrm{~m}, 9 \mathrm{H}), 3.25-3.43(\mathrm{~m}, 3 \mathrm{H})$, $3.55(\mathrm{dt}, J=13.56,5.27 \mathrm{~Hz}, 1 \mathrm{H}), 3.91(\mathrm{dt}, J=19.12,2.50 \mathrm{~Hz}, 1 \mathrm{H}), 4.42-4.56(\mathrm{~m}, 1 \mathrm{H}), 5.70(\mathrm{t}$, $J=4.33 \mathrm{~Hz}, 1 \mathrm{H}), 7.24-7.49(\mathrm{~m}, 5 \mathrm{H})$; MS (ESI) $m / z$ : calcd for $\mathrm{C}_{25} \mathrm{H}_{35} \mathrm{~N}_{3} \mathrm{O}_{3} 425.56$, found $426.6[\mathrm{M}+\mathrm{H}]^{+}$. HPLC $(220 \mathrm{~nm}) t_{\mathrm{R}}=13.43 \mathrm{~min}$.

4.4.27. 3-(2-Methylpropyl)-1-oxo-3-phenyl-N-[2-(piperidin-1-yl)ethyl]-1H,3H,4H, $5 \mathrm{H}, 6 \mathrm{H}, 7 \mathrm{H}$-furo[3,4-c]pyridine-5-carbothioamide (28)

Amine 33 was reacted with 2-piperidinoethyl isothiocyanate according to procedure D to yield compound $28(0.019 \mathrm{~g}, 0.043 \mathrm{mmol}, 29 \%$ yield $) .{ }^{1} \mathrm{H} \mathrm{NMR}\left(300 \mathrm{MHz}, \mathrm{CDCl}_{3}\right)$ $\delta$ ppm 0.81-0.91 (m, 3H), $0.97(\mathrm{~m}, 3 \mathrm{H}), 1.41-1.63(\mathrm{~m}, 5 \mathrm{H}), 1.63-1.75(\mathrm{~m}, 1 \mathrm{H}), 1.84(\mathrm{dd}$, $J=14.69,7.16 \mathrm{~Hz}, 1 \mathrm{H}), 2.27-2.62(\mathrm{~m}, 10 \mathrm{H}), 3.56-3.75(\mathrm{~m}, 3 \mathrm{H}), 3.90(\mathrm{dt}, J=13.85,4.95 \mathrm{~Hz}$, $1 \mathrm{H}), 4.27(\mathrm{dt}, J=18.93,2.40 \mathrm{~Hz}, 1 \mathrm{H}), 5.18(\mathrm{~d}, J=18.84 \mathrm{~Hz}, 1 \mathrm{H}), 7.02(\mathrm{br} \mathrm{s}, 1 \mathrm{H}), 7.26-7.44(\mathrm{~m}$, $5 \mathrm{H}$ ); MS (ESI) $m / z$ : calcd for $\mathrm{C}_{25} \mathrm{H}_{35} \mathrm{~N}_{3} \mathrm{O}_{2} \mathrm{~S} 441.63$, found $442.6[\mathrm{M}+\mathrm{H}]^{+}$. HPLC (220 nm) $t_{\mathrm{R}}=14.19 \mathrm{~min}$.

4.4.28. N-Benzyl-3-(2-methylpropyl)-1-oxo-3-phenyl-hexahydro-1H-[1,3]oxazolo[3,4a]piperazine-5-carboxamide (29)

Amine 95 was reacted with 2-piperidinoethyl isothiocyanate according to procedure D to yield compound $29\left(0.110 \mathrm{~g}, 0.27 \mathrm{mmol}\right.$, quantitative yield). ${ }^{1} \mathrm{H} \mathrm{NMR}\left(300 \mathrm{MHz}, \mathrm{CDCl}_{3}\right)$ $\delta \mathrm{ppm} 0.70(\mathrm{~d}, J=6.78 \mathrm{~Hz}, 3 \mathrm{H}), 0.91(\mathrm{~d}, J=6.78 \mathrm{~Hz}, 3 \mathrm{H}), 1.59(\mathrm{dt}, J=12.62,6.50 \mathrm{~Hz}, 1 \mathrm{H})$, $1.80-1.97(\mathrm{~m}, 1 \mathrm{H}), 1.99-2.13(\mathrm{~m}, 1 \mathrm{H}), 2.74(\mathrm{td}, J=12.81,3.58 \mathrm{~Hz}, 1 \mathrm{H}), 3.02(\mathrm{td}, J=12.72$, $3.58 \mathrm{~Hz}, 1 \mathrm{H}), 3.51-3.92(\mathrm{~m}, 4 \mathrm{H}), 4.35(\mathrm{~d}, J=5.46 \mathrm{~Hz}, 2 \mathrm{H}), 5.01(\mathrm{t}, J=5.46 \mathrm{~Hz}, 1 \mathrm{H}), 6.80-7.57$ $(\mathrm{m}, 5 \mathrm{H})$; MS (ESI) $m / z$ : calcd for $\mathrm{C}_{24} \mathrm{H}_{29} \mathrm{~N}_{3} \mathrm{O}_{3} 407.51$, found $408.4[\mathrm{M}+\mathrm{H}]^{+}$. HPLC $(220 \mathrm{~nm})$ $t_{\mathrm{R}}=3.49 \mathrm{~min}$.

4.4.29. 3-[Hydroxy(diphenyl)methyl]-N,N-bis(1-methylethyl)pyridine-4-carboxamide (34)

The alcohol intermediate was synthesized from $\mathrm{N}, \mathrm{N}$-diisopropylisonicotinamide and benzophenone according to procedure A to yield the desired compound $(0.617 \mathrm{~g}$, $1.59 \mathrm{mmol}, 54 \%$ yield). ${ }^{1} \mathrm{H}$ NMR $\left(300 \mathrm{MHz}, \mathrm{CDCl}_{3}\right) \delta \mathrm{ppm} 0.80(\mathrm{~d}, J=6.40 \mathrm{~Hz}, 3 \mathrm{H}), 1.06$ $(\mathrm{d}, J=6.78 \mathrm{~Hz}, 3 \mathrm{H}), 1.18(\mathrm{~d}, J=6.40 \mathrm{~Hz}, 3 \mathrm{H}), 1.33-1.49(\mathrm{~m}, 3 \mathrm{H}), 1.41(\mathrm{~d} J=6.78 \mathrm{~Hz}, 3 \mathrm{H})$, $3.19-3.36(\mathrm{~m}, 1 \mathrm{H}), 3.60(\mathrm{spt}, J=6.59 \mathrm{~Hz}, 1 \mathrm{H}), 6.65(\mathrm{~d}, J=11.30 \mathrm{~Hz}, 1 \mathrm{H}), 7.22-7.42(\mathrm{~m}, 13 \mathrm{H})$, $8.13(\mathrm{~d}, J=0.75,1 \mathrm{H}), 8.55(\mathrm{~d}, J=4.90 \mathrm{~Hz}, 1 \mathrm{H})$.

\subsubsection{3,3-Diphenylfuro[3,4-c]pyridin-1(3H)-one (35)}

The pyridine intermediate was synthesized from compound 34 using procedure $\mathrm{B}$ to yield the desired compound $(0.368 \mathrm{~g}, 1.29 \mathrm{mmol}, 82 \%$ yield $) .{ }^{1} \mathrm{H}$ NMR $\left(300 \mathrm{MHz}, \mathrm{CDCl}_{3}\right)$ $\delta$ ppm 7.29-7.40 (m, 10H), 7.77-7.88 (m, 1H), $8.89(\mathrm{~d}, J=4.90 \mathrm{~Hz}, 1 \mathrm{H}), 9.04(\mathrm{~d}, J=0.75 \mathrm{~Hz}, 1 \mathrm{H})$.

\subsubsection{3,3-Diphenyl-4,5,6,7-tetrahydrofuro[3,4-c]pyridin-1(3H)-one (36)}

The reduced analog was synthesized from compound 35 using procedure $\mathrm{C}$ to yield the desired compound (0.260 g, $0.89 \mathrm{mmol}, 73 \%$ yield). ${ }^{1} \mathrm{H} \mathrm{NMR}\left(300 \mathrm{MHz}, \mathrm{CDCl}_{3}\right)$ 
$\delta$ ppm $2.37(\mathrm{tt}, J=5.51,2.59 \mathrm{~Hz}, 2 \mathrm{H}), 3.01(\mathrm{t}, J=5.65 \mathrm{~Hz}, 2 \mathrm{H}), 3.63(\mathrm{t}, J=2.45 \mathrm{~Hz}, 2 \mathrm{H})$, 7.19-7.29 (m, 10H), 7.32-7.37 (m, 10H).

\subsubsection{2. (3,7)-3,3-Diphenylhexahydrofuro[3,4-c]pyridin-1(3H)-one (37)}

Intermediate 36 ( $0.26 \mathrm{~g}, 0.89 \mathrm{mmol}, 1$ equiv.) and $\mathrm{NiOAc} \bullet 4 \mathrm{H}_{2} \mathrm{O}(0.33 \mathrm{~g}, 1.34 \mathrm{mmol}$, 1.5 equiv.) were suspended in methanol $(5 \mathrm{~mL}, 0.2 \mathrm{M}) . \mathrm{NaBH}_{4}(0.25 \mathrm{~g}, 6.7 \mathrm{mmol}, 7.5$ equiv. $)$ was then added. The reaction was stirred for $2 \mathrm{~h}$. The reaction was quenched with $\mathrm{H}_{2} \mathrm{O}$ and extracted with EtOAc. The organic layer was dried with sodium sulfate and concentrated under reduced pressure to yield the reduced cis-product $(0.086 \mathrm{~g}, 0.29 \mathrm{mmol}, 33 \%$ yield $)$. ${ }^{1} \mathrm{H}$ NMR $\left(300 \mathrm{MHz}, \mathrm{CDCl}_{3}\right) \delta \mathrm{ppm} 1.71-1.87(\mathrm{~m}, 1 \mathrm{H}), 2.06-2.21(\mathrm{~m}, 2 \mathrm{H}), 2.45(\mathrm{td}, J=12.43$, $3.01 \mathrm{~Hz}, 1 \mathrm{H}), 2.70(\mathrm{dd}, J=12.43,5.65 \mathrm{~Hz}, 1 \mathrm{H}), 2.80-2.97(\mathrm{~m}, 2 \mathrm{H}), 3.44(\mathrm{dt}, J=11.68,5.84 \mathrm{~Hz}$, $1 \mathrm{H}), 7.13-7.43(\mathrm{~m}, 8 \mathrm{H}), 7.51-7.58(\mathrm{~m}, 2 \mathrm{H})$.

4.4.33. (3,7)-3,3-Diphenylhexahydrofuro[3,4-c]pyridin-1(3H)-one and (3aS,7aR)-3,3-Diphenylhexahydrofuro[3,4-c]pyridin-1(3H)-one Mixture (38)

Cis amine $37(0.06 \mathrm{~g}, 0.20 \mathrm{mmol}, 1$ equiv. $)$ was dissolved in THF $(5 \mathrm{~mL}, 0.04 \mathrm{M})$ at $0{ }^{\circ} \mathrm{C}$. $\mathrm{NaH}(0.02 \mathrm{~g}, 0.51 \mathrm{mmol}, 2.6$ equiv. $)$ was added and the reaction was stirred for $30 \mathrm{~min}$. The resulting mixture of cis and trans compounds was inseparable at this stage and was carried forward without further purification.

\subsubsection{1,1-Diphenylfuro[3,4-c]pyridin-3(1H)-one (39)}

Phenyl magnesium bromide ( $15 \mathrm{~mL}(1 \mathrm{M}), 15 \mathrm{mmol}, 2.2$ equiv.) was added to pyridine3,4-dicarboxylic anhydride $\left(1.0 \mathrm{~g}, 6.7 \mathrm{mmol}, 1\right.$ equiv.) in THF $(50 \mathrm{~mL}, 0.13 \mathrm{M})$ at $-78^{\circ} \mathrm{C}$. The reaction was allowed to warm to room temperature. The reaction was quenched with water and extracted with $\mathrm{CH}_{2} \mathrm{Cl}_{2}$. The organic layer was dried with sodium sulfate and concentrated. The resulting material was carried forward without further purification.

\subsubsection{1,1-Diphenyl-4,5,6,7-tetrahydrofuro[3,4-c]pyridin-3(1H)-one (40)}

Pyridine 39 was reduced using procedure $C$ to yield compound $40(0.87 \mathrm{~g}, 2.98 \mathrm{mmol}$, $86 \%$ yield). ${ }^{1} \mathrm{H}$ NMR $\left(300 \mathrm{MHz}, \mathrm{CDCl}_{3}\right) \delta \mathrm{ppm} 2.36(\mathrm{tt}, J=5.46,2.45 \mathrm{~Hz}, 2 \mathrm{H}), 3.00(\mathrm{t}$, $J=5.46 \mathrm{~Hz}, 2 \mathrm{H}), 3.63(\mathrm{t}, J=2.45 \mathrm{~Hz}, 2 \mathrm{H}), 7.20-7.27(\mathrm{~m}, 4 \mathrm{H}), 7.29-7.40(\mathrm{~m}, 6 \mathrm{H})$.

\subsubsection{3-(9-Hydroxy-9H-fluoren-9-yl)-N,N-bis(1-methylethyl)pyridine-4-carboxamide (41)}

The alcohol intermediate $\mathbf{4 1}$ was synthesized from N,N-diisopropylisonicotinamide and 9-fluorenone according to procedure $\mathrm{A}$ to yield the desired compound $(0.79 \mathrm{~g}$, $1.83 \mathrm{mmol}, 38 \%$ yield). ${ }^{1} \mathrm{H}$ NMR $\left(300 \mathrm{MHz}, \mathrm{CDCl}_{3}\right) \delta \mathrm{ppm} 1.15-1.23(\mathrm{~m}, 3 \mathrm{H}), 1.32(\mathrm{~d}$, $J=6.40 \mathrm{~Hz}, 3 \mathrm{H}), 1.54(\mathrm{~d}, J=6.78 \mathrm{~Hz}, 3 \mathrm{H}), 1.61(\mathrm{~d}, J=6.78 \mathrm{~Hz}, 3 \mathrm{H}), 3.48-3.53(\mathrm{~m}, 1 \mathrm{H})$, 3.53-3.64 (m, 1H), 3.81-3.95 (m, 1H), 7.03-7.07 (m, 1H), 7.15-7.36 (m, 4H), $7.42(\mathrm{td}, J=7.54$, $1.13 \mathrm{~Hz}, 1 \mathrm{H}), 7.60-7.72(\mathrm{~m}, 3 \mathrm{H}), 7.78-7.85(\mathrm{~m}, 1 \mathrm{H}), 8.34(\mathrm{~d}, J=4.90 \mathrm{~Hz}, 1 \mathrm{H})$.

\subsubsection{1'H-Spiro[fluorene-9,3'-furo[3,4-c]pyridin]-1'-one (42)}

The pyridine intermediate was synthesized from compound 41 using procedure B to yield the desired compound which was carried forward without further purification.

\subsubsection{1'H-Spiro[fluorene-9,3'-furo[3,4-c]pyridin]-1'-one (43)}

The reduced analog was synthesized from pyridine 42 using procedure $C$ to yield the desired compound $\left(0.28 \mathrm{~g}, 0.97 \mathrm{mmol}, 77 \%\right.$ yield). ${ }^{1} \mathrm{H} \mathrm{NMR}\left(300 \mathrm{MHz}, \mathrm{CDCl}_{3}\right) \delta \mathrm{ppm}$ 2.49-2.53 (m, 3H), 3.05-3.05 (m, 4H), 7.21 (d, J= 7.50 Hz, 2H), 7.29-7.31 (m, 2H), $7.46(\mathrm{t}$, $J=6.30 \mathrm{~Hz}, 2 \mathrm{H}), 7.67(\mathrm{~d}, J=7.50 \mathrm{~Hz}, 2 \mathrm{H})$.

4.4.39. 3-(5-Hydroxy-10,11-dihydro-5H-dibenzo[a,d][7]annulen-5-yl)-N,N-bis(1methYlethyl)pyridine-4-carboxamide (44)

The alcohol intermediate was synthesized from $\mathrm{N}, \mathrm{N}$-diisopropylisonicotinamide and dibenzosuberone according to procedure A to yield the desired compound ( $0.66 \mathrm{~g}$, 
$1.44 \mathrm{mmol}, 30 \%$ yield). ${ }^{1} \mathrm{H}$ NMR $\left(300 \mathrm{MHz}, \mathrm{CDCl}_{3}\right) \delta \mathrm{ppm} 0.55(\mathrm{~d}, J=6.40 \mathrm{~Hz}, 3 \mathrm{H})$, 0.98-1.05 (m, 3H), $1.15(\mathrm{~d}, J=6.78 \mathrm{~Hz}, 3 \mathrm{H}), 1.36(\mathrm{~d}, J=6.78 \mathrm{~Hz}, 3 \mathrm{H}), 2.43-2.56(\mathrm{~m}$, $1 \mathrm{H}), 2.58-2.78(\mathrm{~m}, 1 \mathrm{H}), 2.93-3.25(\mathrm{~m}, 4 \mathrm{H}(, 3.44(\mathrm{dt}, J=13.19,6.59 \mathrm{~Hz}, 1 \mathrm{H}), 6.90(\mathrm{~s}, 1 \mathrm{H})$, 6.97-7.25 (m, 8H), $7.94(\mathrm{dd}, J=7.54,1.51 \mathrm{~Hz}, 1 \mathrm{H}), 8.04-8.14(\mathrm{~m}, 1 \mathrm{H}), 8.35(\mathrm{~s}, 1 \mathrm{H}), 8.56(\mathrm{~d}$, $J=4.90 \mathrm{~Hz}, 1 \mathrm{H})$.

4.4.40. 10,11-Dihydro-1'H-spiro[dibenzo[a,d][7]annulene-5,3'-furo[3,4-c]pyridin]-1'one (45)

The pyridine intermediate was synthesized from compound 44 using procedure $\mathrm{B}$ to yield the desired compound $(0.147 \mathrm{~g}, 0.47 \mathrm{mmol}, 33 \%$ yield $) .{ }^{1} \mathrm{H} \mathrm{NMR}\left(300 \mathrm{MHz}, \mathrm{CDCl}_{3}\right)$ $\delta$ ppm 3.04-3.20 (m, 2H), 3.76-3.95 (m, 2H), 6.84-7.12 (m, 8H), $7.90(\mathrm{~d}, J=4.52 \mathrm{~Hz}, 1 \mathrm{H})$, $8.89-9.03(\mathrm{~m}, 1 \mathrm{H}), 9.21(\mathrm{~s}, 1 \mathrm{H})$.

4.4.41. $4^{\prime}, 5^{\prime}, 6^{\prime}, 7^{\prime}, 10,11-H e x a h y d r o-1^{\prime} H$-spiro[dibenzo[a,d][7]annulene-5, $3^{\prime}$-furo[3,4c]pyridin]-1'-one (46)

The reduced analog was synthesized from pyridine 45 using procedure $C$ to yield the desired compound $\left(0.053 \mathrm{~g}, 0.17 \mathrm{mmol}, 36 \%\right.$ yield). ${ }^{1} \mathrm{H}$ NMR $\left(300 \mathrm{MHz}, \mathrm{CDCl}_{3}\right) \delta \mathrm{ppm} 1.70$ (br s, 1H), 2.27-2.37 (m, 2H), $2.90(\mathrm{t}, J=5.65 \mathrm{~Hz}, 2 \mathrm{H}), 2.96-3.19(\mathrm{~m}, 4 \mathrm{H}), 3.44(\mathrm{t}, J=2.45 \mathrm{~Hz}$, $2 \mathrm{H}), 7.03-7.31(\mathrm{~m}, 8 \mathrm{H})$.

4.4.42. 3-(5-Hydroxy-6,7,8,9-tetrahydro-5H-benzo[7]annulen-5-yl)-N,N-bis(1methylethyl)pyridine-4-carboxamide (47)

The alcohol intermediate was synthesized from N,N-diisopropylisonicotinamide and 1-benzosuberone according to procedure A to yield the desired compound, which was carried forward without further purification.

4.4.43. 6,7,8,9-Tetrahydro-1'H-spiro[benzo[7]annulene-5,3'-furo[3,4-c]pyridin]-1'-one (48)

The pyridine intermediate was synthesized from compound 47 using procedure $B$ to yield the desired compound $(0.400 \mathrm{~g}, 1.51 \mathrm{mmol}, 62 \%$ yield $) .{ }^{1} \mathrm{H}$ NMR $\left(300 \mathrm{MHz}, \mathrm{CDCl}_{3}\right) \delta$ ppm $1.68(\mathrm{dtdd}, J=13.40,11.48,3.58,1.88 \mathrm{~Hz}, 1 \mathrm{H}), 1.87-2.36(\mathrm{~m}, 4 \mathrm{H}), 2.34-2.48(\mathrm{~m}, 1 \mathrm{H})$, $2.90(\mathrm{dd}, J=14.32,6.78 \mathrm{~Hz}, 1 \mathrm{H}), 3.47(\mathrm{ddd}, J=14.03,11.59,1.88 \mathrm{~Hz}, 1 \mathrm{H}), 6.79-6.88(\mathrm{~m}$, $1 \mathrm{H}), 6.97-7.07(\mathrm{~m}, 1 \mathrm{H}), 7.18-7.25(\mathrm{~m}, 2 \mathrm{H}), 7.76-7.85(\mathrm{~m}, 1 \mathrm{H}), 8.85-8.92(\mathrm{~m}, 1 \mathrm{H}), 8.96-9.08$ $(\mathrm{m}, 1 \mathrm{H})$.

4.4.44. $4^{\prime}, 5^{\prime}, 6,6^{\prime}, 7,7^{\prime}, 8,9-$ Octahydro-1'H-spiro[benzo[7]annulene-5,3'-furo[3,4c]pyridin]-1'-one (49)

The reduced analog was synthesized from pyridine 48 using procedure $C$ to yield the desired compound $\left(0.28 \mathrm{~g}, 1.04 \mathrm{mmol}, 67 \%\right.$ yield). ${ }^{1} \mathrm{H}$ NMR $\left(300 \mathrm{MHz}, \mathrm{CDCl}_{3}\right)$ $\delta$ ppm 1.56-2.23 (m, 5H), 2.23-2.44 (m, 2H), 2.74-3.18 (m, 4H), 3.50-3.75 (m, 2H), 6.92-7.02 $(\mathrm{m}, 1 \mathrm{H}), 7.06-7.25(\mathrm{~m}, 3 \mathrm{H})$.

4.4.45. 3-(1-Hydroxy-1-phenylpentyl)-N,N-bis(1-methylethyl)pyridine-4-carboxamide (50)

The alcohol intermediate was synthesized from N,N-diisopropylisonicotinamide and valerophenone according to procedure A to yield the desired compound $(1.2 \mathrm{~g}, 2.90 \mathrm{mmol}$, $30 \%$ yield). ${ }^{1} \mathrm{H}$ NMR $\left(300 \mathrm{MHz}, \mathrm{CDCl}_{3}\right) \delta \mathrm{ppm} 0.38(\mathrm{~d}, \mathrm{~J}-6.78 \mathrm{~Hz}, 3 \mathrm{H}), 0.71-0.93(\mathrm{~m}, 4 \mathrm{H})$, $1.06(\mathrm{~d}, J=6.40 \mathrm{~Hz}, 6 \mathrm{H}), 1.35-1.44(\mathrm{~m}, 3 \mathrm{H}), 1.50-1.58(\mathrm{~m}, 3 \mathrm{H}), 2.02-2.16(\mathrm{~m}, 1 \mathrm{H}), 2.29-2.43$ $(\mathrm{m}, 1 \mathrm{H}), 3.22$ (dquin, $J=9.04,6.69 \mathrm{~Hz}, 1 \mathrm{H}), 3.54(\mathrm{dt}, J=13.66,6.92 \mathrm{~Hz}, 1 \mathrm{H}), 3.76$ (quin, $J=6.59 \mathrm{~Hz}, 1 \mathrm{H}), 7.03(\mathrm{~d}, J=4.90 \mathrm{~Hz}, 1 \mathrm{H}), 7.21-7.32(\mathrm{~m}, 5 \mathrm{H}), 8.51-8.59(\mathrm{~m}, 1 \mathrm{H}), 9.00(\mathrm{~s}, 1 \mathrm{H})$.

\subsubsection{3-Butyl-3-phenylfuro[3,4-c]pyridin-1(3H)-one (51)}

The pyridine intermediate was synthesized from alcohol $\mathbf{5 0}$ using procedure $\mathrm{B}$ to yield the desired compound $\left(0.83 \mathrm{~g}, 3.10 \mathrm{mmol}\right.$, quantitative yield). ${ }^{1} \mathrm{H} \mathrm{NMR}\left(300 \mathrm{MHz}, \mathrm{CDCl}_{3}\right)$ $\delta$ ppm $0.70-0.79(\mathrm{~m}, 3 \mathrm{H}), 0.94-1.10(\mathrm{~m}, 1 \mathrm{H}), 1.15-1.32(\mathrm{~m}, 3 \mathrm{H}), 2.13-2.28(\mathrm{~m}, 1 \mathrm{H}), 2.36-2.54$ $(\mathrm{m}, 1 \mathrm{H}), 7.21-7.37(\mathrm{~m}, 3 \mathrm{H}), 7.44-7.54(\mathrm{~m}, 2 \mathrm{H}), 7.68-7.76(\mathrm{~m}, 1 \mathrm{H}), 8.73-8.82(\mathrm{~m}, 1 \mathrm{H}), 8.99-9.03$ $(\mathrm{s}, 1 \mathrm{H})$. 


\subsubsection{3-Butyl-3-phenyl-4,5,6,7-tetrahydrofuro[3,4-c]pyridin-1(3H)-one (52)}

The reduced analog was synthesized from pyridine $\mathbf{5 1}$ using procedure $\mathrm{C}$ to yield the desired compound (0.48 g, $1.77 \mathrm{mmol}, 57 \%$ yield). ${ }^{1} \mathrm{H}$ NMR $\left(300 \mathrm{MHz}, \mathrm{CDCl}_{3}\right)$ $\delta$ ppm $0.82-0.93(\mathrm{~m}, 3 \mathrm{H}), 1.17-1.42(\mathrm{~m}, 5 \mathrm{H}), 1.63(\mathrm{br} \mathrm{s}, 1 \mathrm{H}), 1.87-2.01(\mathrm{~m}, 1 \mathrm{H}), 2.15-2.41(\mathrm{~m}$, $3 \mathrm{H}), 2.82-3.05(\mathrm{~m}, 2 \mathrm{H}), 3.37-3.50(\mathrm{~m}, 1 \mathrm{H}), 3.56-3.69(\mathrm{~m}, 1 \mathrm{H}), 7.25-7.42(\mathrm{~m}, 5 \mathrm{H})$.

\subsubsection{3-(1-Hydroxy-1,2-diphenylethyl)-N,N-bis(1-methylethyl)pyridine-} 4-carboxamide (53)

The alcohol intermediate was synthesized from N,N-diisopropylisonicotinamide and benzyl phenyl ketone according to procedure A and recrystallized from EtOAc to yield the desired compound (1.73 g, $3.87 \mathrm{mmol}, 40 \%$ yield). ${ }^{1} \mathrm{H} \mathrm{NMR}\left(300 \mathrm{MHz}, \mathrm{CDCl}_{3}\right) \delta \mathrm{ppm} 0.35$ $(\mathrm{d}, J=6.40 \mathrm{~Hz}, 3 \mathrm{H}), 1.01-1.06(\mathrm{~m}, 3 \mathrm{H}), 1.12(\mathrm{~d}, \mathrm{~J}=6.78 \mathrm{~Hz}, 3 \mathrm{H}), 1.32-1.41(\mathrm{~m}, 3 \mathrm{H}), 3.10-3.29$ $(\mathrm{m}, 2 \mathrm{H}), 3.32-3.43(\mathrm{~m}, 1 \mathrm{H}), 3.73-3.85(\mathrm{~m}, 1 \mathrm{H}), 6.23(\mathrm{~d}, J=1.88 \mathrm{~Hz}, 1 \mathrm{H}), 6.73-6.81(\mathrm{~m}, 1 \mathrm{H})$, 7.00-7.20 (m, 10H), 8.55-8.66 (m, 1H), $9.15(\mathrm{~s}, 1 \mathrm{H})$.

\subsubsection{3-Benzyl-3-phenylfuro[3,4-c]pyridin-1(3H)-one (54)}

The pyridine intermediate was synthesized from alcohol 53 using procedure B to yield the desired compound $\left(1.19 \mathrm{~g}, 3.95 \mathrm{mmol}\right.$, quantitative yield). ${ }^{1} \mathrm{H}$ NMR $(300 \mathrm{MHz}$, $\left.\mathrm{CDCl}_{3}\right) \delta$ ppm $3.69(\mathrm{q}, J=14.07 \mathrm{~Hz}, 2 \mathrm{H}), 6.84-6.93(\mathrm{~m}, 2 \mathrm{H}), 7.06-7.15(\mathrm{~m}, 3 \mathrm{H}), 7.33-7.47(\mathrm{~m}$, $3 \mathrm{H}), 7.54(\mathrm{dd}, J=4.90,1.13 \mathrm{~Hz}, 1 \mathrm{H}), 7.57-7.64(\mathrm{~m}, 2 \mathrm{H}), 8.74(\mathrm{~d}, J=4.90 \mathrm{~Hz}, 1 \mathrm{H}), 9.03(\mathrm{~d}$, $J=1.13 \mathrm{~Hz}, 1 \mathrm{H})$.

\subsubsection{3-Benzyl-3-phenyl-4,5,6,7-tetrahydrofuro[3,4-c]pyridin-1(3H)-one (55)}

The reduced analog was synthesized from pyridine 54 using procedure $C$ to yield the desired compound $(0.22 \mathrm{~g}, 0.72 \mathrm{mmol}, 18 \%$ yield $) .{ }^{1} \mathrm{H} \mathrm{NMR}\left(300 \mathrm{MHz}, \mathrm{CDCl}_{3}\right) \delta \mathrm{ppm}$ 1.49 (br s, $1 \mathrm{H}), 1.75-2.04(\mathrm{~m}, 2 \mathrm{H}), 2.56-2.78(\mathrm{~m}, 2 \mathrm{H}), 3.23-3.32(\mathrm{~m}, 1 \mathrm{H}), 3.33-3.51(\mathrm{~m}, 2 \mathrm{H})$, 3.62-3.75 (m, 1H), 7.03-7.18 (m, 5H), 7.20-7.34 (m, 5H).

\subsubsection{3,3-Dimethyl-1-phenylbutan-1-one (56)}

t-Butylacetyl chloride (10 g, $74.3 \mathrm{mmol}, 1$ equiv.) was added dropwise to $\mathrm{AlCl}_{3}(14.6 \mathrm{~g}$, $111.45 \mathrm{mmol}, 1.5$ equiv.) in benzene $(100 \mathrm{~mL}, 0.7 \mathrm{M})$. The reaction was heated to reflux for $8 \mathrm{~h}$, cooled, and then quenched with water and extracted with EtOAc. The organic layer was dried with sodium sulfate, filtered, and concentrated to yield the desired ketone (13.8 g, $78.29 \mathrm{mmol}$, quantitative). ${ }^{1} \mathrm{H} \mathrm{NMR}\left(300 \mathrm{MHz}, \mathrm{CDCl}_{3}\right) \delta \mathrm{ppm} 1.07(\mathrm{~s}, 9 \mathrm{H}), 2.86(\mathrm{~s}, 2 \mathrm{H})$, 7.43-7.46 (m, 2H), 7.52-7.55 (m, 1H), 7.94-7.95 (m, 2H).

4.4.52. 3-(1-Hydroxy-3,3-dimethyl-1-phenylbutyl)-N,N-bis(1-methylethyl)pyridine-4carboxamide (57)

The alcohol intermediate was synthesized from N,N-diisopropylisonicotinamide and ketone 56 according to procedure A to yield the desired compound $(1.8 \mathrm{~g}, 4.21 \mathrm{mmol}, 43 \%$ yield). ${ }^{1} \mathrm{H}$ NMR $\left(300 \mathrm{MHz}, \mathrm{CDCl}_{3}\right) \delta \mathrm{ppm} 0.40(\mathrm{~d}, J=6.59 \mathrm{~Hz}, 3 \mathrm{H}), 0.77(\mathrm{~s}, 9 \mathrm{H}), 1.03(\mathrm{~d}$, $J=6.40 \mathrm{~Hz}, 3 \mathrm{H}), 1.36(\mathrm{~d}, J=6.78 \mathrm{~Hz}, 3 \mathrm{H}), 1.42(\mathrm{~d}, J=6.78 \mathrm{~Hz}, 3 \mathrm{H}), 2.27(\mathrm{dd}, J=13.94,1.70$ $\mathrm{Hz}, 1 \mathrm{H}), 2.43-2.56(\mathrm{~m}, 1 \mathrm{H}), 3.04-3.18(\mathrm{~m}, 1 \mathrm{H}), 3.19-3.36(\mathrm{~m}, 1 \mathrm{H}), 5.85(\mathrm{~d}, J=1.51 \mathrm{~Hz}, 1 \mathrm{H})$, $6.99(\mathrm{~d}, J=5.09 \mathrm{~Hz}, 1 \mathrm{H}), 7.14-7.29(\mathrm{~m}, 3 \mathrm{H}), 7.37-7.43(\mathrm{~m}, 2 \mathrm{H}), 8.51(\mathrm{~d}, J=4.90 \mathrm{~Hz}, 1 \mathrm{H}), 9.01$ $(\mathrm{s}, 1 \mathrm{H})$.

\subsubsection{3-(2,2-Dimethylpropyl)-3-phenylfuro[3,4-c]pyridin-1(3H)-one (58)}

The pyridine intermediate was synthesized from alcohol 57 using procedure $B$ to yield the desired compound $\left(1.5 \mathrm{~g}, 5.33 \mathrm{mmol}\right.$, quantitative yield). ${ }^{1} \mathrm{H}$ NMR $\left(300 \mathrm{MHz}, \mathrm{CDCl}_{3}\right)$ $\delta$ ppm $0.83(\mathrm{~s}, 9 \mathrm{H}), 2.18(\mathrm{~d}, J=15.07 \mathrm{~Hz}, 1 \mathrm{H}), 2.65(\mathrm{~d}, J=15.07 \mathrm{~Hz}, 1 \mathrm{H}), 7.23-7.33(\mathrm{~m}, 1 \mathrm{H})$, 7.33-7.45 (m, 2H), 7.55-7.67 (m, 2H), $7.75(\mathrm{dd}, J=5.09,1.13 \mathrm{~Hz}, 1 \mathrm{H}), 8.81(\mathrm{~d}, J=5.09 \mathrm{~Hz}$, $1 \mathrm{H}), 9.16(\mathrm{~d}, J=0.94 \mathrm{~Hz}, 1 \mathrm{H})$. 
4.4.54. 3-(2,2-Dimethylpropyl)-3-phenyl-4,5,6,7-tetrahydrofuro[3,4-c]pyridin$1(3 \mathrm{H})$-one (59)

The reduced analog was synthesized from pyridine 58 using procedure $C$ to yield the desired compound (1.21 g, $4.24 \mathrm{mmol}, 80 \%$ yield). ${ }^{1} \mathrm{H}$ NMR (300 $\left.\mathrm{MHz}, \mathrm{CDCl}_{3}\right)$ $\delta$ ppm ${ }^{1} \mathrm{H}$ NMR (300 MHz, CHLOROFORM-d) d ppm 0.88 (s, 9H), 1.86 (d, J = 14.88 Hz, $1 \mathrm{H}), 2.21-2.35(\mathrm{~m}, 2 \mathrm{H}), 2.32(\mathrm{~d}, J=14.88 \mathrm{~Hz}, 1 \mathrm{H}), 2.74(\mathrm{~s}, 1 \mathrm{H}), 2.78-2.92(\mathrm{~m}, 1 \mathrm{H}), 3.00(\mathrm{~s}, 1 \mathrm{H})$, 3.55 (br. s, 1H), 3.74 (s, 1H), 7.05-7.56 (m, 5H).

4.4.55. 3-(1-Hydroxy-1-phenylethyl)-N,N-bis(1-methylethyl)pyridine-4-carboxamide (60)

The alcohol intermediate was synthesized from N,N-diisopropylisonicotinamide and acetophenone according to procedure A to yield the desired compound $(2.1 \mathrm{~g}, 5.66 \mathrm{mmol}$, $58 \%$ yield). ${ }^{1} \mathrm{H}$ NMR $\left(300 \mathrm{MHz}, \mathrm{CDCl}_{3}\right) \delta \mathrm{ppm} 0.43(\mathrm{~d}, J=6.78 \mathrm{~Hz}, 3 \mathrm{H}), 1.03-1.11(\mathrm{~m}, 3 \mathrm{H})$, 1.15-1.24 (m, 6H), 1.33-1.43 (m, 3H), 3.14-3.37 (m, 2H), 6.30-6.50 (m, 1H), 6.96-7.09 (m, 1H), 7.13-7.38 (m, 5H), 8.52-8.58 (m, 1H), $8.93(\mathrm{~s}, 1 \mathrm{H})$.

4.4.56. 3-Methyl-3-phenylfuro[3,4-c]pyridin-1(3H)-one (61)

The pyridine intermediate was synthesized from alcohol 60 using procedure $B$ to yield the desired compound ( $0.60 \mathrm{~g}, 2.66 \mathrm{mmol}, 82 \%$ yield). ${ }^{1} \mathrm{H} \mathrm{NMR}\left(300 \mathrm{MHz}, \mathrm{CDCl}_{3}\right) \delta \mathrm{ppm}$ 2.07-2.13 (m, 3H), 7.28-7.41 (m, 3H), 7.46-7.51 (m, 2H), $7.79(\mathrm{dd}, J=4.90,1.13 \mathrm{~Hz}, 1 \mathrm{H}), 8.86$ $(\mathrm{d}, J=4.90 \mathrm{~Hz}, 1 \mathrm{H}), 8.94-9.00(\mathrm{~m}, 1 \mathrm{H})$.

\subsubsection{3-Methyl-3-phenyl-4,5,6,7-tetrahydrofuro[3,4-c]pyridin-1(3H)-one (62)}

The reduced analog was synthesized from pyridine $\mathbf{6 1}$ using procedure $\mathrm{C}$ to yield the desired compound $(0.44 \mathrm{~g}, 1.91 \mathrm{mmol}, 72 \%$ yield $) .{ }^{1} \mathrm{H} \mathrm{NMR}\left(300 \mathrm{MHz}, \mathrm{CDCl}_{3}\right) \delta \mathrm{ppm} 1.75$ (br s, 1H), $1.83(\mathrm{~s}, 3 \mathrm{H}), 2.29(\mathrm{dq}, J=5.37,2.48 \mathrm{~Hz}, 2 \mathrm{H}), 2.84-3.03(\mathrm{~m}, 2 \mathrm{H}), 3.26-3.38(\mathrm{~m}, 1 \mathrm{H})$, 3.53-3.70 (m, 1H), 7.26-7.39 (m, 5H).

4.4.58. 3-[1-Hydroxy-3-methyl-1-(2-methylpropyl)butyl]-N,N-bis(1methylethyl)pyridine-4-carboxamide (63)

The alcohol intermediate was synthesized from N,N-diisopropylisonicotinamide and 2,6-dimethyl-4-heptanone according to procedure A to yield the desired compound (2.16 $\mathrm{g}$, $5.49 \mathrm{mmol}, 57 \%$ yield). ${ }^{1} \mathrm{H}$ NMR $\left(300 \mathrm{MHz}, \mathrm{CDCl}_{3}\right) \delta \mathrm{ppm} 0.66-0.79(\mathrm{~m}, 6 \mathrm{H}), 0.87-1.01$ (m, $6 \mathrm{H}), 1.13-1.23(\mathrm{~m}, 6 \mathrm{H}), 1.49-1.58(\mathrm{~m}, 6 \mathrm{H}), 1.49-1.58(\mathrm{~m}, 6 \mathrm{H}), 1.71-1.91(\mathrm{~m}, 6 \mathrm{H}), 3.15(\mathrm{~s}, 1 \mathrm{H})$, 3.43-3.58 (m, 1H), 3.61-3.76 (m, 1H), 6.95-7.03 (m, 1H), 8.38-8.47 (m, 1H), $8.52(\mathrm{~s}, 1 \mathrm{H})$.

\subsubsection{3,3-bis(2-Methylpropyl)furo[3,4-c]pyridin-1(3H)-one (64)}

The pyridine intermediate was synthesized from alcohol 63 using procedure B to yield the desired compound which was carried forward without further purification.

\subsubsection{3,3-bis(2-Methylpropyl)-4,5,6,7-tetrahydrofuro[3,4-c]pyridin-1(3H)-one (65)}

The reduced analog was synthesized from pyridine $\mathbf{6 4}$ using procedure $C$ to yield the desired compound $\left(0.12 \mathrm{~g}, 0.48 \mathrm{mmol}, 60 \%\right.$ yield). ${ }^{1} \mathrm{H}$ NMR (300 $\left.\mathrm{MHz} \mathrm{CDCl}_{3}\right)$ $\delta$ ppm $0.89(\mathrm{dd}, J=6.59,2.83 \mathrm{~Hz}, 12 \mathrm{H}), 1.34-1.89(\mathrm{~m}, 7 \mathrm{H}), 2.20-2.35(\mathrm{~m}, 2 \mathrm{H}), 2.90-3.05(\mathrm{~m}$, 2H), 2.90-3.05 (m, 2H), 3.41-3.54 (m, 2H).

4.4.61. 3-[3-(Dimethylamino)-1-hydroxy-1-phenylpropyl]-N,N-bis(1methylethyl)pyridine-4-carboxamide (66)

The alcohol intermediate was synthesized from N,N-diisopropylisonicotinamide and 3-(dimethylamino)propiophenone according to procedure A to yield the desired compound (0.450 g, $1.05 \mathrm{mmol}, 11 \%$ yield). ${ }^{1} \mathrm{H} \mathrm{NMR}\left(300 \mathrm{MHz}, \mathrm{CDCl}_{3}\right) \delta \mathrm{ppm} 0.99-1.10(\mathrm{~m}, 3 \mathrm{H})$, 1.19-1.28 (m, 3H), 1.52-1.59 (m, 6H), 2.14-2.23 (m, 6H), 2.57-2.89 (m, 2H), 3.49 (quin, $J=6.78 \mathrm{~Hz}, 1 \mathrm{H}), 3.55-3.67(\mathrm{~m}, 1 \mathrm{H}), 6.95-7.04(\mathrm{~m}, 1 \mathrm{H}), 7.21-7.29(\mathrm{~m}, 1 \mathrm{H}), 7.32-7.43(\mathrm{~m}, 2 \mathrm{H})$, 7.50-7.57 (m, 2H), 8.10-8.15 (m, 1H), 8.34-8.41 (m, 1H). 


\subsubsection{3-[2-(Dimethylamino)ethyl]-3-phenylfuro[3,4-c]pyridin-1(3H)-one (67)}

The pyridine intermediate was synthesized from alcohol 66 using procedure $B$ to yield the desired compound ( $0.34 \mathrm{~g}, 1.20 \mathrm{mmol}$, quantitative). ${ }^{1} \mathrm{H} \mathrm{NMR}\left(300 \mathrm{MHz}, \mathrm{CDCl}_{3}\right)$ $\delta$ ppm $2.07(\mathrm{~s}, 6 \mathrm{H}), 2.15-2.25(\mathrm{~m}, 2 \mathrm{H}), 2.30-2.45(\mathrm{~m}, 1 \mathrm{H}), 2.61-2.78(\mathrm{~m}, 1 \mathrm{H}), 7.18-7.38(\mathrm{~m}$, $3 \mathrm{H}), 7.41-7.51(\mathrm{~m}, 2 \mathrm{H}), 7.63-7.72(\mathrm{~m}, 1 \mathrm{H}), 8.76(\mathrm{~d}, J=5.27 \mathrm{~Hz}, 1 \mathrm{H}), 8.91-9.01(\mathrm{~m}, 1 \mathrm{H})$.

4.4.63. 3-[2-(Dimethylamino)ethyl]-3-phenyl-4,5,6,7-tetrahydrofuro[3,4-c]pyridin$1(3 \mathrm{H})$-one (68)

The reduced analog was synthesized from pyridine 67 using procedure $C$ to yield the desired compound $\left(0.050 \mathrm{~g}, 0.17 \mathrm{mmol}, 25 \%\right.$ yield). ${ }^{1} \mathrm{H}$ NMR $\left(300 \mathrm{MHz}, \mathrm{CDCl}_{3}\right)$ $\delta$ ppm 2.06-2.52 (m, 12H), 2.83-3.06 (m, 2H), 3.35-3.48 (m, 1H), 3.62-3.75 (m, 1H), 7.26-7.46 $(\mathrm{m}, 5 \mathrm{H})$.

\subsubsection{2-(Methoxymethoxy)-1-phenylethanone (69)}

Hunig's base (9.49 g, $73.45 \mathrm{mmol}, 1.25$ equiv.) was added to 2-hydroxyacetophenone ( $8 \mathrm{~g}, 58.76 \mathrm{mmol}, 1$ equiv.) in THF $(50 \mathrm{~mL}, 1.1 \mathrm{M})$ at $0{ }^{\circ} \mathrm{C}$. $\mathrm{MOMCl}(5.91 \mathrm{~g}, 73.45 \mathrm{mmol}$, 1.25 equiv.) was slowly added and the reaction was stirred at $0{ }^{\circ} \mathrm{C}$ for $2 \mathrm{~h}$, followed by stirring for $2 \mathrm{~h}$ at room temperature. The reaction was quenched with saturated sodium bicarbonate and extracted with EtOAc. The organic layer was separated, dried with sodium sulfate, filtered, and concentrated. The material was carried forward without further purification.

4.4.65. 3-[1-Hydroxy-2-(methoxymethoxy)-1-phenylethyl]-N,N-bis(1methylethyl)pyridine-4-carboxamide (70)

The alcohol intermediate was synthesized from N,N-diisopropylisonicotinamide and ketone 69 according to procedure A to yield the desired compound, which was carried forward without further purification.

\subsubsection{3-(Hydroxymethyl)-3-phenylfuro[3,4-c]pyridin-1(3H)-one (71)}

The pyridine intermediate was synthesized from alcohol 70 using procedure $\mathrm{B}$ to yield the desired compound $\left(0.50 \mathrm{~g}, 2.07 \mathrm{mmol}, 45 \%\right.$ yield). ${ }^{1} \mathrm{H}$ NMR (300 MHz, DMSO- $d_{6}$ ) $\delta$ ppm 4.00-4.17 (m, 1H), 4.20-4.35 (m, 1H), $5.52(\mathrm{~s}, 1 \mathrm{H}), 7.45(\mathrm{~s}, 3 \mathrm{H}), 7.61(\mathrm{~d}, J=1.13 \mathrm{~Hz}$, $2 \mathrm{H}), 7.83-7.93(\mathrm{~m}, 1 \mathrm{H}), 8.89(\mathrm{~s}, 1 \mathrm{H}), 9.30(\mathrm{~d}, J=1.13 \mathrm{~Hz}, 1 \mathrm{H})$.

\subsubsection{3-(Hydroxymethyl)-3-phenyl-4,5,6,7-tetrahydrofuro[3,4-c]pyridin-1(3H)-one (72)}

The reduced analog was synthesized from pyridine 71 using procedure $C$ to yield the desired compound $\left(0.128 \mathrm{~g}, 0.52 \mathrm{mmol}, 29 \%\right.$ yield). ${ }^{1} \mathrm{H}$ NMR (300 MHz, DMSO- $d_{6}$ ) $\delta$ ppm 2.00-2.14 (m, 2H), 2.20-2.44 (m, 1H), 2.65-2.85 (m, 2H), 3.46-3.69 (m, 2H), 3.80-3.93 $(\mathrm{m}, 1 \mathrm{H}), 3.98-4.09(\mathrm{~m}, 1 \mathrm{H}), 5.26-5.36(\mathrm{~m}, 1 \mathrm{H}), 7.28-7.51(\mathrm{~m}, 5 \mathrm{H})$.

4.4.68. 3-(3-Hydroxyphenyl)-3-methyl-4,5,6,7-tetrahydrofuro[3,4-c]pyridin-1(3H)-one (73)

Benzyl-amino analog 77 (230 mg, $0.65 \mathrm{mmol}, 1$ equiv.) was dissolved in EtOAc and $\mathrm{Pd} / \mathrm{C}$ was added ( $5 \mathrm{~mol} \%)$. The mixture was placed on the hydrogenator at $40 \mathrm{psi}$ for $7 \mathrm{~h}$. The mixture was then filtered and concentrated, and the residue was purified by column chromatography to yield the deprotected intermediate $X(75 \mathrm{mg}, 0.31 \mathrm{mmol}, 47 \%$ yield $)$. ${ }^{1} \mathrm{H}$ NMR $\left(300 \mathrm{MHz}, \mathrm{CDCl}_{3}\right) \delta \mathrm{ppm} 1.73-1.84(\mathrm{~m}, 3 \mathrm{H}), 2.19-2.40(\mathrm{~m}, 2 \mathrm{H}), 2.98(\mathrm{t}, J=5.65 \mathrm{~Hz}$, $4 \mathrm{H}), 3.32-3.46(\mathrm{~m}, 1 \mathrm{H}), 3.54-3.70(\mathrm{~m}, 1 \mathrm{H}), 6.65-6.84(\mathrm{~m}, 3 \mathrm{H}), 7.11-7.30(\mathrm{~m}, 1 \mathrm{H})$.

\subsubsection{3-Benzyloxyacetophenone (74)}

DMF ( $50 \mathrm{~mL}, 0.7 \mathrm{M})$, benzyl chloride $(6.4 \mathrm{~mL}, 55.1 \mathrm{mmol}, 1.5$ equiv.) and potassium carbonate $\left(10.1 \mathrm{~g}, 73.4 \mathrm{mmol}, 2\right.$ equiv.) were added to $3^{\prime}$-hydroxyacetophenone $(5 \mathrm{~g}$, $36.7 \mathrm{mmol}, 1$ equiv.). The mixture was stirred at $80^{\circ} \mathrm{C}$ for $2 \mathrm{~h}$. The reaction was cooled to room temperature, diluted with EtOAc, and washed with water three times. The organic layer was separated, dried with sodium sulfate, and concentrated. The residue was purified 
by column chromatography to yield the desired ketone ( $6.6 \mathrm{~g}, 29.1 \mathrm{mmol}, 79 \%$ yield). ${ }^{1} \mathrm{H}$ NMR $\left(300 \mathrm{MHz}, \mathrm{CDCl}_{3}\right) \delta \mathrm{ppm} 2.56(\mathrm{~s}, 3 \mathrm{H}), 5.08(\mathrm{~s}, 2 \mathrm{H}), 7.10-7.21(\mathrm{~m}, 1 \mathrm{H}), 7.27-7.47(\mathrm{~m}$, $6 \mathrm{H}), 7.50-7.62(\mathrm{~m}, 2 \mathrm{H})$.

4.4.70. 3-(1-Hydroxy-1-phenylethyl)-N,N-bis(1-methylethyl)pyridine-4-carboxamide (75)

The alcohol intermediate was synthesized from N,N-diisopropylisonicotinamide and ketone 74 according to procedure A to yield the desired compound as an inseparable mixture with starting material. The impure material was carried forward without further purification.

\subsubsection{3-[3-(Benzyloxy)phenyl]-3-methylfuro[3,4-c]pyridin-1(3H)-one (76)}

The pyridine intermediate was synthesized from alcohol 75 using procedure $B$ to yield the desired compound $\left(0.70 \mathrm{~g}, 2.11 \mathrm{mmol}, 7 \%\right.$ yield over two steps). ${ }^{1} \mathrm{H}$ NMR $(300 \mathrm{MHz}$, $\left.\mathrm{CDCl}_{3}\right) \delta \mathrm{ppm} 2.06(\mathrm{~s}, 3 \mathrm{H}), 4.97-5.07(\mathrm{~m}, 2 \mathrm{H}), 6.86-7.10(\mathrm{~m}, 3 \mathrm{H}), 7.22-7.47(\mathrm{~m}, 6 \mathrm{H}), 7.67-7.82$ $(\mathrm{m}, 1 \mathrm{H}), 8.75-9.98(\mathrm{~m}, 2 \mathrm{H})$.

4.4.72. 3-[3-(Benzyloxy)phenyl]-3-methyl-4,5,6,7-tetrahydrofuro[3,4-c]pyridin$1(3 \mathrm{H})$-one $(77)$

The reduced analog was synthesized from pyridine 76 using procedure $C$ to yield the desired compound $\left(0.35 \mathrm{~g}, 1.04 \mathrm{mmol}, 50 \%\right.$ yield). ${ }^{1} \mathrm{H}$ NMR $\left(300 \mathrm{MHz}, \mathrm{CDCl}_{3}\right) \delta \mathrm{ppm} 1.66$ $(\mathrm{s}, 1 \mathrm{H}), 1.75-1.86(\mathrm{~m}, 3 \mathrm{H}), 2.19-2.35(\mathrm{~m}, 2 \mathrm{H}), 2.80-3.02(\mathrm{~m}, 2 \mathrm{H}), 3.21-3.35(\mathrm{~m}, 1 \mathrm{H}), 3.45-3.63$ $(\mathrm{m}, 1 \mathrm{H}), 4.99-5.09(\mathrm{~m}, 2 \mathrm{H}), 6.76-6.98(\mathrm{~m}, 4 \mathrm{H}), 7.22-7.47(\mathrm{~m}, 5 \mathrm{H})$.

\subsubsection{3-Methyl-1-naphthalen-2-ylbutan-1-ol (78)}

Iso-butyl magnesium chloride ( $48 \mathrm{~mL}, 2 \mathrm{M}$ solution, $96 \mathrm{mmol}$, 1.5 equiv.) was slowly added to 2-napthaldehyde ( $10 \mathrm{~g}, 64.0 \mathrm{mmol}, 1$ equiv.) in THF $(50 \mathrm{~mL}, 1.3 \mathrm{M})$ at $0{ }^{\circ} \mathrm{C}$. The mixture was stirred for $3 \mathrm{~h}$. The reaction was quenched with water and aqueous ammonium chloride. The reaction was diluted with EtOAc and extracted. Then, $3 \mathrm{M} \mathrm{HCl}$ was added to break the emulsion. The organic layer was separated, dried with sodium sulfate, filtered, and concentrated. The residue was purified by column chromatography to yield the desired compound (5.8 g, $27.1 \mathrm{mmol}, 42 \%$ yield). ${ }^{1} \mathrm{H} \mathrm{NMR}\left(300 \mathrm{MHz}, \mathrm{CDCl}_{3}\right)$ $\delta$ ppm 0.97-0.99 (m, 6H), 1.55-1.83 (m, 3H), 2.05 (br s, 1H), 4.88-4.92 (m, 1H), 7.43-7.50 (m, $3 \mathrm{H}), 7.78(\mathrm{~s}, 1 \mathrm{H}), 7.80-7.83(\mathrm{~m}, 3 \mathrm{H})$.

\subsubsection{3-Methyl-1-naphthalen-2-ylbutan-1-one (79)}

PCC (10.7 g, $49.5 \mathrm{mmol}, 2$ equiv.) was added to alcohol 78 (5.3 g, $24.7 \mathrm{mmol}$, 1 equiv.) in $\mathrm{CH}_{2} \mathrm{Cl}_{2}(100 \mathrm{~mL}, 0.25 \mathrm{M})$. The reaction was stirred, and upon completion, celite was added and the mixture was filtered. The filtrate was concentrated and purified by column chromatography to yield the desired ketone ( $1.2 \mathrm{~g}, 5.8 \mathrm{mmol}, 23 \%$ yield). ${ }^{1} \mathrm{H}$ NMR $\left(300 \mathrm{MHz}, \mathrm{CDCl}_{3}\right) \delta \mathrm{ppm} 1.03(\mathrm{~d}, J=6.5 \mathrm{~Hz}, 6 \mathrm{H}), 2.36(\mathrm{sept}, J=6.5 \mathrm{~Hz}, 1 \mathrm{H}), 2.96(\mathrm{~d}, J=7.0$ $\mathrm{Hz}, 2 \mathrm{H}), 7.52-7.60(\mathrm{~m}, 2 \mathrm{H}), 7.87(\mathrm{t}, J=8.5 \mathrm{~Hz}, 2 \mathrm{H}), 7.96(\mathrm{~d}, J=8.0 \mathrm{~Hz}, 1 \mathrm{H}), 8.03(\mathrm{dd}, J=8.5$, $2.0 \mathrm{~Hz}, 1 \mathrm{H}), 8.45(\mathrm{~s}, 1 \mathrm{H})$.

4.4.75. 3-(1-Hydroxy-3-methyl-1-naphthalen-2-ylbutyl)-N,N-bis(1-methylethyl)pyridine4-carboxamide (80)

The alcohol intermediate was synthesized from N,N-diisopropylisonicotinamide and ketone 79 according to procedure A to yield the desired compound $(1.37 \mathrm{~g}, 2.96 \mathrm{mmol}, 51 \%$ yield). ${ }^{1} \mathrm{H}$ NMR $\left(300 \mathrm{MHz}, \mathrm{CDCl}_{3}\right) \delta \mathrm{ppm}-0.11(\mathrm{~d}, J=6.0 \mathrm{~Hz}, 3 \mathrm{H}), 0.55(\mathrm{~d}, J=6.0 \mathrm{~Hz}, 3 \mathrm{H})$, 0.89-1.05 (m, 6H), $1.35(\mathrm{~d}, J=7.0 \mathrm{~Hz}, 2 \mathrm{H}), 1.56-1.63(\mathrm{~m}, 5 \mathrm{H}), 2.18-2.21(\mathrm{~m}, 1 \mathrm{H}), 2.35-2.42$ $(\mathrm{m}, 2 \mathrm{H}), 3.01-3.08(\mathrm{~m}, 2 \mathrm{H}), 6.42(\mathrm{~d}, J=2.0 \mathrm{~Hz}, 1 \mathrm{H}), 7.02(\mathrm{~d}, J=5.0 \mathrm{~Hz}, 1 \mathrm{H}), 7.20-7.22(\mathrm{~m}$, $1 \mathrm{H}), 7.43-4.49(\mathrm{~m}, 3 \mathrm{H}), 7.69(\mathrm{~d}, J=8.5 \mathrm{~Hz}), 7.98(\mathrm{~s}, 1 \mathrm{H}), 8.58(\mathrm{~d}, J=5.0 \mathrm{~Hz}, 1 \mathrm{H}), 9.08(\mathrm{~s}, 1 \mathrm{H})$.

\subsubsection{3-(2-Methylpropyl)-3-naphthalen-2-ylfuro[3,4-c]pyridin-1(3H)-one (81)}

The pyridine intermediate was synthesized from alcohol $\mathbf{8 0}$ using procedure $\mathrm{B}$ to yield the desired compound ( $0.80 \mathrm{~g}, 2.52 \mathrm{mmol}, 85 \%$ yield). ${ }^{1} \mathrm{H} \mathrm{NMR}\left(300 \mathrm{MHz}, \mathrm{CDCl}_{3}\right)$ 
$\delta$ ppm 0.80-0.95 (m, 6H), 1.53-1.78 (m, 1H), $2.15(\mathrm{dd}, J=14.88,6.97 \mathrm{~Hz}, 1 \mathrm{H}), 2.64(\mathrm{dd}$, $J=14.88,5.09 \mathrm{~Hz}, 1 \mathrm{H}), 7.45-7.56(\mathrm{~m}, 2 \mathrm{H}), 7.65(\mathrm{dd}, J=8.85,2.07 \mathrm{~Hz}, 1 \mathrm{H}), 7.74-7.94(\mathrm{~m}, 4 \mathrm{H})$, $7.99(\mathrm{~d}, J=1.88 \mathrm{~Hz}, 1 \mathrm{H}), 8.84(\mathrm{~d}, J=5.27 \mathrm{~Hz}, 1 \mathrm{H}), 9.12(\mathrm{~d}, J=1.13 \mathrm{~Hz}, 1 \mathrm{H})$.

4.4.77. 3-(2-Methylpropyl)-3-naphthalen-2-yl-4,5,6,7-tetrahydrofuro[3,4-c]pyridin-1(3H) -one (82)

The reduced analog was synthesized from pyridine 81 using procedure $C$ to yield the desired compound $(0.60 \mathrm{~g}, 0.19 \mathrm{mmol}, 8 \%$ yield $) .{ }^{1} \mathrm{H} \mathrm{NMR}\left(300 \mathrm{MHz}, \mathrm{CDCl}_{3}\right) \delta \mathrm{ppm}$ $0.88(\mathrm{~d}, J=6.78 \mathrm{~Hz}, 3 \mathrm{H}), 0.98(\mathrm{~d}, J=6.40 \mathrm{~Hz}, 3 \mathrm{H}), 1.57$ (br s, 1H), 1.71 (dqd, $J=13.54,6.73$, $6.73,6.73,4.71 \mathrm{~Hz}, 1 \mathrm{H}), 1.87(\mathrm{dd}, J=14.32,7.16 \mathrm{~Hz}, 1 \mathrm{H}), 2.17-2.42(\mathrm{~m}, 3 \mathrm{H}), 2.76-2.88(\mathrm{~m}$, $1 \mathrm{H}), 2.93-3.05(\mathrm{~m}, 1 \mathrm{H}), 3.40-3.55(\mathrm{~m}, 1 \mathrm{H}), 3.68-3.81(\mathrm{~m}, 1 \mathrm{H}), 7.33(\mathrm{dd}, J=8.67,2.26 \mathrm{~Hz}, 1 \mathrm{H})$, 7.45-7.54 (m, 2H), 7.77-7.90 (m, 4H).

\subsubsection{1-[2-(Benzyloxy)phenyl]-3-methylbutan-1-ol (83)}

Isobutyl magnesium bromide (16.25 mL (2.0 M in THF), $32.5 \mathrm{mmol}, 1.5$ equiv.) was added to 2-OBn-benzaldehyde ( $4.6 \mathrm{~g}, 21.6 \mathrm{mmol}, 1$ equiv.) in THF (50 mL, $0.4 \mathrm{M})$ at $-78^{\circ} \mathrm{C}$. The reaction was allowed to warm to room temperature. The reaction was quenched with water and extracted with $\mathrm{CH}_{2} \mathrm{Cl}_{2}$. The organic layer was dried with sodium sulfate and concentrated. The resulting residue was purified by silica gel column chromatography to yield the desired compound ( $3.15 \mathrm{~g}, 11.65 \mathrm{mmol}, 54 \%$ yield). ${ }^{1} \mathrm{H} \mathrm{NMR}\left(300 \mathrm{MHz}, \mathrm{CDCl}_{3}\right)$

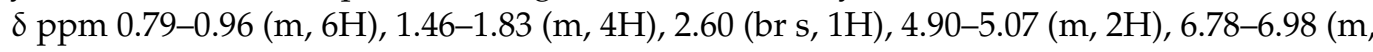
$3 \mathrm{H}), 7.07-7.20(\mathrm{~m}, 1 \mathrm{H}), 7.23-7.44(\mathrm{~m}, 5 \mathrm{H})$.

\subsubsection{1-[2-(Benzyloxy)phenyl]-3-methylbutan-1-one (84)}

Celite ( $3 \mathrm{~g}$ ) was added to alcohol 83 (3.15 g, $11.65 \mathrm{mmol}, 1$ equiv.) in $\mathrm{CH}_{2} \mathrm{Cl}_{2}$ (50 mL, $0.2 \mathrm{M})$. PCC (3.76 g, 17.48, 1.5 equiv.) was then added, and the reaction was allowed to stir at room temperature for $2 \mathrm{~h}$. The reaction was filtered and then concentrated. The residue was purified by silica gel column chromatography to yield the desired ketone ( $3.0 \mathrm{~g}$, $11.18 \mathrm{mmol}, 96 \%$ yield). ${ }^{1} \mathrm{H}$ NMR $\left(300 \mathrm{MHz}, \mathrm{CDCl}_{3}\right) \delta \mathrm{ppm} 0.71-0.90(\mathrm{~m}, 6 \mathrm{H}), 2.07-2.30(\mathrm{~m}$, 1H), 2.75-2.87 (m, 2H), 4.95-5.09 (m, 2H), 6.83-6.99 (m, 3H), 7.18-7.44 (m, 5H), 7.56-7.70 $(\mathrm{m}, 1 \mathrm{H})$.

4.4.80. 3-\{1-[2-(Benzyloxy)phenyl]-1-hydroxy-3-methylbutyl\}-N,N-bis(1methylethyl)pyridine-4-carboxamide (85)

The alcohol intermediate was synthesized from N,N-diisopropylisonicotinamide and ketone 84 according to procedure A to yield the desired compound $(1.4 \mathrm{~g}, 2.70 \mathrm{mmol}, 53 \%$

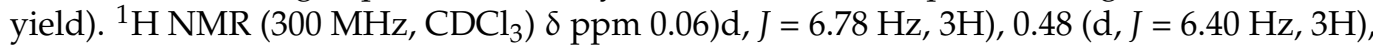
0.90-1.03 (m, 6H), $1.20(\mathrm{~d}, J=6.78 \mathrm{~Hz}, 3 \mathrm{H}), 1.35(\mathrm{~d}, J=6.78 \mathrm{~Hz}, 3 \mathrm{H}), 1.45-1.63(\mathrm{~m}, 2 \mathrm{H}), 2.24$ $(\mathrm{dd}, J=13.00,5.09 \mathrm{~Hz}, 1 \mathrm{H}), 2.47-2.65(\mathrm{~m}, 1 \mathrm{H}), 2.88-3.22(\mathrm{~m}, 1 \mathrm{H}), 4.69-4.97(\mathrm{~m}, 2 \mathrm{H}), 6.39(\mathrm{~d}$, $J=2.64 \mathrm{~Hz}, 1 \mathrm{H}), 6.71-7.02(\mathrm{~m}, 4 \mathrm{H}), 7.11-7.28(\mathrm{~m}, 5 \mathrm{H}), 7.76-7.85(\mathrm{~m}, 1 \mathrm{H}), 8.44-8.56(\mathrm{~m}, 1 \mathrm{H})$, $8.92(\mathrm{~s}, 1 \mathrm{H})$.

\subsubsection{3-[2-(Benzyloxy)phenyl]-3-(2-methylpropyl)furo[3,4-c]pyridin-1(3H)-one (86)}

The pyridine intermediate was synthesized from alcohol 85 using procedure B to yield the desired compound $(0.41 \mathrm{~g}, 1.10 \mathrm{mmol}, 41 \%$ yield $) .{ }^{1} \mathrm{H} \mathrm{NMR}\left(300 \mathrm{MHz}, \mathrm{CDCl}_{3}\right)$ $\delta$ ppm 0.69-0.94 (m, 6H), 1.43-1.69 (m, 1H), 1.92 (ddd, $J=14.60,7.63,4.90 \mathrm{~Hz}, 1 \mathrm{H}), 2.69-2.91$ $(\mathrm{m}, 1 \mathrm{H}), 5.03-5.24(\mathrm{~m}, 2 \mathrm{H}), 6.86-7.08(\mathrm{~m}, 2 \mathrm{H}), 7.19-7.34(\mathrm{~m}, 1 \mathrm{H}), 7.38-7.50(\mathrm{~m}, 5 \mathrm{H}), 7.53-7.70$ $(\mathrm{m}, 2 \mathrm{H}), 8.61-8.79(\mathrm{~m}, 1 \mathrm{H}), 8.99-9.20(\mathrm{~m}, 1 \mathrm{H})$.

4.4.82. 3-[2-(Benzyloxy)phenyl]-3-(2-methylpropyl)-4,5,6,7-tetrahydrofuro[3,4-c]pyridin$1(3 \mathrm{H})$-one $(87)$

The reduced analog was synthesized from pyridine 86 using procedure $C$ to yield the desired compound $\left(0.096 \mathrm{~g}, 0.52 \mathrm{mmol}, 25 \%\right.$ yield). ${ }^{1} \mathrm{H}$ NMR (300 $\left.\mathrm{MHz} \mathrm{CDCl}_{3}\right)$ $\delta$ ppm 0.73-0.92 (m, 6H), 1.36-1.64 (m, 3H), 2.11-2.23 (m, 2H), 2.50-2.65 (m, 1H), 2.70-2.86 (m, 1H), 2.86-3.01 (m, 1H), 3.36-3.57 (m, 2H), 4.96-5.11 (m, 2H), 6.89-7.06 (m, 1H), 7.23-7.34 
$(\mathrm{m}, 2 \mathrm{H}), 7.37-7.47(\mathrm{~m}, 5 \mathrm{H}), 7.50-7.63(\mathrm{~m}, 1 \mathrm{H})$. ESI MS m/z: Calculated for $\mathrm{C}_{24} \mathrm{H}_{27} \mathrm{NO}_{3} 377.20$, Found $378.3(\mathrm{M}+\mathrm{H})^{+}$.

4.4.83. 3-(2-Hydroxyphenyl)-3-(2-methylpropyl)-4,5,6,7-tetrahydrofuro[3,4-c]pyridin $-1(3 \mathrm{H})$-one (88)

Pd on carbon (10 mol\%) was added to amine 87 (0.064 g, $0.17 \mathrm{mmol}, 1$ equiv.) in methanol $(5 \mathrm{~mL}, 0.03 \mathrm{M})$. The reaction was put under hydrogen at $50 \mathrm{psi}$ for $1 \mathrm{~h}$. The reaction was filtered and carried forward crude.

4.4.84. 3-[1-(3-Chlorophenyl)-1-hydroxy-3-methylbutyl]-N,N-bis(1-methylethyl)pyridine4-carboxamide (89)

The alcohol intermediate was synthesized from $\mathrm{N}, \mathrm{N}$-diisopropylisonicotinamide and 1-(3-chlorophenyl)-3-methyl-1-butanone according to procedure A to yield the desired compound (1.8 g, $4.02 \mathrm{mmol}, 50 \%$ yield). ${ }^{1} \mathrm{H}$ NMR (300 MHz, $\left.\mathrm{CDCl}_{3}\right) \delta \mathrm{ppm} 0.40-0.50$ $(\mathrm{m}, 3 \mathrm{H}), 0.56-0.66(\mathrm{~m}, 3 \mathrm{H}), 0.96-1.02(\mathrm{~m}, 4 \mathrm{H}), 1.09(\mathrm{~d}, J=6.40 \mathrm{~Hz}, 3 \mathrm{H}), 1.20-1.29(\mathrm{~m}, 3 \mathrm{H})$, $1.36-1.43(\mathrm{~m}, 3 \mathrm{H}), 1.50-1.70(\mathrm{~m}, 2 \mathrm{H}), 1.97-2.06(\mathrm{~m}, 1 \mathrm{H}), 2.22-2.38(\mathrm{~m}, 1 \mathrm{H}), 3.09-3.35(\mathrm{~m}, 2 \mathrm{H})$, 6.34-6.45 (m, 1H), 6.99-7.09 (m, 1H), 7.13-7.40 (m, 3H), 8.53-8.61 (m, 1H), $8.99(\mathrm{~s}, 1 \mathrm{H})$.

\subsubsection{3-(3-Chlorophenyl)-3-(2-methylpropyl)furo[3,4-c]pyridin-1(3H)-one (90)}

The pyridine intermediate was synthesized from alcohol 89 using procedure $\mathrm{B}$ to yield the desired compound ( $0.50 \mathrm{~g}, 1.66 \mathrm{mmol}, 41 \%$ yield). ${ }^{1} \mathrm{H} \mathrm{NMR}\left(300 \mathrm{MHz}, \mathrm{CDCl}_{3}\right)$ $\delta$ ppm 0.78-0.94 (m, 6H), 1.43-1.53 (m, 1H), 1.53-1.72 (m, 2H), 2.08-2.14 (m, 1H), $2.50(\mathrm{dd}$, $J=15.07,5.27 \mathrm{~Hz}, 1 \mathrm{H}), 7.22-7.40(\mathrm{~m}, 2 \mathrm{H}), 7.42-7.49(\mathrm{~m}, 1 \mathrm{H}), 7.53-7.59(\mathrm{~m}, 1 \mathrm{H}), 7.74-7.84(\mathrm{~m}$, $1 \mathrm{H}), 8.87(\mathrm{~d}, J=4.90 \mathrm{~Hz}, 1 \mathrm{H}), 9.06(\mathrm{~d}, J=1.13 \mathrm{~Hz}, 1 \mathrm{H})$.

4.4.86. 3-(3-Chlorophenyl)-3-(2-methylpropyl)-4,5,6,7-tetrahydrofuro[3,4-c]pyridin$1(3 \mathrm{H})$-one (91)

The reduced analog was synthesized from pyridine 90 using procedure $\mathrm{C}$ to yield the desired compound (310 mg, $1.01 \mathrm{mmol}, 61 \%$ yield). ${ }^{1} \mathrm{H}$ NMR (300 $\mathrm{MHz}, \mathrm{CDCl}_{3}$ ) $\delta$ ppm 0.82-1.02 (m, 6H), 1.55-1.84 (m, 3H), 2.14-2.40 (m, 3H), 2.95 (tdd, $J=18.32,12.90$, $5.84 \mathrm{~Hz}, 2 \mathrm{H}), 3.37-3.52(\mathrm{~m}, 1 \mathrm{H}), 3.62-3.73(\mathrm{~m}, 1 \mathrm{H}), 7.15-7.23(\mathrm{~m}, 1 \mathrm{H}), 7.26-7.39(\mathrm{~m}, 3 \mathrm{H})$.

\subsubsection{Tert-Butyl 4-Benzylpiperazine-1-carboxylate (92)}

$\mathrm{Boc}_{2} \mathrm{O}(2.43 \mathrm{~g}, 11.1 \mathrm{mmol}, 1.2$ equiv.) and triethyl amine ( $6.45 \mathrm{~mL}, 46.5 \mathrm{mmol}, 5$ equiv.) were added to 1-(phenylmethyl)-piperazine dihydrochloride (1.98 g, $9.3 \mathrm{mmol}, 1$ equiv.) in THF $(40 \mathrm{~mL}, 0.2 \mathrm{M})$. The reaction was stirred until complete by TLC. The reaction was quenched with water, diluted with EtOAc, and extracted. The organic layer was dried with sodium sulfate, filtered, and concentrated. The resulting residue was purified by column chromatography to yield the desired Boc-protected piperazine $(1.12 \mathrm{~g}, 4.0 \mathrm{mmol}$, $43 \%$ yield). ${ }^{1} \mathrm{H}$ NMR $\left(300 \mathrm{MHz}, \mathrm{CDCl}_{3}\right) \delta \mathrm{ppm} 1.45(\mathrm{~s}, 9 \mathrm{H}), 2.25-2.45(\mathrm{~m}, 4 \mathrm{H}), 3.35-3.46(\mathrm{~m}$, $4 \mathrm{H}), 3.50(\mathrm{~s}, 2 \mathrm{H}), 7.01-7.55(\mathrm{~m}, 5 \mathrm{H})$.

4.4.88. 7-Benzyl-1-(2-methylpropyl)-1-phenylhexahydro[1,3]oxazolo[3,4-a]pyrazin-3one (93)

TMEDA ( $1 \mathrm{~mL}, 6.6 \mathrm{mmol}, 2.2$ equiv.), sec-butyl lithium ( $4.7 \mathrm{~mL}, 1.4 \mathrm{M}$ solution, $6.6 \mathrm{mmol}, 2$ equiv.) and isovalerophenone $(0.97 \mathrm{~g}, 6.0 \mathrm{mmol}, 2$ equiv.) were added to piperazine $92(830 \mathrm{mg}, 3.0 \mathrm{mmol}, 1$ equiv.) in THF $(10 \mathrm{~mL}, 0.3 \mathrm{M})$. The reaction was monitored by TLC, and upon completion, was quenched with aqueous sodium bicarbonate, diluted with EtOAc, and extracted. The organic layer was dried with sodium sulfate, filtered, and concentrated. The resulting residue was purified by column chromatography to yield the desired compound ( $324 \mathrm{mg}, 0.89 \mathrm{mmol}, 30 \%$ yield). ${ }^{1} \mathrm{H} \mathrm{NMR}\left(300 \mathrm{MHz}, \mathrm{CDCl}_{3}\right)$ $\delta$ ppm $0.64(\mathrm{~d}, J=6.78 \mathrm{~Hz}, 3 \mathrm{H}), 0.91(\mathrm{~d}, J=6.59 \mathrm{~Hz}, 3 \mathrm{H}), 1.80(\mathrm{~d}, J=6.03 \mathrm{~Hz}, 2 \mathrm{H}), 2.04-2.15$ $(\mathrm{m}, 1 \mathrm{H}), 2.24(\mathrm{t}, J=10.83 \mathrm{~Hz}, 1 \mathrm{H}), 2.72(\mathrm{dd}, J=11.49,3.39 \mathrm{~Hz}, 1 \mathrm{H}), 2.83-3.09(\mathrm{~m}, 2 \mathrm{H}), 3.60$ $(\mathrm{q}, J=13.25 \mathrm{~Hz}, 2 \mathrm{H}), 3.69-3.82(\mathrm{~m}, 2 \mathrm{H}), 6.99-7.63(\mathrm{~m}, 10 \mathrm{H})$. 
4.4.89. 9. H-Fluoren-9-ylmethyl 1-(2-methylpropyl)-3-oxo-1phenyltetrahydro[1,3] oxaZolo[3,4-a]pyrazine-7 $(1 \mathrm{H})$-carboxylate $(\mathbf{9 4})$

Fmoc- $\mathrm{Cl}$ (0.17 g, $0.66 \mathrm{mmol}, 1.1$ equiv.) was added to oxazolidinone $93(220 \mathrm{mg}$, $0.60 \mathrm{mmol}, 1$ equiv.) in acetonitrile $(10 \mathrm{~mL}, 0.06 \mathrm{M})$. The reaction was heated to $90{ }^{\circ} \mathrm{C}$ for $4 \mathrm{~h}$. The reaction was quenched with aqueous sodium bicarbonate, diluted with EtOAc, and extracted. The organic layer was dried with sodium sulfate, filtered, and concentrated. The residue was carried forward crude.

\subsubsection{1-(2-Methylpropyl)-1-phenylhexahydro[1,3] oxazolo[3,4-a]pyrazin-3-one (95)}

Piperidine $(0.1 \mathrm{~mL}, 0.90 \mathrm{mmol}$, 1.5 equiv.) was added to oxazolidinone 94 (30 mg, $0.6 \mathrm{mmol}, 1$ equiv.) in acetonitrile $(5 \mathrm{~mL}, 0.01 \mathrm{M})$. The reaction was stirred until complete by TLC. The reaction was quenched with aqueous sodium bicarbonate, diluted with EtOAc, and extracted. The organic layer was separated, dried with sodium sulfate, filtered, and concentrated. The residue was purified by column chromatography to yield the desired amine (164 mg, $0.6 \mathrm{mmol}$, quantitative yield). ${ }^{1} \mathrm{H}$ NMR $\left(300 \mathrm{MHz}, \mathrm{CDCl}_{3}\right) \delta \mathrm{ppm} 0.70(\mathrm{~d}$, $J=6.78 \mathrm{~Hz}, 3 \mathrm{H}), 0.86-0.99(\mathrm{~m}, 3 \mathrm{H}), 1.51-1.70(\mathrm{~m}, 1 \mathrm{H}), 1.83(\mathrm{t}, J=11.59 \mathrm{~Hz}, 1 \mathrm{H}), 1.93-2.11$ $(\mathrm{m}, 2 \mathrm{H}), 2.41-2.62(\mathrm{~m}, 2 \mathrm{H}), 2.84(\mathrm{dd}, J=11.96,3.67 \mathrm{~Hz}, 1 \mathrm{H}), 3.06(\mathrm{ddd}, J=13.00,12.06$, $3.77 \mathrm{~Hz}, 1 \mathrm{H}), 3.60(\mathrm{dd}, J=11.11,3.58 \mathrm{~Hz}, 1 \mathrm{H}), 3.83(\mathrm{dd}, J=13.09,2.92 \mathrm{~Hz}, 1 \mathrm{H}), 7.03-7.58$ $(\mathrm{m}, 5 \mathrm{H})$.

\section{5. $\mathrm{Ca}^{+2}$ Mobilization Assay}

A stable cell line overexpressing the human NPSR-107I was created in CHO-G $\alpha_{\mathrm{q} 16}$ cells (RD-HGA16, Molecular Devices), as previously described [10]. Briefly, $\mathrm{CHO}-\mathrm{G} \alpha_{\mathrm{q} 16}$ cells were transfected with pcDNA 3.1 human NPSR-107I using Lipofectamine reagent. Transfected cells were plated into $10 \mathrm{~cm}^{2}$ dishes $24 \mathrm{~h}$ post-transfection and were selected using Geneticin. After 2 weeks, individual clones were selected, grown to confluence, and screened in a functional 96-well calcium mobilization assay that measured the response to NPS (100 nM final). Concentration-response curves of NPS were run in clones that showed a high response to the agonist in the screen. A final working clone was chosen for all subsequent studies based on NPS potency and the calcium mobilization signal window. CHO-G $\alpha 16-\mathrm{hNPSR}-107 \mathrm{I}$ cells were cultured in Ham's F12 media supplemented with 10\% FBS, 100 units $/ \mathrm{mL}$ penicillin, $100 \mu \mathrm{g} / \mathrm{mL}$ streptomycin, $200 \mu \mathrm{g} / \mathrm{mL}$ hygromycin, and $400 \mu \mathrm{g} / \mathrm{mL}$ geneticin. Media were purchased from HyClone (GE Life Sciences); FBS, penicillin/streptomycin, hygromycin, and geneticin were purchased from Invitrogen (Thermo Scientific). The day before the assay, cells were plated into 96-well black-walled assay plates at 25,000-40,000 cells / well in growth medium without selection antibiotics. Cells were incubated overnight at $37^{\circ} \mathrm{C}, 5 \% \mathrm{CO}_{2}$. The FLIPR Calcium 5 assay kit (Molecular Devices) was used according to the manufacturer's instructions with minor modifications. Briefly, reconstituted dye was diluted in pre-warmed assay buffer (HBSS, $20 \mathrm{mM}$ HEPES, $2.5 \mathrm{mM}$ probenecid, $\mathrm{pH} 7.4$ at $37^{\circ} \mathrm{C}$ ). Growth medium was removed, and the cells were gently washed with assay buffer. Calcium 5 dye was added to the cells and the plate was incubated for $45 \mathrm{~min}$ at $37^{\circ} \mathrm{C}, 5 \% \mathrm{CO}_{2}$. A single concentration of test compound and 10-point concentration-response curves of NPS (ranging from $100 \mathrm{nM}$ to $1 \mathrm{pM}$ ) were prepared at $10 \times$ the desired final concentration. Cells were pretreated with the test compound or vehicle in a final concentration of $0.25 \% \mathrm{BSA} / 1 \% \mathrm{DMSO}$ for $15 \mathrm{~min}$ at $37^{\circ} \mathrm{C}$. Assay plates were read with a FlexStation II instrument (excitation at $485 \mathrm{~nm}$, detection at $525 \mathrm{~nm}$, Molecular Devices). Calcium-mediated changes in fluorescence were monitored every $1.5 \mathrm{~s}$ over a $90 \mathrm{~s}$ time period. NPS was added during the read and the maximum kinetic reduction (SoftMax [Max-Min], Molecular Devices) in relative fluorescent units (RFU) was measured. Data were fitted to a three-parameter logistic curve to generate $\mathrm{EC}_{50}$ values (GraphPad Prism 6.0). Antagonism was quantified by measuring the ratio of equi-active concentrations of agonist measured in the presence or absence of the antagonist. Apparent Ke values were calculated using the equation $\mathrm{Ke}=[\mathrm{L}] /\left(\left(\mathrm{EC}_{50}{ }^{+} / \mathrm{EC}_{50}{ }^{-}\right)-1\right)$, where $[\mathrm{L}]$ is the concentration of test compound, $\mathrm{EC}_{50}{ }^{+}$is the $\mathrm{EC}_{50}$ of NPS with test compound, and 
$\mathrm{EC}_{50}{ }^{-}$is the $\mathrm{EC}_{50}$ of NPS alone. Ke values were considered valid when the $\mathrm{EC}_{50}{ }^{+} / \mathrm{EC}_{50}{ }^{-}$ ratio was at least 4. HBSS and HEPES were purchased from Gibco (Thermo Scientific); probenecid, BSA, and DMSO were purchased from Sigma-Aldrich.

\subsection{Animal Studies}

Male mice between 8 and 12 weeks of age were used for all tests. C57/Bl6 were obtained from the former NCI colony maintained by Charles River. Animals were housed with ad libitum access to food and water on a 12:12 h light:dark cycle with lights on at 06:00. Experiments were conducted between the hours of 09:00 and 15:00. All experiments were approved by the Institutional Animal Care and Use Committee of the State University of New York at Buffalo (PMY09073N) and conducted in accordance with the National Institutes of Health Guide for the Care and Use of Laboratory animals.

\subsection{Pharmacokinetics}

Animals were administered vehicle (1\% n-methyl-2-pyrrolidone (NMP) with $0.5 \%$ Tween 80 in $0.5 \%$ carboxymethyl cellulose (CMC) in water) or compound $\mathbf{1 4 b}$ dissolved in the same vehicle $(30 \mathrm{mg} / \mathrm{kg}$, i.p.), and were euthanized at the appropriate timepoints by isoflurane overdose with decapitation. Trunk blood and brains were taken at 15, 30, 60, 120, and $240 \mathrm{~min}$ post-injection. Blood was collected in $5 \mathrm{~mL}$ tubes that had been preloaded with $0.5 \mathrm{M}$ EDTA so that the final concentration would be approximately $5 \mathrm{mM}$. Blood/EDTA was centrifuged at $1000 \times g$ at $4{ }^{\circ} \mathrm{C}$ for $10 \mathrm{~min}$. Plasma was collected and flash-frozen on dry ice and stored at $-80^{\circ} \mathrm{C}$ until analysis.

\subsection{Standard Curve Preparation}

Stock solutions of $\mathbf{1 4 b}$ were prepared and diluted serially to generate standard curve and quality control spiking solutions. The concentrations in plasma and brain homogenate for $\mathbf{1 4 b}$ were $0.5,1,5,10,50,100,500$, and $1000 \mathrm{ng} / \mathrm{mL}$ for standard curves.

\subsection{Sample Preparation}

Brains were weighed and homogenized at 1:5 (wt:vol) with 50:50 ethanol:water using a Geno/Grinder 2010 (SPEXSamplePrep, Metuchen, NJ, USA) twice at $1750 \mathrm{rpm}$ for $30 \mathrm{~s}$. Subsequently, $50 \mu \mathrm{L}$ of plasma or brain homogenate was mixed with $150 \mu \mathrm{L}$ of acetonitrile containing reserpine as internal standard $(100 \mathrm{ng} / \mathrm{mL})$ in a 96-well plate. The plate was shaken at $700 \mathrm{rpm}$ for $3 \mathrm{~min}$ and then centrifuged at $4000 \mathrm{rpm}$ for $10 \mathrm{~min}$ at $4 \mathrm{C}$. Then, $50 \mu \mathrm{L}$ of supernatant was mixed with $50 \mu \mathrm{L}$ of water in a new plate and analyzed by LC/MS-MS.

\subsection{LC/MS-MS Conditions}

A SCIEX Exion AD UHPLC system (Framingham, MA) was used to inject $10 \mu \mathrm{L}$ of the processed samples/calibration standards onto a Waters Acquity BEH C18 $(2.1 \mathrm{~mm} \times 100 \mathrm{~mm}$, $1.7 \mu \mathrm{M}$ ) column (Milford, MA). Mobile phase A consisted of $0.1 \%$ formic acid in water, and mobile phase B consisted of $0.1 \%$ formic acid in acetonitrile. Chromatography was conducted using a linear gradient starting at initial conditions of $10 \% \mathrm{~B}$, and holding for $0.5 \mathrm{~min}$ before increasing linearly to $95 \% \mathrm{~B}$ over $3.5 \mathrm{~min}$, and holding for $1 \mathrm{~min}$ before returning to initial conditions over $0.1 \mathrm{~min}$. Total run time was $7 \mathrm{~min}$ and the flow rate was $0.400 \mathrm{~mL} / \mathrm{min}$. Quantitation was achieved by multiple reaction monitoring in positive ion mode using an SCIEX 6500+ (Framingham, MA) QTRAP mass spectrometer. Compound $\mathbf{1 4 b}$ was quantitated by monitoring the transition of $m / z 445.044 \rightarrow 251.1$, and the internal standard, reserpine, was monitored by $m / z 609.300 \rightarrow 194.9$. Mass spectrometry parameters were as follows: $\mathrm{CUR}=30, \mathrm{GS} 1=50, \mathrm{GS} 2=50, \mathrm{TEM}=700, \mathrm{CAD}=1$ low, and $\mathrm{IS}=4500$. Calibration curves were processed using Analyst 1.7.1 software by plotting the analyte to internal standard peak area ratio against the calibration standard concentrations. 


\subsection{Cannula Implantation}

Mice were anesthetized using ketamine $(100 \mathrm{mg} / \mathrm{kg})$ and xylazine $(5 \mathrm{mg} / \mathrm{kg})$ and were secured to a stereotaxic frame once the appropriate plane of anesthesia was reached. An incision was made in order to expose the skull. A hole was drilled and the cannulae were placed at $\mathrm{AP}$ of $-0.4 \mathrm{~mm}$ from bregma ML of $-1.0 \mathrm{~mm}$ from the midline and at a depth (DV) of $-2.0 \mathrm{~mm}$ from the dura. The cannulae were then secured with Metabond dental cement (Parkell Inc., Edgewood, NY, USA). The incision was then closed around the cement with surgical staples. Dummy cannulae were placed in the cannula to prevent the entry of foreign material. Post-operative care included saline $(1 \mathrm{~mL}, \mathrm{sc})$, enrofloxacin $(5 \mathrm{mg} / \mathrm{kg}, \mathrm{sc})$, and carprofen $(5 \mathrm{mg} / \mathrm{kg}$, sc). All mice were placed under a heating lamp and observed until they were awake. For three additional days after surgery, mice were given carprofen $(5 \mathrm{mg} / \mathrm{kg}, \mathrm{sc})$. They were housed in their home cages for one week to recover from surgery.

\subsection{Locomotor Activity Analysis}

Open-field testing was conducted in clear plexiglass cages measuring $40 \times 40 \mathrm{~cm}^{2}$ interfaced by a grid array of infrared beams connected to a computer system which tracked and quantified the animals' location and movements (OMNITECH Instruments, Columbus, $\mathrm{OH}$, USA). Testing was conducted in a room novel to the mice.

Mice were moved to the testing room and immediately placed in the testing boxes, where they remained undisturbed for $90 \mathrm{~min}$. Each mouse was removed and administered vehicle or compound $\mathbf{1 4 b}(3 \mathrm{mg} / \mathrm{kg}$, i.p.), placed back into the test arena for $10 \mathrm{~min}$ before administering either artificial cerebral spinal fluid with $0.1 \%$ bovine serum albumin (aCSF) or NPS (0.3 nmole; Anaspec, Fremont, CA, USA) via the indwelling cannula in a volume of 2 microliters. Recording of locomotor activity began immediately after the ICV injection.

Statistical analyses were performed by ANOVA with Tukey's multiple comparisons test analysis within GraphPad Prism 8 software (GraphPad Software, San Diego, CA, USA). All results are expressed as mean values \pm SEM. Group means were considered significantly different when $p<0.05$.

\subsection{Glutathione Incubation Assay}

For the glutathione incubation assay, $20 \mathrm{mM}$ stock solutions of compound $14 \mathrm{~b}$ in $\mathrm{MeCN}(400 \mu \mathrm{L})$ and glutathione GSH in MeCN: Milli-Q $\mathrm{H}_{2} \mathrm{O}(10 \mathrm{~mL}, 1: 1, v / v)$ were prepared in separate scintillation vials. To prepare the incubation solution, $100 \mu \mathrm{L}$ of 14b solution and $900 \mu \mathrm{L}$ of GSH solution were taken in a clean HPLC vial. The final concentrations of $\mathbf{1 4 b}$ and GSH were $2 \mathrm{mM}$ and $18 \mathrm{mM}$, respectively. In addition, a $2 \mathrm{mM}$ reference solution of $\mathbf{1 4 b}$ was prepared by adding $100 \mu \mathrm{L}$ of $\mathbf{1 4 b}$ stock solution to an HPLC vial containing $900 \mu \mathrm{L}$ of $\mathrm{MeCN}$ : $\mathrm{H}_{2} \mathrm{O}$ (1:1), and an $18 \mathrm{mM}$ reference solution of GSH was prepared by adding $900 \mu \mathrm{L}$ of GSH stock solution to an HPLC vial containing $100 \mu \mathrm{L}$ of MeCN.

Low-resolution mass spectra were obtained using an Agilent InfinityLab MSD single quadrupole mass spectrometer system (ESI). Mass detection was carried out both in positive and negative mode ESI at 200-2000 $\mathrm{m} / z$ range. The reference solutions of $\mathbf{1 4 b}$ and GSH were injected once, individually. Consecutive injections were submitted from the incubation solution $(\mathbf{1 4}+\mathrm{GSH})$ at $\mathrm{t}=5 \mathrm{~min}, 1 \mathrm{~h}, 2 \mathrm{~h}, 6 \mathrm{~h}, 24 \mathrm{~h}$, and $48 \mathrm{~h}$. Chromatograms were detected using 254 and $280 \mathrm{~nm}$ wavelengths with $5 \mu \mathrm{L}$ injections and data were processed using a general walkup method*.

*LC/MS Walkup Method: an Agilent InfinityLab MSD single quadrupole mass spectrometer equipped with an API-ES and an Agilent Infinity II 1260 HPLC equipped with an Agilent Infinity 1260 variable wavelength detector and a Phenomenex Synergi $2.5 \mathrm{~mm}$ Hydro-RP 100A C18 $30 \times 2 \mathrm{~mm}$ column. HPLC Method: starting with a flow rate of $0.6 \mathrm{~mL} / \mathrm{min}$ for $0.4 \mathrm{~min}$ at $20 \%$ solvent $\mathrm{B}$ followed by a 1.6-min gradient of $20-95 \%$ solvent $\mathrm{B}$ at $0.6 \mathrm{~mL} / \mathrm{min}$ followed by $2 \mathrm{~min}$ at $95 \%$ solvent $\mathrm{B}$ with a gradual ramp-up of the flow rate to $1.2 \mathrm{~mL} / \mathrm{min}$ at the end (solvent $\mathrm{A}$, water with $0.1 \%$ formic acid; solvent $\mathrm{B}$, acetoni- 
trile with $0.1 \%$ formic acid and 5\% water; absorbance monitored at 220 and $280 \mathrm{~nm}$ ). MS Method: using atmospheric pressure ionization-electrospray, positive and negative ions were monitored in the range of 70-700 or 200-2000 (for compounds with a MW > 700).

\section{Conclusions}

This study was designed to evaluate a new series of NPSR antagonists and provide a deeper understanding of the key features of the SHA scaffold that lead to high potency at the NPSR. The diaryl system of SHA appears to be required for high antagonist potency when the oxazolidinone core is intact. Once the oxazolidinone nitrogen is replaced with a double bond, the binding mode appears to shift in the NPSR binding site and aliphatic groups are now tolerated for one of the aryl rings. Comparison of compound 29 with $14 \mathrm{~b}$ demonstrates that the binding sites for these two series are distinct. It was anticipated that the replacement of one aryl ring would enhance the solubility and drug-like properties of this class. Compound $\mathbf{1 4 b}$ was selected for further study based on antagonist potency and the potential to exhibit differing physiochemical properties in vivo. Pharmacokinetic evaluation of $\mathbf{1 4 b}$ indicated that it accesses the CNS in sufficient quantities but is cleared rapidly from plasma, suggesting the need to reduce oxidative metabolism. Behavioral evaluation of $\mathbf{1 4 b}$ in a mouse model of NPS-stimulated locomotor activity demonstrated that a relatively low dose of $\mathbf{1 4 b}(3 \mathrm{mg} / \mathrm{kg}$ i.p.) was sufficient to significantly decrease NPS (0.3 nmol)-mediated locomotor stimulation. Although $\mathbf{1 4 b}$ is approximately sevenfold less potent than SHA-68, it possessed enhanced in vivo activity compared to published reports. Typically, SHA-68 is dosed at $50 \mathrm{mg} / \mathrm{kg}$ to significantly block $0.1 \mathrm{nmol}$ of NPSstimulated locomotor activity [12,20]. In this study, a significant reduction in NPS-mediated locomotor activity with a reduced dose of $14 b(3 \mathrm{mg} / \mathrm{kg})$ and a threefold higher dose of NPS $(0.3 \mathrm{nmol})$ was achieved. Although it is difficult to compare behavioral results across different labs, our data suggest that further improvements in potency and clearance of $\mathbf{1 4 b}$ should result in substantially improved antagonists for the NPSR. Overall, we have now identified a novel NPSR antagonist scaffold with enhanced properties in vivo.

Supplementary Materials: The following are available online at https: / www.mdpi.com/article/ 10.3390/ph14101024/s1, Figure S1: Compound $3{ }^{13} \mathrm{C}-\mathrm{NMR}$, Figure S2. Compound $3{ }^{1} \mathrm{H}-\mathrm{NMR}$, Figure S3. Compound 2, Figure S4. Compound 3, Figure S5. Compound 4, Figure S6. Compound 5, Figure S7. Compound 6, Figure S8. Compound 7, Figure S9. Compound 8, Figure S10. Compound 9, Figure S11. Compound 10, Figure S12. Compound 11, Figure S13. Compound 12, Figure S14. Compound 13, Figure S15. Compound 15, Figure S16. Compound 16, Figure S17. Compound 17, Figure S18. Compound 18, Figure S19. Compound 19, Figure S20. Compound 20, Figure S21. Compound 21, Figure S22. Compound 22, Figure S23. Compound 23, Figure S24. Compound 24, Figure S25. Compound 25, Figure S26. Compound 26, Figure S27. Compound 27, Figure S28. Compound 28, Figure S29. Compound 29.

Author Contributions: Conceptualization, S.R., Y.Z. and S.D.C.; methodology, C.M., H.B., G.J., H.B. and A.Z.; formal analysis, S.R., S.D.C., A.Z., H.B. and R.J.; investigation C.M., R.S., R.U., H.B. and G.J.; resources, S.R. and S.D.C.; data curation, E.G., S.D.C., A.Z., H.B. and R.J.; writing-original draft preparation, A.Z. and R.J.; writing review and editing, S.R., S.D.C., A.Z., R.U., E.G. and R.J.; supervision, S.R. and S.D.C.; project administration, S.R.; funding acquisition, S.R. and S.D.C.; All authors have read and agreed to the published version of the manuscript.

Funding: This research was funded by NIH, grant number MH122196.

Institutional Review Board Statement: Not applicable.

Informed Consent Statement: Not applicable.

Data Availability Statement: Data available within article and Supplementary Materials.

Conflicts of Interest: The authors declare no conflict of interest. 


\section{References}

1. Xu, Y.-L.; Reinscheid, R.K.; Huitron-Resendiz, S.; Clark, S.D.; Wang, Z.; Lin, S.H.; Brucher, F.A.; Zeng, J.; Ly, N.K.; Henriksen, S.J.; et al. Neuropeptide S: A neuropeptide promoting arousal and anxiolytic-like effects. Neuron 2004, 43, 487-497. [CrossRef] [PubMed]

2. Okamura, N.; Hashimoto, K.; Iyo, M.; Shimizu, E.; Dempfle, A.; Friedel, S.; Reinscheid, R.K. Gender-specific association of a functional coding polymorphism in the Neuropeptide $S$ receptor gene with panic disorder but not with schizophrenia or attention-deficit/hyperactivity disorder. Prog. Neuro-Psychopharmacol. Biol. Psychiatry 2007, 31, 1444-1448. [CrossRef] [PubMed]

3. Clark, S.D.; Kenakin, T.P.; Gertz, S.; Hassler, C.; Gay, E.A.; Langston, T.L.; Reinscheid, R.K.; Runyon, S.P. Identification of the first biased NPS receptor agonist that retains anxiolytic and memory promoting effects with reduced levels of locomotor stimulation. Neuropharmacology 2017, 118, 69-78. [CrossRef] [PubMed]

4. Clark, S.D.; Duangdao, D.M.; Schulz, S.; Zhang, L.; Liu, X.; Xu, Y.-L.; Reinscheid, R.K. Anatomical characterization of the neuropeptide $\mathrm{S}$ system in the mouse brain by in situ hybridization and immunohistochemistry. J. Comp. Neurol. 2011, 519, 1867-1893. [CrossRef] [PubMed]

5. Cannella, N.; Kallupi, M.; Ruggeri, B.; Ciccocioppo, R.; Ubaldi, M. The role of the neuropeptide S system in addiction: Focus on its interaction with the CRF and hypocretin/orexin neurotransmission. Prog. Neurobiol. 2013, 100, 48-59. [CrossRef] [PubMed]

6. Fedeli, A.; Braconi, S.; Economidou, D.; Cannella, N.; Kallupi, M.; Guerrini, R.; Calò, G.; Cifani, C.; Massi, M.; Ciccocioppo, R. The paraventricular nucleus of the hypothalamus is a neuroanatomical substrate for the inhibition of palatable food intake by neuropeptide S. Eur. J. Neurosci. 2009, 30, 1594-1602. [CrossRef] [PubMed]

7. Pañeda, C.; Huitron-Resendiz, S.; Frago, L.M.; Chowen, J.A.; Picetti, R.; De Lecea, L.; Roberts, A.J. Neuropeptide S Reinstates Cocaine-Seeking Behavior and Increases Locomotor Activity through Corticotropin-Releasing Factor Receptor 1 in Mice. J. Neurosci. 2009, 29, 4155-4161. [CrossRef] [PubMed]

8. Schmoutz, C.D.; Zhang, Y.; Runyon, S.P.; Goeders, N.E. Antagonism of the neuropeptide S receptor with RTI-118 decreases cocaine self-administration and cocaine-seeking behavior in rats. Pharmacol. Biochem. Behav. 2012, 103, 332-337. [CrossRef] [PubMed]

9. Kushikata, T.; Yoshida, H.; Kudo, M.; Salvadori, S.; Calo, G.; Hirota, K. The Effects of Neuropeptide S on General Anesthesia in Rats. Anesth. Analg. 2011, 112, 845-849. [CrossRef] [PubMed]

10. Hassler, C.; Zhang, Y.; Gilmour, B.; Graf, T.; Fennell, T.; Snyder, R.; Deschamps, J.R.; Reinscheid, R.K.; Garau, C.; Runyon, S.P. Identification of Neuropeptide S Antagonists: Structure-Activity Relationship Studies, X-ray Crystallography, and in Vivo Evaluation. ACS Chem. Neurosci. 2014, 5, 731-744. [CrossRef] [PubMed]

11. Trotter, B.W.; Nanda, K.K.; Manley, P.J.; Uebele, V.N.; Condra, C.L.; Gotter, A.L.; Menzel, K.; Henault, M.; Stocco, R.; Renger, J.J.; et al. Tricyclic imidazole antagonists of the Neuropeptide S Receptor. Bioorganic Med. Chem. Lett. 2010, 20, 4704-4708. [CrossRef] [PubMed]

12. Okamura, N.; Habay, S.A.; Zeng, J.; Chamberlin, A.R.; Reinscheid, R.K. Synthesis and Pharmacological in Vitro and in Vivo Profile of 3-Oxo-1,1-diphenyl-tetrahydro-oxazolo[3,4-a]pyrazine-7-carboxylic Acid 4-Fluoro-benzylamide (SHA 68), a Selective Antagonist of the Neuropeptide S Receptor. J. Pharmacol. Exp. Ther. 2008, 325, 893-901. [CrossRef] [PubMed]

13. Patnaik, S.; Marugan, J.J.; Liu, K.; Zheng, W.; Southall, N.; Dehdashti, S.J.; Thorsell, A.; Heilig, M.; Bell, L.; Zook, M.; et al. Structure-Activity Relationship of Imidazopyridinium Analogues as Antagonists of Neuropeptide S Receptor. J. Med. Chem. 2013, 56, 9045-9056. [CrossRef] [PubMed]

14. Melamed, J.Y.; Zartman, A.E.; Kett, N.R.; Gotter, A.L.; Uebele, V.N.; Reiss, D.R.; Condra, C.L.; Fandozzi, C.; Lubbers, L.S.; Rowe, B.A.; et al. Synthesis and evaluation of a new series of Neuropeptide S receptor antagonists. Bioorg. Med. Chem. Lett. 2010, 20, 4700-4703. [CrossRef] [PubMed]

15. Micheli, F.; Di Fabio, R.; Giacometti, A.; Roth, A.; Moro, E.; Merlo, G.; Paio, A.; Merlo-Pich, E.; Tomelleri, S.; Tonelli, F.; et al. Synthesis and pharmacological characterization of 5-phenyl-2-[2-(1-piperidinylcarbonyl)phenyl]-2,3-dihydro-1H-pyrrolo[1,2c]imidazol-1-ones: A new class of Neuropeptide S antagonists. Bioorg. Med. Chem. Lett. 2010, 20, 7308-7311. [CrossRef] [PubMed]

16. Epsztajn, J.; Berski, Z.; Brzezinski, J.Z.; Jozwiak, A. Reactions of the N,N-Dialkylpyridylcarboxylic Amides with Lithium Amides-Regioselective Lithiation of N,N-Diisopropylpyridylcarboxylic Amides, a Useful Method for Synthesis of 2,3- and 3,4-Disubstituted Pyridines. Tetrahedron Lett. 1980, 21, 4739-4742. [CrossRef]

17. Niiyama, K.; Mase, T.; Takahashi, H.; Naya, A.; Katsuki, K.; Nagase, T.; Ito, S.; Hayama, T.; Hisaka, A.; Ozaki, S.; et al. 6-carboxy5,7-diaryleyclopenteno[1,2-b]pyridine derivatives: A novel class of endothelin receptor antagonists. Bioorganic Med. Chem. 2002, 10, 2461-2470. [CrossRef]

18. Bonano, J.S.; Runyon, S.P.; Hassler, C.; Glennon, R.A.; Negus, S.S. Effects of the neuropeptide S receptor antagonist RTI-118 on abuse-related facilitation of intracranial self-stimulation produced by cocaine and methylenedioxypyrovalerone (MDPV) in rats. Eur. J. Pharmacol. 2014, 743, 98-105. [CrossRef] [PubMed]

19. Cevher, H.A.; Schaller, D.; Gandini, M.; Kaplan, O.; Gambeta, E.; Zhang, F.X.; Çelebier, M.; Tahir, M.N.; Zamponi, G.W.; Wolber, G.; et al. Discovery of Michael acceptor containing 1,4-dihydropyridines as first covalent inhibitors of L-/T-type calcium channels. Bioorg. Chem. 2019, 91, 103187. [CrossRef] [PubMed] 
20. Ruzza, C.; Rizzi, A.; Trapella, C.; Pela', M.; Camarda, V.; Ruggieri, V.; Filaferro, M.; Cifani, C.; Reinscheid, R.K.; Vitale, G.; et al. Further studies on the pharmacological profile of the neuropeptide S receptor antagonist SHA 68. Peptides 2010, 31, 915-925. [CrossRef] [PubMed] 